\title{
How Far Have Public Financial Management Reforms Come in Africa?
}

\author{
Matthew Andrews \\ CID Working Paper No. 208 \\ October 2010
}

(C) Copyright 2010 Matthew Andrews

and the President and Fellows of Harvard College

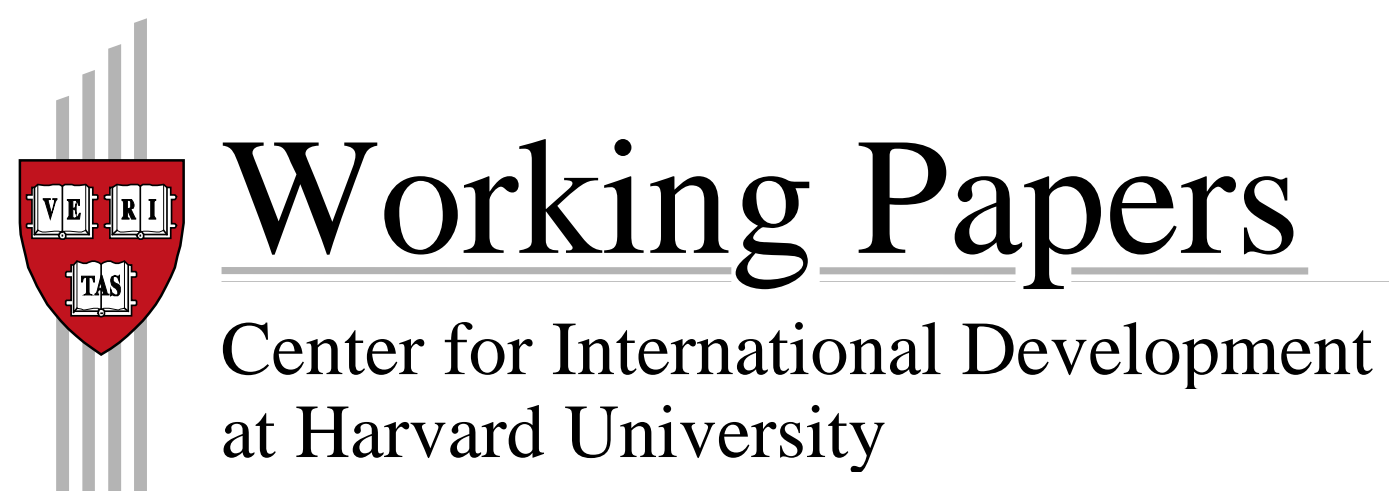




\title{
How Far Have Public Financial Management Reforms Come in Africa?
}

\author{
Matthew Andrews
}

October, 2010

\begin{abstract}
This paper asks how strong African Public Financial Management (PFM) has become, after a decade and more of reform. How well do African PFM systems in place now facilitate effective public financial management? Where are the next challenges and how can they be met? It analyzes recent PFM assessments in 31 governments to answer these questions, identifying patterns of strengths and weaknesses across the PFM system and across countries. In respect of the former, the study finds that budgets are made better than they are executed, practice lags behind the creation of processes and laws, and processes are stronger where concentrated actors are engaged. In respect of the latter, the study finds that different countries fall into different 'PFM performance leagues' and countries in the different leagues look very different to each other. A range of factors influence which league a country is associated with; including economic growth, stability, reform tenure and colonial heritage. On the basis of this evidence, the paper argues that existing reforms face limits that can only be overcome with adjustments in reform approach; with less focus on pushing reform technicalities and more on creating 'space' in which reform takes place, less concentration of engagements with small sets of actors and more on expanding engagements, and less emphasis on reproducing the same reform models and more on better understanding what context-appropriate reforms look like.
\end{abstract}




\section{How Far Have Public Financial Management Reforms Come in Africa? Faculty Research Working Paper Series}

\section{Matt Andrews}

Harvard Kennedy School

\section{May 2010 RWP10-018}

The views expressed in the HKS Faculty Research Working Paper Series are those of the author(s) and do not necessarily reflect those of the John F. Kennedy School of Government or of Harvard University. Faculty Research Working Papers have not undergone formal review and approval. Such papers are included in this series to elicit feedback and to encourage debate on important public policy challenges. Copyright belongs to the author(s). Papers may be downloaded for personal use only. 


\title{
How Far Have Public Financial Management Reforms Come in Africa?
}

\author{
Lessons from recent PEFA data and World Bank Public Financial Management \\ Performance Reports, with an additional focus on the potential role of civil society
}

\author{
Matt Andrews ${ }^{1}$ \\ Assistant Professor, Harvard Kennedy School of Government \\ 116 Rubenstein \\ 79 John F. Kennedy Street \\ Cambridge, MA \\ 02138 \\ USA. \\ Matt_andrews@hks.harvard.edu
}

\footnotetext{
${ }^{1}$ The current paper was facilitated by Hewlett Foundation support to the Transparency and Accountability Project (TAP) at the Brookings Institution and by the Financial Management group in the Africa region of the World Bank. Thanks are especially due to Charles Griffin, (Then) Senior Fellow, Global Economy and Development Program of The Brookings Institution, Ed Olowo-Okere, T.K. Balakrishnan and Renaud Seligmann at the World Bank. Lead Financial Management Specialist, Africa Region of the World Bank. All errors in this working paper are those of the author alone, and the contents and arguments in the paper do not necessarily reflect on Harvard University, Brookings or the World Bank.
} 


\begin{abstract}
This paper asks how strong African Public Financial Management (PFM) has become, after a decade and more of reform. How well do African PFM systems in place now facilitate effective public financial management? Where are the next challenges and how can they be met? It analyzes recent PFM assessments in 31 governments to answer these questions, identifying patterns of strengths and weaknesses across the PFM system and across countries. In respect of the former, the study finds that budgets are made better than they are executed, practice lags behind the creation of processes and laws, and processes are stronger where concentrated actors are engaged. In respect of the latter, the study finds that different countries fall into different 'PFM performance leagues' and countries in the different leagues look very different to each other. A range of factors influence which league a country is associated with; including economic growth, stability, reform tenure and colonial heritage. On the basis of this evidence, the paper argues that existing reforms face limits that can only be overcome with adjustments in reform approach; with less focus on pushing reform technicalities and more on creating 'space' in which reform takes place, less concentration of engagements with small sets of actors and more on expanding engagements, and less emphasis on reproducing the same reform models and more on better understanding what context-appropriate reforms look like.
\end{abstract}




\section{Frequently Used Acronyms}

$\begin{array}{ll}\text { CFAA } & \text { Country Financial Accountability Assessment } \\ \text { COFOG } & \text { Classifications of the Functions of Government } \\ \text { CPAR } & \text { Country Procurement Assessment Report } \\ \text { CSO } & \text { Civil Society Organization } \\ \text { EITI } & \text { Extractive Industries Transparency Initiative } \\ \text { FMIS } & \text { Financial Management Information Systems } \\ \text { GFS } & \text { Government Financial Statistics } \\ \text { IMF } & \text { International Monetary Fund } \\ \text { IFMS } & \text { Integrated Financial Management Information Systems } \\ \text { IPSAS } & \text { International Public Sector Accounting Standards } \\ \text { MDA } & \text { Ministries, Departments and Agencies } \\ \text { NGOs } & \text { Non-Governmental Organizations } \\ \text { PEFA } & \text { Public Expenditure and Financial Accountability } \\ \text { PFM } & \text { Public Financial Management } \\ \text { PFM-PR } & \text { Public Financial Management Performance Report } \\ \text { PRSP } & \text { Poverty Reduction Strategy Paper } \\ \text { TSA } & \text { Treasury Single Accounts } \\ \text { WAEMU } & \text { West African Economic and Monetary Union }\end{array}$




\section{Contents}

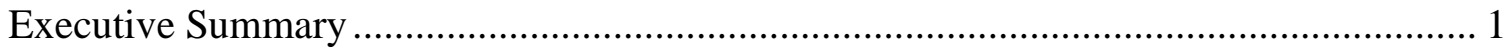

A. Taking stock 1: Themes across PFM process areas................................................ 1

B. Taking stock 2: Themes across countries .............................................................. 2

C. Strategy: Themes from past reforms, thoughts for the future.................................. 4

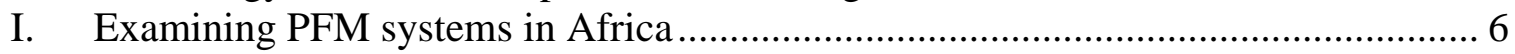

II. Themes from stories across PFM processes ………….......................................... 12

A. Budgets are made better than they are executed.................................................. 12

B. Practice lags behind the creation of processes and laws....................................... 15

C. Actor concentration pays (at least to date) …………......................................... 19

III. Themes from stories across countries ………….......................................... 23

A. Countries are in different PFM performance leagues ............................................ 23

B. Growing economies have stronger PFM........................................................... 26

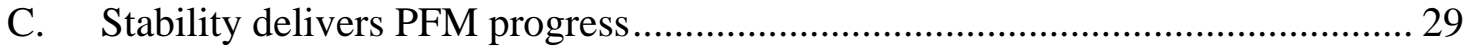

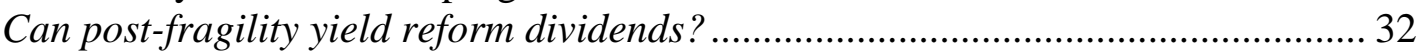

D. Fiscal states have stronger PFM systems .......................................................... 34

E. Longer periods of reform commitment foster PFM progress ................................ 36

F. Colonial heritage matters (maybe)....................................................................... 39

G. Summing the country-specific themes............................................................ 41

IV. Themes from past reforms, ideas for the future............................................... 43

A. Reform similarities belie country differences....................................................... 43

B. Existing reforms can deliver better law, stronger central agencies ...................... 45

Can countries learn from each other about strengthening dimensions?.................... 46

C. Getting past reform limits: Some theory and ideas ................................................ 53

D. Reform adjustments are needed to meet looming challenges................................. 55

Direction 1. Reforms need less focus on technicalities, more on 'space'.............. 58

Direction 2. Reforms need less concentration, more coverage .............................. 61

Direction 3. Reforms need less similarity, more context-appropriateness ............. 63

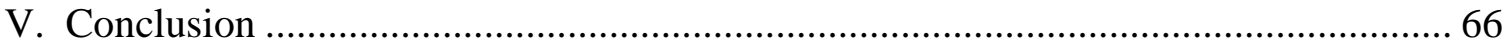




\section{Executive Summary}

1. How strong has African PFM become? How do African public financial management (PFM) systems in place now facilitate effective public financial management? Where are the next challenges and how can they be met? This paper intends to inform those trying to answer such questions by identifying central themes of the continent's recent PFM story. The themes are also used to promote a conversation about the role of Civil Society Organizations (CSOs) in African PFM: How much have CSOs been a part of the main story lines to date? Where could they occupy the story more in future?

2. Themes arise from the analysis of recent quantitative and qualitative data on PFM system characteristics and reform initiatives in 31 African governments. The quantitative data comes from studies of country systems using the PEFA methodology, which evaluates systems on over 70 dimensions; each dimension receives an $A$ to $D$ score (equating with 1-4). The qualitative materials include performance reports used to explain the evidence behind each score. Themes emerge in three main parts focused first on a stock taking exercise aimed at identifying (i) themes across PFM processes, and (ii) themes across countries. This stock-taking is followed by a strategic analysis focused on themes emerging from past reforms and a discussion of current and future reform challenges in African PFM.

\section{A. $\quad$ Taking stock 1: Themes across PFM process areas}

3. Three themes are identified across the process areas in African PFM systems: (i) Budgets are made better than they are executed; (ii) Practice lags behind the creation of processes and laws; and (iii) Actor concentration pays:

- The first theme relates the observation that budget preparation processes are comparatively stronger than budget execution and oversight processes across all African countries. In PFM jargon, this is commonly presented as 'upstream processes are stronger than downstream processes'.

- The second theme is more nuanced, showing across all process areas that African PFM systems generally suffer from an implementation deficit-laws and processes may be in place but seldom affect actual behavior. The theme reflects a new institutional differentiation between de jure and de facto reform and is shown in the words of one recent diagnostic, "Legislation and procedures have been improved ... [but] implementation has not yet been achieved."

- The third theme offers even more specificity, suggesting that processes are stronger when narrower, concentrated sets of actors are involved in implementation. Processes are weaker where they involve multiple players, especially outside of central PFM entities like the budget department or treasury.

4. These themes all emerge as significant in a statistical sense and from written descriptions of experience. They are bought together in Figure E1, which shows the average scores for different PEFA dimensions according to the thematic classification. The weakest dimension types, averaging 1.9 out of 4 over all 31 countries and shown in the solid black bar at the top of the figure, are downstream 
(budget execution and oversight), practice oriented (de-facto), and involving deconcentrated sets of actors. The strongest dimension types, averaging more than 2.5 and shown in the clear bar at the foot of the figure, are upstream (budget preparation), process oriented (or de-jure) and involving concentrated actor sets.

Fig. E1. Different strengths of different process types, by theme

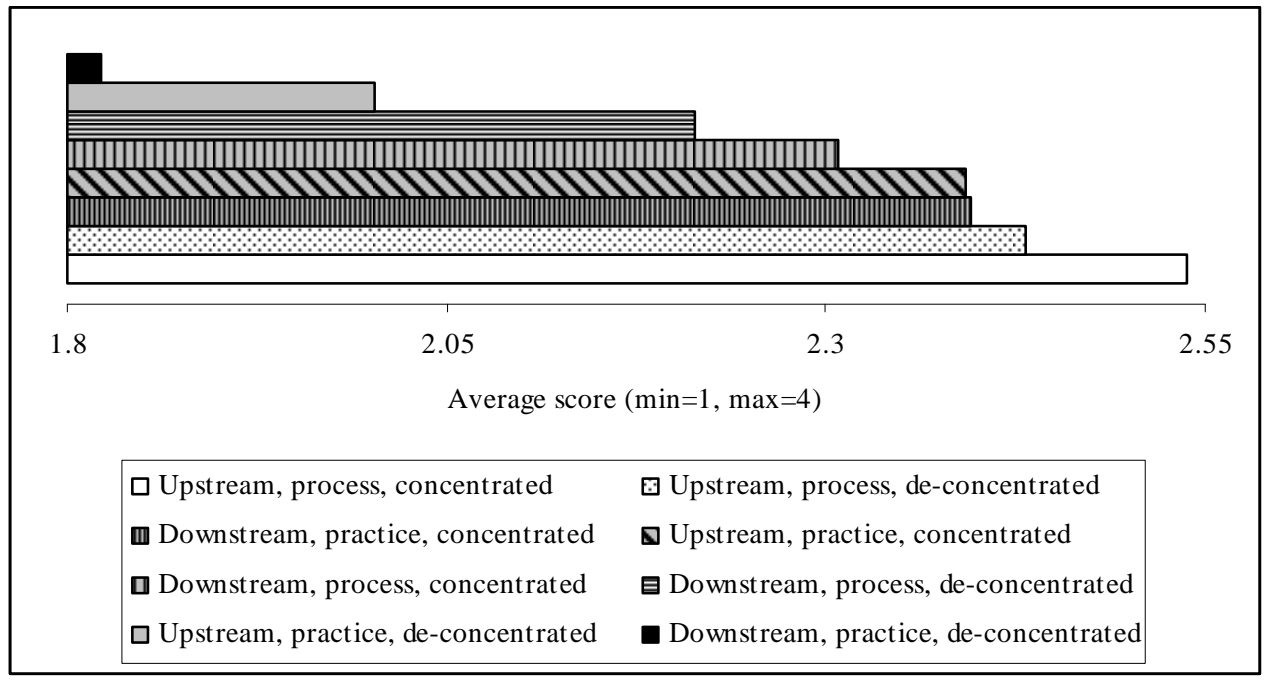

\section{B. Taking stock 2: Themes across countries}

5. Figure E1 captures general differences in dimension strengths, paying no regard to inter-country difference in the process. Substantial variation exists in dimension strength across countries as well, however. The variation is significant enough to suggest that different countries fall into different 'PFM performance leagues'. These leagues are identified empirically, based on PEFA scores, and in the contrasting written descriptions of country performance. They are shown in Figures E2 and E3, which illustrate how countries in top leagues (4 and 5 at the right) have stronger processes and outcomes than those in lower leagues (1, 2 and 3 at the left).

Fig. E2. PFM process strength differs by performance league

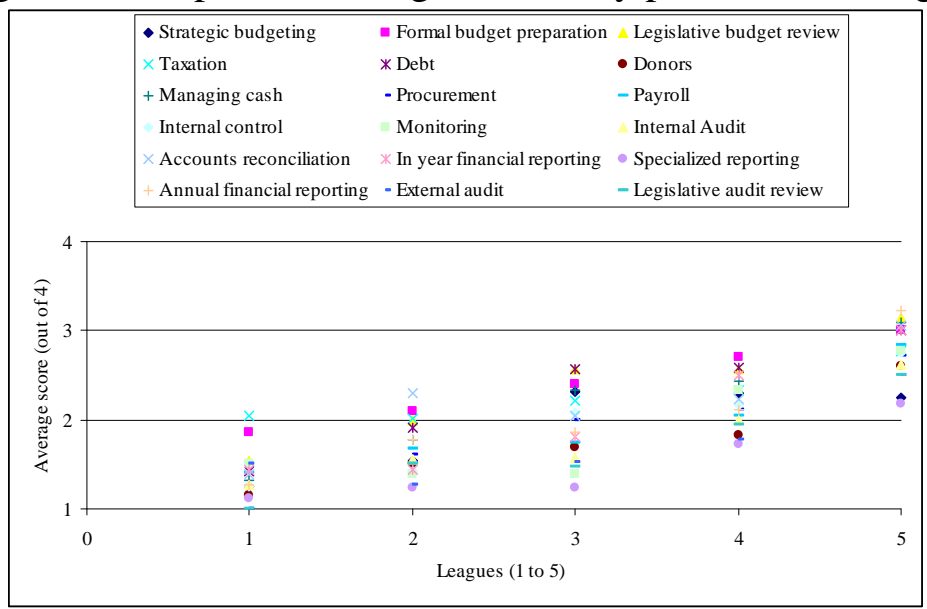


Figure E3. PFM outcomes also differ by league

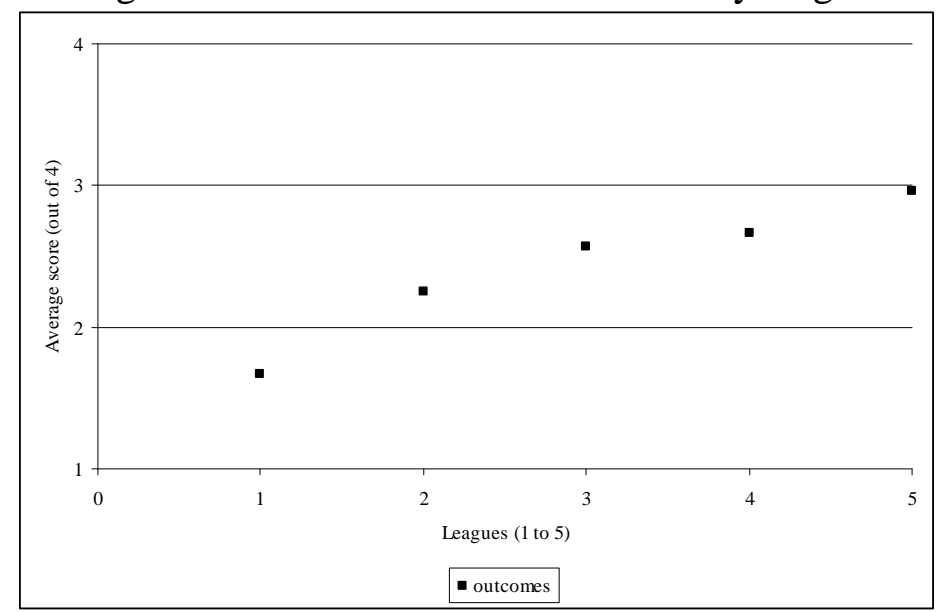

6. The evidence shows that countries in the different leagues look very different to each other. Lower league countries have weak dimensions no matter how these are categorized; de jure and de facto are weak, as are concentrated and de-concentrated dimensions, as are upstream and downstream. League 3 countries share weak downstream, de facto and de-concentrated dimensions with lower league countries; but league 3 countries are strengthening PFM dimensions that are in the upstream, de jure in nature, and centered on the engagement of concentrated actor sets. League 5 countries share strengthened upstream, de jure and concentrated PFM areas with league 3; but these countries appear to be strengthening the other dimensionsdownstream, de facto and de-concentrated. These are their current challenges.

7. Themes also arise in explaining why countries fall into different leagues. A range of factors are seen to influence the quality of PFM systems and outcomes, presented as five major themes:

- Growing economies have stronger PFM.

- Stability delivers PFM progress, although there may be a peculiar 'starting from scratch' dividend for countries enjoying post conflict stability.

- States with larger domestic, non-mineral income sources have stronger PFM.

- Longer periods of broad reform commitment foster PFM progress. And,

- Colonial heritage matters (maybe).

8. These themes are all presented on the basis of quantitative and qualitative evidence. They are not explained (and indeed various explanations could be offered, implying different directions of causality for example). It is apparent that the thematic influences interlink, however, and that there may be an as yet unidentified factor underlying them all-Higher growth states might raise more domestic revenues than others, have more political stability and have more space for reform, for example. This is the basic message behind Figure E4, which shows which countries have the 'positive' aspect of the four themes, organized from weakest to strongest PFM performance (league 1 through league 5). (Some countries are denoted as a number, reflecting confidentiality of these PEFA assessments.) The higher bars on the right reflect more 'positives' in place, apparently facilitating PFM reform and reform 
space, and ultimately better PFM performance. These countries are mostly in league 5, which also has higher PFM system quality and outcomes.

Fig. E4. Country characteristics combine to impede, facilitate PFM across leagues

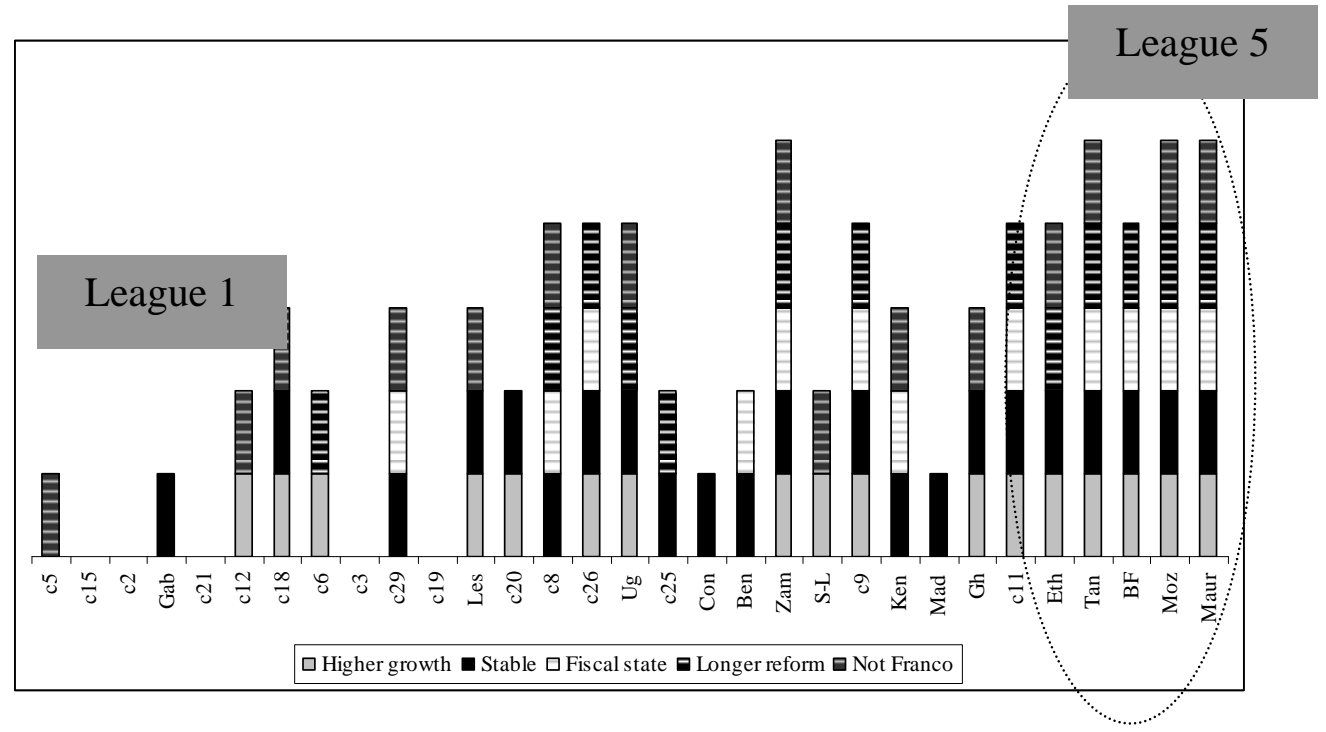

9. The strongest message from this section is simply that country characteristics matter a great deal in understanding what PFM system quality looks like. Some countries are substantially ahead of others in a general sense because they fall on the positive side of all the themes identified. They are in Africa's top leagues, climbing rungs at the very top of the PFM performance ladder. Other countries find themselves struggling with contextual realities that put them on the negative side of the themes discussed. Their PFM processes and outcomes are weak, and they are in the bottom leagues, struggling to get past the lower rungs of the PFM performance ladder. These observations, and the themes underlying them, raise important questions for reformers, chief among these being, "Is context taken seriously in reform design?"

\section{Strategy: Themes from past reforms, thoughts for the future}

10. The final section addresses this and other questions pertaining to PFM reform experience across Africa. The main theme centers on the apparent similarities in reform models across the 31 countries. The theme is reflected in the observation that similarities belie country differences. The 'similar' model is composed of a set of international reform 'products' and follows a common modality of engagement, whereby central, concentrated entities like treasuries, budget departments and even revenue and procurement agencies are strengthened and laws and processes are modified. This reform approach is seen to deliver better law and stronger central agencies, but may be limited to these gains only.

11. This reform approach lends itself to identifying 'low hanging fruit' options for lower league countries, especially those in league 3. These options tend to be in PFM dimensions that are upstream, de jure and involving concentrated players, visible to donors and potential investors. League 3 countries stand a good chance of achieving 
reform success in these dimensions because they are building on foundations already developed. Other 'higher hanging fruit' options for league 3 are in downstream, de facto and de-concentrated player dimensions, where the foundations are weaker, and the reform approach less suited.

12. Given this discussion, and drawing from the new institutional theory about isomorphic change, the paper suggests that the existing reform approach may have successfully delivered strong laws and central agencies to date but is less well suited to looming challenges with other dimensions. In higher league countries these challenges involve a need for de-facto implementation by de-concentrated entities, which have to date fallen out of the 'reach' of reforms. In lower league countries the deleterious effect of challenging contexts yields static, externally imposed models unsuitable for replication. The paper proposes adjustments needed to meet looming challenges embodied in calls for:

- less focus on technicalities, more on 'space'

- less concentration and more coverage, and

- less similarity, more context-appropriateness.

D.

CSOs and PFM in Africa

13. The paper consistently explores the existing and potential role of CSOs in Africa's PFM story, in context of the 'gaps' implied in themes. There are considerable findings:

- CSOs already engage as external watchdogs and partners in shoring up capacity for reporting and fostering transparency.

- CSOs are also engaged in situations where laws allow and even require practices that governments are not acting on.

- The lack of PFM reach to de-concentrated entities also plays into CSO strengths to convene across organizational bridges.

14. Even with these opportunities, CSOs face their own challenges in engagement and serious questions about whether they have the 'right stuff' for engagement. Do CSOs have the ability to choose appropriate roles for different settings, for example, working as partners in some instances, introducing new ideas in others, and occupying adversarial corners in others? It is vital that CSOs not become agents of one-best-way models of engagement, reflective of PFM reform modalities. CSOs could play a role challenging these reform modalities, contributing to creative space, facilitating greater reach, and helping to shape interventions to context. CSOs need legitimacy to do this, reflected most basically in having their own financial management 'house in order'. If CSOs do not have this kind of 'right stuff' they will be marginalized in the PFM story. CSO roles in this regard are also dependent on opportunities in the PFM system itself: if basic PFM information is unavailable to professional associations, business groups and such, these CSOs have few instruments to have an impact. Right now CSOs seem to have lots of access to information about upstream, de jure processes but still face a black box when it comes to downstream, de facto PFM issues, severely limiting their potential to engage. 


\section{Examining PFM systems in Africa}

15. Recent papers cite the ubiquitous nature of public sector reform in the developing world. The World Bank’s Independent Evaluation Group (IEG) cites particularly high engagement in the last ten years. This period has seen increased lending to such initiatives by organizations like the World Bank, with governance and public sector reform leading many country assistance strategies. Wescott notes similarly in regard to public financial management (PFM), "a sharp increase in [World Bank] PFM diagnostic work and lending since 2000."2 What has this work achieved? What does past experience suggest for future reform? What, in particular, can we learn about the potential role of Civil Society Organization's in PFM?

16. These are the questions underlying the current research, which aims to identify themes emerging from efforts to improve PFM systems in Africa. The themes were identified through comparative analysis of PFM characteristics and experience in a sample of African countries. The analysis was predominantly based on statistical manipulation of quantitative data emerging from 31 recent PEFA PFM performance assessments. This analysis was supplemented by the review of documentary discussions of the same systems and countries (PFM-PRs). Qualitative examination of these documents, using content analysis, allows triangulation of evidence to enhance the validity of themes.

\section{A. The quantitative/qualitative approach}

17. The PEFA Public Financial Management Performance Measurement Framework allows assessment of PFM system quality in respect of 31 indicators, most 'scored' with reference to multiple dimensions. 73 independently assessed dimensions constitute the full PEFA framework, with each dimension assessed on a four point ordinal scale from A to D, against detailed criteria that require evidencebased argument. In enumerating PEFA's ordinal symbols, the current research looks with interest at which dimensions scored 4 (A), 3 (B), 2 (C) and 1 (D) based on the idea that the higher the score, the more like "international good practice". ${ }^{3}$ Table 1 lists the 31 countries in the sample. Readers will identify a good mix of Anglophone, Francophone and Lusophone countries and of income per capita levels in the group.

Table 1. Countries in the PEFA dataset, in African and Non-African group

\begin{tabular}{|c|c|}
\hline $\begin{array}{c}\text { Group (and } \\
\text { size) }\end{array}$ & Country (African group) and Regional Representation (Non-African group) \\
\hline \multirow{3}{*}{ African (31) } & $\begin{array}{c}\text { Benin, Burkina Faso, Cameroon, Central African Republic, Comoros, Congo, Cote } \\
\text { d'Ivoire, Democratic republic of the Congo, Ethiopia, Gabon, Ghana, Guinea, Guinea } \\
\text { Bissau, Kenya, Lesotho, Madagascar, Malawi, Mali, Mauritania, Mauritius, } \\
\text { Mozambique, Nigeria, Rwanda, Senegal, Siera Leone, Sao Tome and Principe, } \\
\text { Swaziland, Tanzania, Togo, Uganda and Zambia }\end{array}$ \\
\hline
\end{tabular}

\footnotetext{
${ }^{2}$ Wescott, C.G. (2008) "World Bank Support for Public Financial Management: Conceptual Roots and Evidence of Impact” World Bank Independent Evaluation Working Group Working Paper. Washington D.C.: World Bank.

${ }^{3}$ Based on the convention developed in de Renzio, P. (2008) "Taking Stock: What Do PEFA Assessments Tell Us About PFM Systems Across Countries?” Unpublished manuscript, The PEFA Secretariat, p.6.
} 
18. The legitimacy of the PEFA data is partly reflected in recent research findings that, "The PEFA instrument itself appears to be valued by both governments and development partners." 4 Quality is enhanced by the PEFA Secretariat's own controls which include the tight, evidence-based criteria, oversight in most assessment processes, and the requirement that all analyses be supplemented with a PFM Performance Report (PFM-PR) in which experts involved must provide evidence supporting scores. The Secretariat also conducts its own reviews of assessments, in which it identifies possible quality concerns. Their 2007 report indicated issues amenable to different solutions, which have been considered in the current study: ${ }^{5}$

- Concerns that are difficult to treat relate to the date of PEFA assessment and the way it was produced. These issues are acknowledged at various points in this text, especially noting where the readers (at least two) agreed on specific problems in earlier studies (produced before 2006) and those studies conceived in difficult circumstances (where noted in the PFM-PR).

- Issues that are easier to address include some concerns about compliance with criteria and missing scores, particularly regarding specific indicators and dimensions. These concerns are mostly addressed through checks of all the PEFA scores against PFM-PR descriptions and PEFA criteria. Missing scores were all identified independently and careful checks against PFM-PR descriptions (by at least two readers in each case) allowed identification of cases where the missing score reflected a complete lack of information (where the score was left missing) or where the description suggested lower than a D (where D was assigned). ${ }^{6}$

- Some concerns over compliance are harder to address, especially related to systematic problems with interpretation. The PEFA Secretariat notes some areas subject to this problem, including internal and external audit. Differences in interpretation arise for a variety of reasons, including different colonial heritage; there are accounts of Francophone governments disagreeing with the PEFA approach to external audit, for example. These concerns are considered in interpreting the data, and discussed explicitly in the text.

- Questions about weighting the dimensions have also been raised. The PEFA Secretariat was particularly concerned about weighting where the 73 dimensions were used as individual data points, given that some of the 31 PEFA indicators (like PI-23 on reporting of revenues at service delivery points) have only one dimension, whereas others have many (like PI-12, which looks at strategic budgeting and has four dimensions). We gave all dimensions equal weighting, having no theoretical reason to do otherwise. We did not feel that the multiple dimensions in indicator areas duplicated each other: In PI-12, for example, there

\footnotetext{
${ }^{4}$ Betley, M. (2008). “Assessing Impact of the PEFA Framework” Manuscript produced for PEFA Steering Committee, available at: www.pefa.org, p.34.

5 PEFA (2008) “PFM Performance Measurement Framework Monitoring Report 2007” www.pefa.org.

${ }^{6}$ Such checks allowed adjustment of 97 scores (to ensure descriptions reflected criteria) and identification of some missing dimension. 85 missing scores were impossible to identify because no information was provided in the PFM-PR. This amounts to 3.7\% of the total number of indicator scores (2294).
} 
19. Quality control considerations like those noted above enhance validity and reliability of the PEFA scores and their use in the current study. The most important control is the standardized criterion used for assessment. Tight criteria mean that similar scores in different assessments refer to similar general PFM characteristics. ${ }^{7}$ The dimensions are also well suited to identifying themes and patterns, which one expects to be more vivid over larger data sets. To allow easy theme identification, the dimensions are at times organized into clusters reflecting PFM process areas. These build on the 'budget cycle' categories in the PEFA framework, locating dimensions in 18 process areas shown in Figure 1. Dimensions are aggregated at times into 'process indexes' reflecting each cluster, all of which enjoy acceptable levels of internal consistency. The first few PEFA indicators are not included as they reflect outcomes.

Fig. 1. Clustering the PEFA dimensions

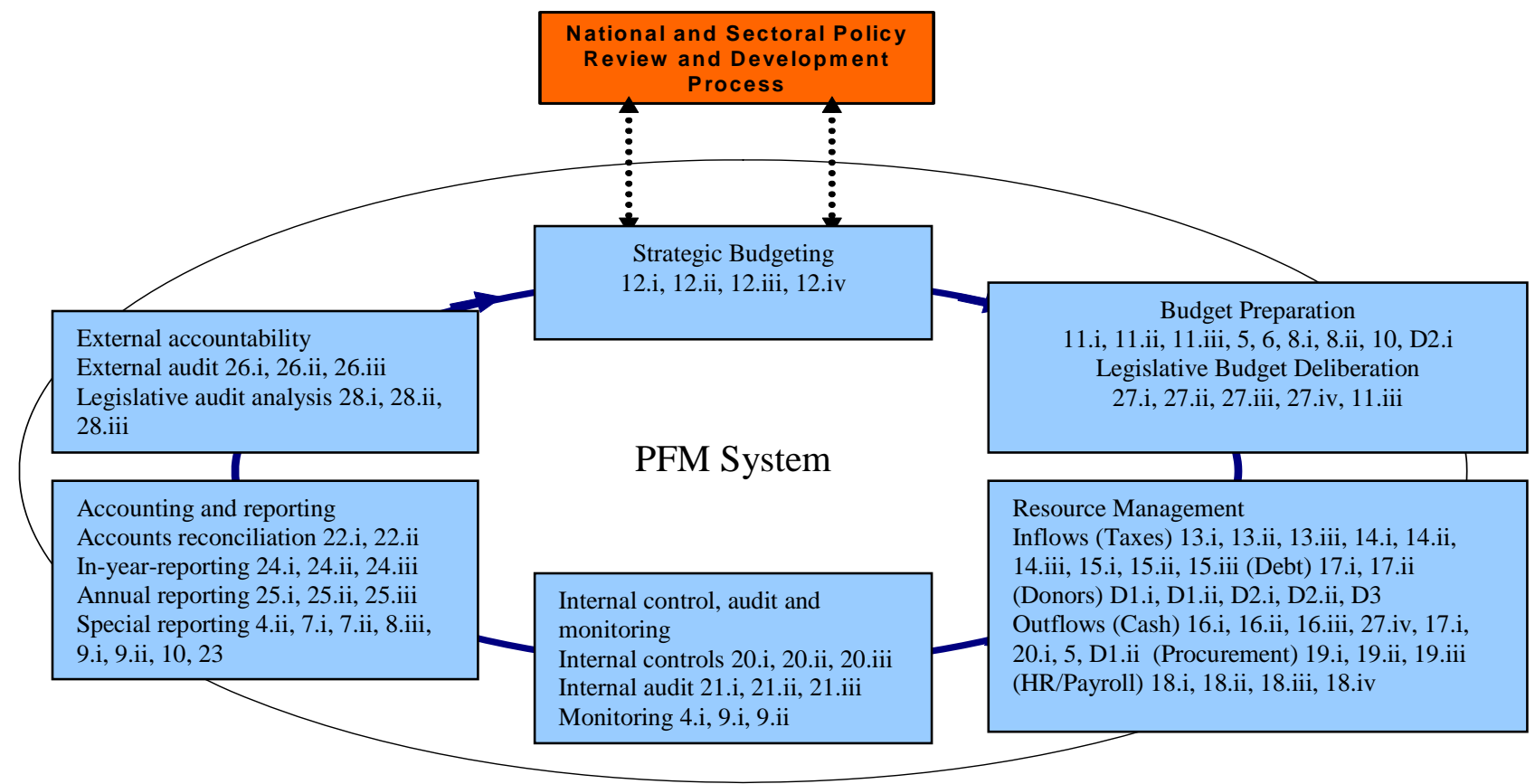

Source: Andrews (2007) ${ }^{8}$

\footnotetext{
${ }^{7}$ Even though the detailed characteristics and reasons for weakness might differ, a point made explicit in Dorotinsky's recent comment on the IMF's PFM blog (August 4, 2008, http://blog-pfm.imf.org/): “The indicators provide an over-view of performance, but would not necessarily provide the reasons why performance was weak (one would know why the score was assessed at a 'c', for example, but not perhaps whether this was due to human capital, IT systems, management, legislation or policy).”

8 Andrews, M. 2007. “What would an ideal PFM system look like?” in Shah, A. (ed). Budgeting and Budgetary Institutions. Washington, D.C.: World Bank, 359-383. Available at: http://siteresources.worldbank.org/PSGLP/Resources/BudgetingandBudgetaryInstitutions.pdf See also the description at http://siteresources.worldbank.org/INTPRS1/Resources/3836061119904390686/bbl121905_background.pdf
} 
20. The PEFA data is well suited to the task of identifying general PFM themes across the 18 process areas listed in Figure 1. As already noted, its value is enhanced by the ability to check scores against written descriptions in PFM-PR documents. These documents and other recently written diagnostic pieces also accommodate a stronger, triangulated research design. Triangulation in this case involves looking for themes through multiple evidence types, sources and methods of analysis. Building on Webb et al., the idea is simply that, "Once a proposition [or theme] has been confirmed by two or more independent measurement processes, the uncertainty of its interpretation is greatly reduced."9

21. In the spirit of triangulation, therefore, documentary evidence was analyzed to support themes identified in the quantitative work, accommodating greater certainty about the themes that are identified. The documents produced in concert with the PEFA data are the main sources. These are called different names with only some officially termed Public Financial Management Performance Reports (PFM-PRs). For the sake of reference, however, they are termed PFM-PRs when referred to here. Other World Bank publications are also referenced, including Public Expenditure Reviews (PERs), Country Financial Accountability Assessments (CFAAs) and Public Expenditure Management and Financial Accountability Reports (PEMFARs). ${ }^{10}$ One should note that all of these documents were endorsed and often co-written by other donor groups as well as government entities (notably Ministries of Finance). Their legitimacy is thus broader than their published status as World Bank documents. There were some confidentiality issues to consider in using these documents (hence some countries are shown by number and not name) and translation concerns did make the content analysis complex in places.

\section{B. An early story line}

22. The search for a story-line begins with Figure 2, which compares the average African score on each PEFA dimension with the average score in the 42 non-African countries, and three other 'performance levels'-the "international good practice" 4 score (an A), 3 (a B) and 2 (a C). It shows that African averages are mostly below "international good practice" and mostly lag other countries (in more than $60 \%$ of dimension scores). ${ }^{11}$ African averages generally fall between 2 and 3 scores (57 \% of dimensions). Why does Africa lag behind other countries? Is "international good practice” an appropriate benchmark?

Fig.2. Benchmarking African PFM; climbing the PFM performance ladder?

\footnotetext{
${ }^{9}$ Webb, E. J., D. T. Campbell, R. D. Schwartz and L. Sechrest (1966) Unobtrusive Measures: Nonreactive Research in the Social Sciences. New York: Rand McNally.

${ }^{10}$ Other documents related to projects affecting PFM, accounting ROSCs and PRSP-related documents, which leads to referencing IMF updates as well.

${ }^{11}$ In 60 of 73 dimensions.
} 


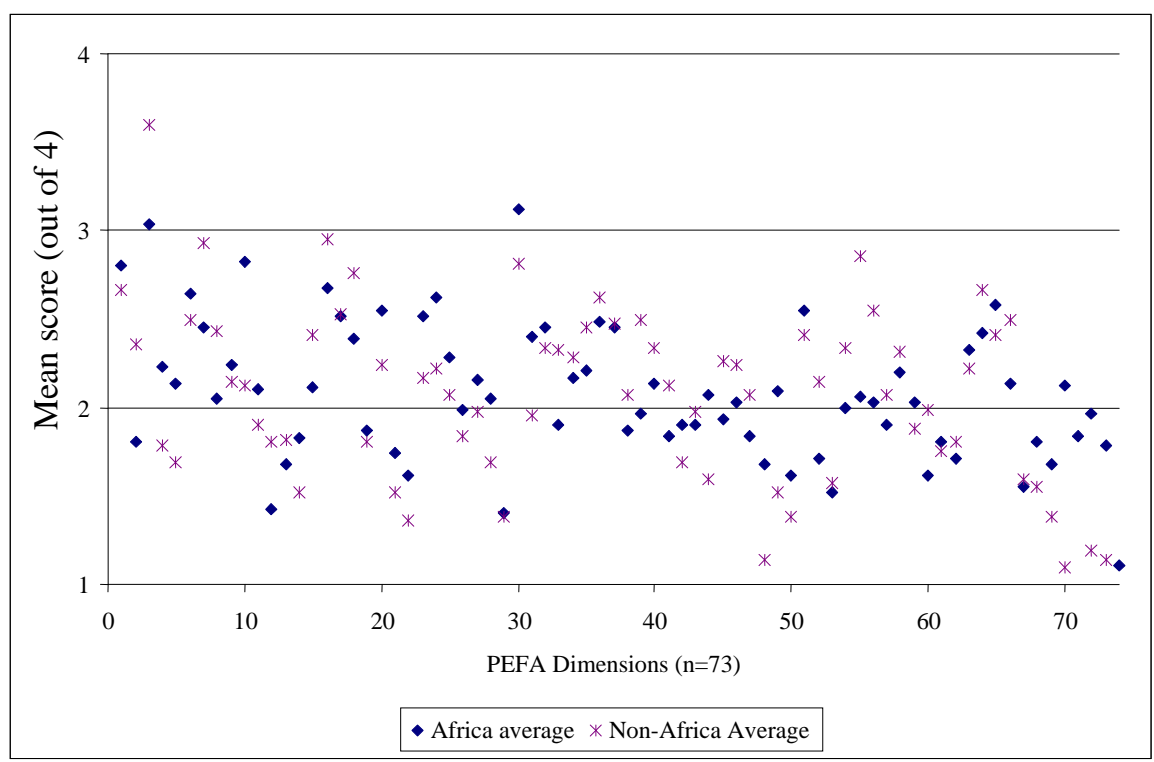

23. Answers to the questions suggest the importance of context in understanding PEFA scores. African scores lag the other group on the PEFA dimensions and income per capita measures, with the latter being a notable and significant determinant of PEFA performance. Country wealth, or development status, is also a major predictor on attainment of the "international good practice" score (4). Countries with income per capita exceeding $\$ 4,000$ are more than twice as likely to score a 4 over the entire set of dimensions. ${ }^{12}$ There are obviously many explanations of this, ${ }^{13}$ but attaining "good international practice" does seem strongly akin to reaching the top rungs of the development ladder. (Even though country context suggests the 4 scores may not always represent replicable good practice: Norway defends some sub-4 PEFA scores as appropriate to its context, for example. ${ }^{14}$ )

24. Given the apparent correlation between PEFA scores and level of development, Figure 2 proposes potential 'developmental' benchmarks for the African group. The 2 and 3 scores equate with $\mathrm{C}$ and $\mathrm{B}$ symbols and appear as second and third rungs on the short ladder to the ultimate 4 . These are useful comparisons for countries still climbing the ladder. They imply the 4 score as a generally worthy end goal, not necessarily a hard "good practice", and allow perspective on country progress towards the top rungs. Assessed against these two ladder benchmarks, the African group can best be described by words in Uganda's most recent report: "Still in progress and yet to achieve the desired level of success." The description reflects these total numbers: $35 \%$ of African PEFA dimension scores (800) suggest PFM process and practice areas are still on the bottom run of the ladder (a 1 or D); $29 \%$

\footnotetext{
12 The eight countries in this category make up $10 \%$ of the sample but account for $22.5 \%$ of the 4 scores. These countries record 25 "good practice” 4's on average, higher than the 10.5 average for other countries.

13 The work here does not suggest causality in the relationship, for example: It is possible that wealthier economies create conditions for stronger PFM, or that a commitment to strong PFM fosters progress towards wealth accumulation.

${ }^{14}$ Norway’s PEFA assessment is available at http://www.norad.no/default.asp?V_ITEM_ID=12361. The response to this is presented at http://www.oecd.org/dataoecd/28/25/41084040.ppt\#275,7,Conclusions. This presentation argues that $\mathrm{C}$ and $\mathrm{D}$ scores on dimensions including medium term budgeting, internal audit and decentralized public financial management may reflect Norwegian context and not a need for change.
} 
(669) are on the second rung up (2 or C); $20 \%$ (445) are on the third rung up (3 or B); and $12.3 \%$ (284) are at the top (4 or A).

25. The picture is also of a continent with variation in experience, which Figure 2 shows nicely across the 73 PEFA dimensions. Why do African means on some PEFA dimensions, and thus PFM practices, place the continent at the bottom rung (on average) while showing it on the third rung for others? This variation is not only shown in mean scores across PFM dimensions, however, but also in variation within the dimensions. Figure 3 illustrates this, showing both the mean and standard deviation for the African group in regard to all dimensions. Why do scores vary within dimensions, and why is there inter country variation reflected in standard deviations above 0.7 in all cases?

Fig.3. Noting variation in African PEFA PFM dimension scores

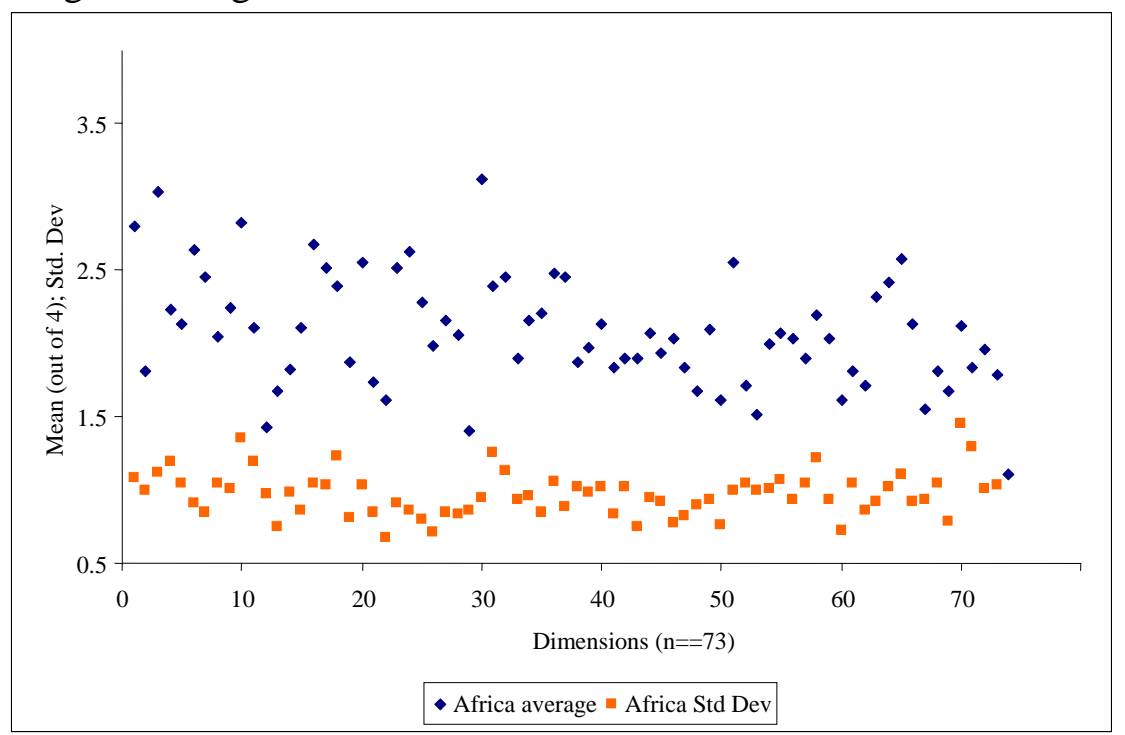

26. The picture of variation across Africa suggests two primary PFM theme types, which are discussed as the basis of a stock taking exercise: (i) themes emerging from variation across PFM process areas; (ii) themes arising from variation across countries. 


\section{Themes from stories across PFM processes}

27. The search for themes to explain varying scores on PEFA's dimensions centered on three issues: differences in process type itself, different challenges in process areas, and different actor combinations involved in meeting challenges. Research into these yields the following themes: (i) Budgets are made better than they are executed; (ii) Practice lags behind the creation of processes and laws; and (iii) Actor concentration pays.

\section{A. Budgets are made better than they are executed}

28. In PFM jargon upstream processes relate to budget planning and preparation while downstream processes involve resource management and execution, accounting and all aspects of external accountability. Figure 4 organizes the scores on the nonoutcome PEFA dimensions into the process area clusters introduced in Figure 1, to show how scores vary as one moves from the upstream on left to downstream at right.

Fig. 4. Showing PEFA dimension variation by process area cluster

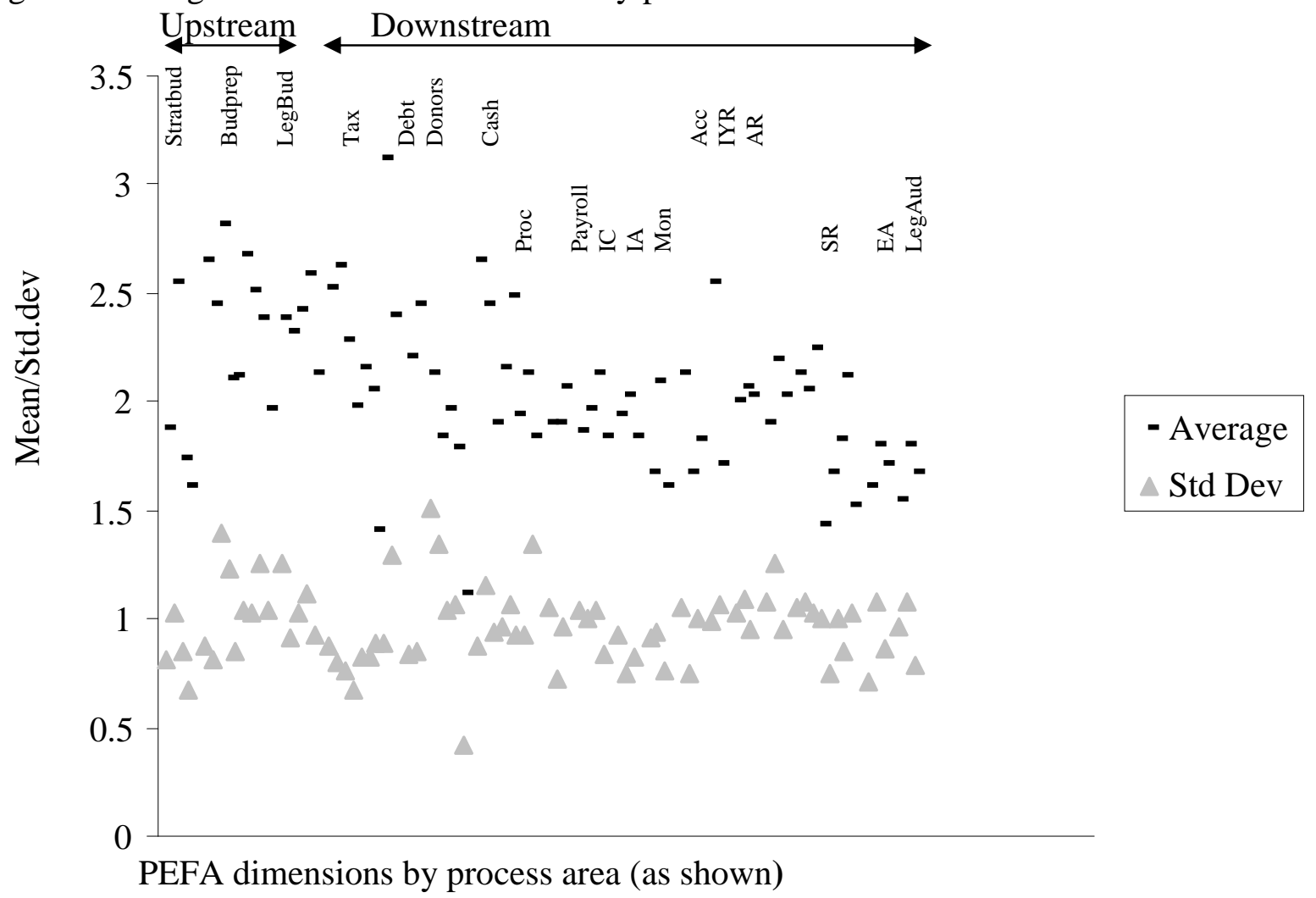

Note: Stratbud = strategic budgeting; Budprep = Budget preparation; Legbud= Legislative budget analysis; Tax= Tax management; Debt=Debt management; Don=Donor engagement; Cash = Cash management; Proc=procurement; Payroll= Human Resources and Payroll management; IC=Internal Control; IA=Internal Audit; Mon=Monitoring; Acc=Accounts reconciliation; IYR=In year reporting; AR = Annual reporting; $\mathrm{SR}=$ Special reporting; EA=External audit; Legaud=Legislative audit analysis. 
29. Figure 4 illustrates that, while not uniform, dimension averages appear higher upstream than downstream. In lay-man's terms, African countries tend to make budgets better than they execute them. de Renzio describes a similar finding: "Average scores tend to deteriorate the further one moves down the various phases of the budget cycle, from formulation to execution, reporting and scrutiny." 15 Recent work by the Open Budget Initiative also resonates, finding that transparency is often higher in the budget preparation stages of the PFM process than in execution and external accountability stages. ${ }^{16}$ The difference in average upstream and downstream scores is just under $0.25,{ }^{17}$ with twice as many countries scoring $\mathrm{D}$ on downstream dimensions (11 compared with 6.9 in upstream processes). ${ }^{18}$ Figure 5 shows the averages of each process index to reflect these differences, noting the four strongest (1-4) and weakest (15-18) process areas.

Fig. 5. Variation across the PFM system, by process area index scores

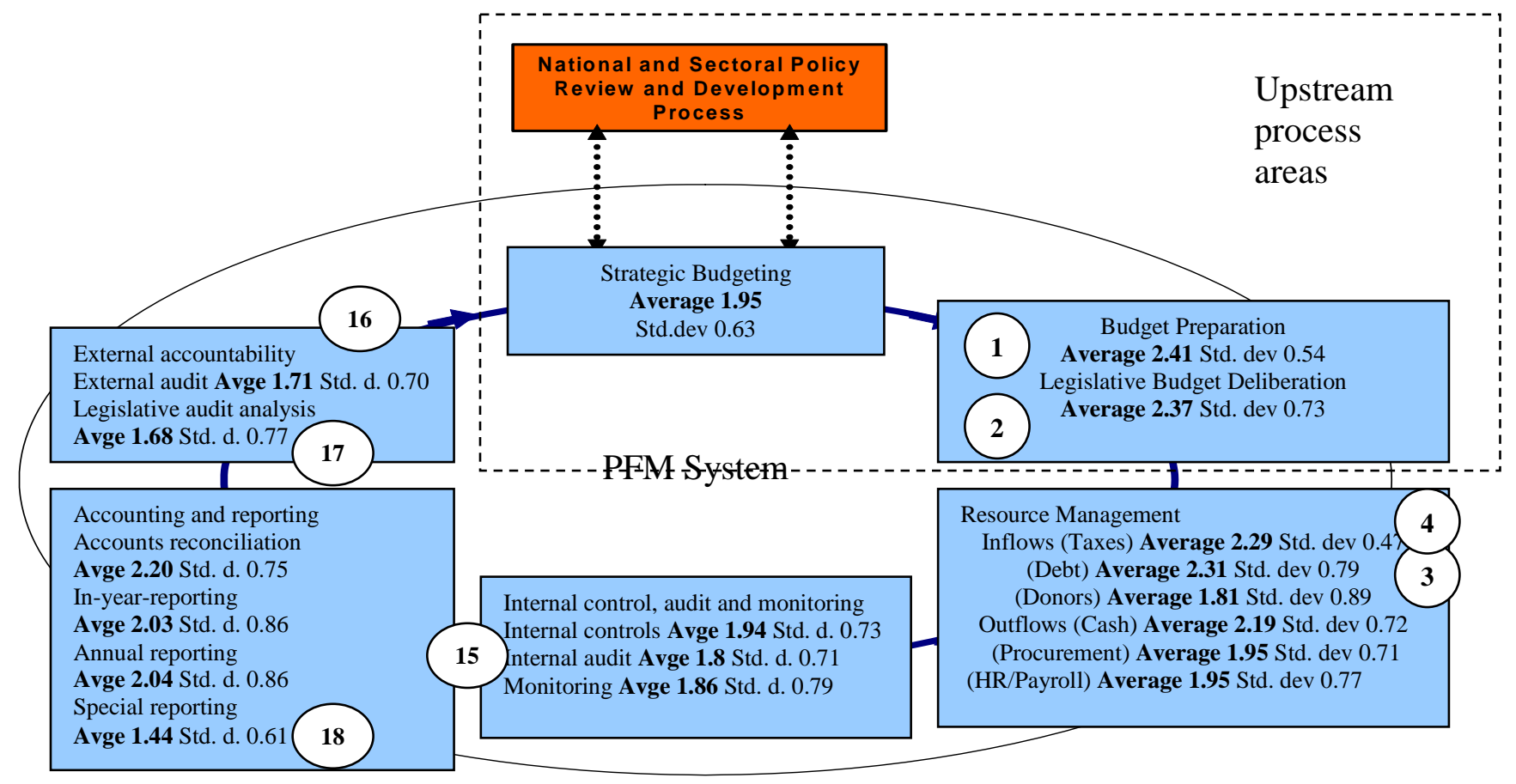

30. The top two index scores are in the budget preparation area-related to formal budget process issues (like presence of a calendar) and legislative engagement in budget preparation. The bottom three are in the downstream reporting and external accountability sections. Among the weaker areas, one finds internal controls, internal audit, monitoring and payroll and procurement (all non-budget areas). The difference between the budget preparation and special reporting indexes is about one (a rung on

15 de Renzio, P. (2008) “Taking Stock: What Do PEFA Assessments Tell Us About PFM Systems Across Countries?” Unpublished manuscript produced with support of the PEFA Secretariat, p.6.

${ }^{16}$ See the 2008 Open Budget Initiative Report: openbudgetindex.org/files/FinalFullReportEnglish1.pdf.

${ }^{17}$ Statistically significant at 0.05 .

${ }^{18}$ A statistically significant difference at 0.01 
the 'ladder' in figure 2!). This means that the average African country is mid-way up the ladder in the way it makes the budget, but only just above the lowest rung in regard to reporting of arrears, extra-budgetary expenditure, donor funded projects, activities in public enterprises and sub-national governments, and resources collected at points of service delivery. An interesting number is the statistically significant 0.69 difference between legislative practices in budget preparation and legislative practices in audit analysis. The same entity is involved in both process areas, but upstream activities are materially and significantly stronger than downstream ones!

31. This 'stronger upstream' theme manifests in the content of introductory and summary sections of PFM-PR documents as well. 13 of the 31 documents reflect on the issue, either broadly (referring to stronger budget preparation versus execution processes) or narrowly (contrasting strengths in specific upstream areas with weaknesses in those downstream). The theme cuts across all countries, regardless of income or colonial legacy and suggests simply that budgets are made better than they are executed (and overseen). There are demand and supply side reasons why this is so: some evidence suggests that budget reforms are more emphasized by donors, for example, and that budget offices are more resourced than others, for example. These reasons raise some questions about potential civil society impacts: Could CSO demand for downstream processes and CSO downstream capacity building decrease the upstream-downstream gap? This issue is explored in Box $1 .{ }^{19}$

Box 1- Civil society engagements can stimulate demand, supply in the PFM downstream Kenyan civil society has been engaged in a variety of PFM areas since 2000, including participating in budget hearings, tender board negotiations and - most recently — assisting with the production of public expenditure tracking surveys (PETS). Civil society in Sierra Leone monitors government expenditure through district level budget oversight committees, which involve widespread community sensitisation meetings on budgetary and public financial matters.

Gabon's reporting streams are particularly weak and its spending is non-transparent. The PFM-PR notes, however, that efforts to comply with EITI have led to government hiring a special auditor to identify oil-related revenue and expenditure streams, potentially bolstering the supply side of transparency. EITI, motivated by international development organizations and CSOs, is also undergirding demand for improved transparency in budgetary reporting and accountability mechanisms. Country 18 cites EITI as a major source of demand for downstream strengtheningparticularly for reporting and audit. CSOs work with government in a National Stakeholder's Working Group to analyze audit reports. CSOs are becoming more budget-literate in the process, demand for audits has increased, and the quality of reporting is increasingly under scrutiny."

In contrast, Zambia's PFM-PR laments the lack of demand for accountability and the lack of civil society pressure for such. It argues that, "The degree of public scrutiny and pressure on the Government to meet its reform commitments should be improved ... [and] ... civil society can play a role in exercising sufficient pressure for good PFM." CSOs do operate in the upstream of the budget processwith entities like the Civil Society for Poverty Reduction programme (CSPR) focusing attention on connections between the budget and PRSP. The CSPR does less work in the PFM downstream, monitoring and reporting on actual spending. Similarly, legislative strengthening initiatives often focus on budget reviews but not audit review. Lesotho is an example. CSO engagements of the watchdog and advocacy varieties are required to help balance the upstream-downstream process divide.

\footnotetext{
${ }^{19}$ The evidence of CSO engagement was typically not identified in World Bank analytical products but rather through personal correspondence with civil society groups in specific countries. This correspondence was corroborated with published references of civil society engagement, in the media as well as-where possible-literature coming out of development organizations. References are available from the author.
} 


\section{B. Practice lags behind the creation of processes and laws}

32. If the first PFM process theme is about where a dimension or process area is found in the PFM stream, the second relates to its depth. Different PEFA dimensions reflect different types and depth of challenge. Some center on legislation or process development only. While they may have some element of practice inferred, countries can achieve $\mathrm{C}$ and $\mathrm{B}$ scores on these dimensions largely by attending to de jure issues (having a procedural step in place, even if it has little influence on behavior). Other dimensions involve implementation of laws and action within processes, or ongoing activity or production. Countries can only achieve C and B scores by overcoming de facto hurdles of practice. Consider the comparison between the following criteria: A government can get a $\mathrm{C}$ on the budget preparation dimension PI 11.i. if it has a rudimentary budget calendar in place (most often in law), even if substantial delays exist in implementation; ${ }^{20} \mathrm{~A} \mathrm{C}$ on the strategic budgeting PI 12.i. requires, in contrast, that actual forecasts be developed, on the basis of economic classification, for at least two years, on a rolling annual basis. Readers may not relate to the technicalities of the last sentence, but should get the idea that it demands evidence of practice.

33. Systematic differences in the way governments meet the different kinds of challenges implied in these examples show up in an important theme; practice lags behind the creation of processes and laws. The theme reflects a prominent new institutional differentiation between de jure and de facto institutions, which argues that the former are less demanding to adopt and change than the latter. It is apparent in comparing the more de jure budget preparation dimension and the more de facto strategic budgeting dimension shown above: There are double the number of $\mathrm{D}$ scores (10) on the more de facto strategic budgeting dimension than on the more de jure budget preparation dimension (which has a low 5 Ds, and $10 \mathrm{Bs}$ ). Similar observations were made when comparing other high scoring and low scoring dimensions in the budget preparation and strategic budgeting areas, especially after these were coded as 'de jure' (if a C could be achieved with minimal de facto engagement) and de facto (if scoring a $\mathrm{C}$ required more implementation). ${ }^{21}$ Coding was done blind by three independent people, with little variation. 64 dimensions were coded (excluding nine outcome and donor dimensions) with 26 coded as de jure and 38 as de facto. Table 2 shows how types differ in averages and number of Ds.

Table 2. Comparing scores in de jure and de facto dimension categories

\begin{tabular}{|c|c|c|c|c|c|}
\hline $\begin{array}{c}\text { Mean all } \\
\text { dimensions }\end{array}$ & $\begin{array}{c}\text { Countries } \\
\text { scoring D in all } \\
\text { dimensions } \\
\text { (average) }\end{array}$ & $\begin{array}{c}\text { Mean for de } \\
\text { jure dimensions }\end{array}$ & $\begin{array}{c}\text { Countries scoring } \\
\text { D in de jure } \\
\text { dimensions } \\
\text { (average) }\end{array}$ & $\begin{array}{c}\text { Mean for de } \\
\text { facto } \\
\text { dimensions }\end{array}$ & $\begin{array}{c}\text { Countries } \\
\text { scoring D in de } \\
\text { facto } \\
\text { dimensions } \\
\text { (average) }\end{array}$ \\
\hline 2.08 & 10.69 & 2.33 & 6.57 & 1.91 & 13.50 \\
\hline
\end{tabular}

\footnotetext{
${ }^{20}$ Governments can even score a B with "some delays”, suggesting a low de facto hurdle even at this level. An A requires that the budget calendar is adhered to, reflecting a significant de facto hurdle.

${ }^{21} \mathrm{C}$ was chosen as a benchmark here because it appears the crucial point of differentiation between stronger and weaker dimensions.
} 
34. Not surprisingly, the averages of the dimension categories are quite different, with the de jure dimensions having a mean almost half a point above the de facto dimensions (2.33 compared with 1.91). More countries score D on de facto dimensions as well; 13.5 countries fall in this category on average, compared with just 6.57 for the de jure dimensions. Both the differences in means and number of countries scoring $\mathrm{D}$ are significant at the $1 \%$ level, suggesting the statistical strength of the theme. Interestingly, $75 \%$ of the total number of D scores (across all countries) in the 64 dimension sample is in the de facto category. This, with the other evidence, implies that African systems are stronger in a de jure than a de facto sense, at least on average. Put simply once again, African PFM practice lags behind the creation of processes and laws. Figures 6 and Figure 7 illustrate higher averages in de jure dimensions, and higher number of $\mathrm{D}$ scores in de facto dimensions.

Fig. 6. Average scores on dimensions : Separating de jure and de facto dimensions

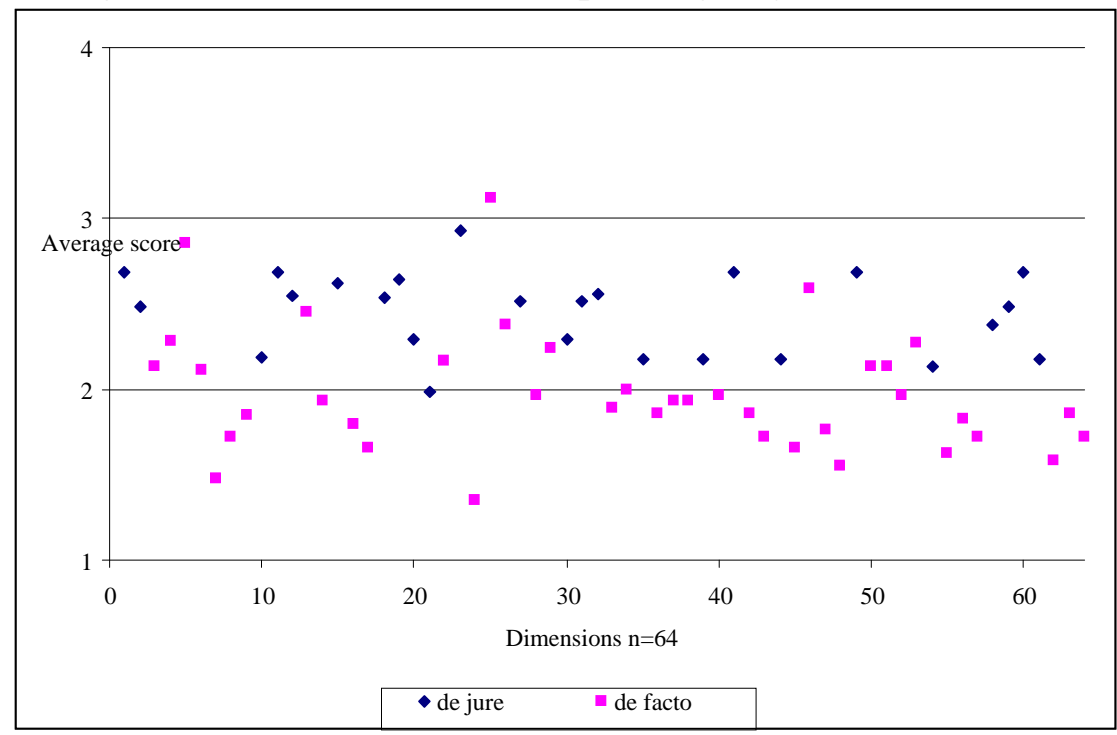

Figure 7. Countries scoring $\mathrm{D}$ on dimensions : Separating de jure and de facto dimensions

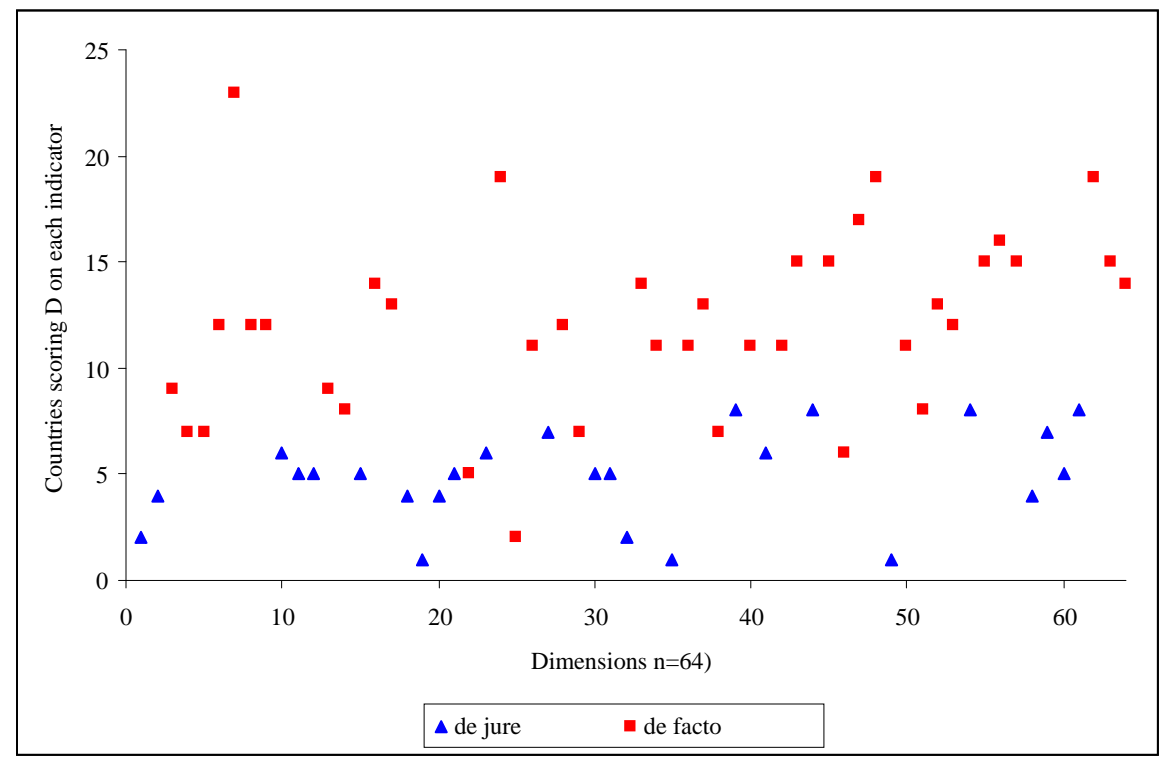


35. Qualitative evidence speaks to this theme as well. The content of all 31 PFMPR documents was analyzed to see how frequently dimension descriptions in the introductory and analytical sections explicitly noted an implementation deficit, using key words (like implementation, practice, and adherence). These explicit references were noted in the descriptions of 297 dimension scores-about $15 \%$ of the total or nine and a half dimension areas per country. Six PFM-PRs were analyzed in more detail to identify less explicit references to this theme as well (where the key words were not used but more lengthy descriptions still showed that laws and/or procedures were in place but not being translated into action). 27 extra dimension areas were identified in the six PFM-PRs, averaging four and a half dimensions per country. When added to the explicit references, these suggest that an average of 14 dimension scores per country reference the gap between laws and practice (a $22 \%$ frequency).

36. Readers should note that there are also numerous references to de jure weaknesses in the PFM-PRs. Summary sections of five PFM-PRs note generalized legal deficiencies and at least half of the documents cite specific weaknessesespecially affecting medium-term budgeting, internal and external audit, and the scope of legislative scrutiny. Most of the legal shortcomings are noted in Francophone countries, relating particularly to audit and legislative analysis of audits. The PFM-PRs include numerous calls for legal and procedural reform in response to such perceived weaknesses, which may be appropriate and have certainly constituted first steps to reform in many of the other countries and process areas (as will be discussed later in the paper). However, it should also be noted that some of the perceived weaknesses referenced in the PFM-PRs are viewed as variations in legal practices across other countries: OECD countries legislate differently in regard to the role of the legislature and even the scope and practice of internal and external audit, and most OECD countries still do not legislate multi-year budgets (even for capital).

37. The basic story appears to be that de jure needs for effective PFM are contextually defined, and may not be the same across all settings. Taken in concert with the theme that many laws and procedures actually on the books in Africa are not implemented, the current message would suggest caution in emphasizing de jure solutions, even when such appear to respond to de jure deficits. Especially where the deficits in question may reflect different governing heritage, culture or level of political fragility (as is also the case in the Francophone countries noted above). The challenge appears to be ensuring that laws in place are actually implemented, and new procedures are selectively introduced with specific strategies to ensure they shape behavior. Evidence suggests a number of reasons why laws are not implemented, including: de jure structures are new in many cases, and secondary regulations that authorize de facto action are yet to be introduced; problems of coordination undermine implementation; Capacity constraints undermine execution; laws are not accepted and incentives undermine their effect; political will is lacking. On top of these issues, some might argue that time is the major missing ingredient and that countries just need a few years to close the gap between practice and the processes and laws they have just introduced. This may be so, but the argument would be 
simplified: 'Time' matters only insofar as it is well used, and the above list of hurdles to de facto effectiveness pose a major challenge for even the best users of time.

38. It is not hard to see how civil society engagements might make a difference in addressing the gap at the center of this theme. It is also not hard to see how the gap itself might create opportunities for CSOs. Box 2 explores some of these. ${ }^{22}$

\section{Box 2- CSOs filling the gap between new laws and old practices in Africa}

CSOs all over Africa are taking advantage of new opportunities created by de jure reforms in the PFM system, especially filling the gap in situations where old practice persists despite new laws.

Malawi is a prime example. The PFM-PR indicates that "the Government has implemented a number of statutory measures in recent years to develop a sound legal framework for effective PFM" (manifest particularly in a string of 2003 laws). It notes, however, that "concerns remain over the level of compliance by Ministries etc. with existing PFM regulations and a continuing lack of enforcement” suggesting that practice lags behind the creation of processes and laws. A local CSO called Malawi Economic Justice Network (MEJN) is engaging where law allows and government practice is falling behind. It played a key role mobilizing civil society in preparing and monitoring the Malawi Poverty Reduction Strategy (MPRS), for example. Cameroon's Dynamique Citoyenne du Cameroun emerged as an umbrella organization of multiple CSOs to participate in developing and monitoring the PRSP. Since 2005 it has played a growing role building independent capacity to monitor the budget process in Cameroon, taking advantage of legal and procedural innovations accommodating public scrutiny in government activities. Benin has modernized its procurement process in recent years, and introduced competitive bidding requirements. The challenge is now to ensure that officials adhere to the requirements. A local CSO called Fonac is working hard to ensure that transactions are monitored, government is held accountable, and incentives are clearly developed to foster adherence. Similar examples can be found across the 31 countries, including the Centre for Budget Advocacy at the Integrated Social Development Centre in Ghana (CBA/ISODEC), the Civil Society for Poverty Reduction programme in Zambia (CSPR) and Nigeria’s National Budget Monitoring Project (NBMP).

Much international support for CSOs is predicated on observations that CSOs can engage more in PFM issues than before, because of de jure 'space'. International engagement can undermine legitimacy of local actors, however, and must be carefully thought out. Some of the more successful engagementsthough on the margins at present-arise through international professional associations. The International Consortium of Governmental Financial Managers, IFAC, and other international accounting and auditing groups are working in places like Ethiopia and Mozambique, Uganda and Tanzania, to assist in capacity building in government, supporting and strengthening audit offices, and facilitating transfers of professional norms vital to the implementation of technical tools (like accounting standards). These engagements are often tied to development of profession-based domestic CSOs (like local accounting associations or public finance professional groups). Historical evidence from western countries like the United States shows that these entities are pivotal in establishing formal, norm-based, professional financial management structures in public and private settings. ${ }^{1}$ One should note that most African countries have only fledgling professional CSOs of this variety, with few members (which accounting ROSCs will attest). The formal legislation of government accounting without such professional backbone will not lead to de facto change; as American accountant Joseph Sterret said in 1904, "Legislation for a profession only grants opportunity."

\footnotetext{
${ }^{22}$ As noted earlier, the evidence of CSO engagement was typically not identified in World Bank analytical products but rather through personal correspondence with civil society groups in specific countries. This correspondence was corroborated with published references of civil society engagement, in the media as well as - where possible - literature coming out of development organizations. References are available from the author.
} 


\section{Actor concentration pays (at least to date)}

39. The first two themes distinguish between upstream and downstream and de jure and de facto process types. The third contrasts the strength of processes involving small, concentrated sets of actors from those requiring the engagement of broad, deconcentrated actor sets. It notes that actor concentration pays (at least to date). This theme manifests as a reason why some downstream dimensions score unexpectedly well. PI 22.i, the dimension speaking to regularity of bank reconciliations, averages 2.55, the $8^{\text {th }}$ highest process dimension. The other reconciliation dimension is PI.22.ii. It centers on reconciliation of suspense accounts and advances, and scores a low 1.71 on average (ranking $54^{\text {th }}$ of 64 ). Nineteen countries score a D on the second dimension compared with the low number of 7 countries scoring a D on the first. Why? The answer is alluded to in score descriptions across the countries, which relate the concentrated role played by Treasuries (or Accountant General Offices) in regard to the first dimension, as contrasted with the de-concentrated roles played by multiple Ministries, Departments and Agencies (MDAs) in regard to the second. A C is scored on 22.i. when treasury managed accounts only are reconciled. Suspense and advance account reconciliation is a more complicated activity, given that these are often managed by MDAs, a more de-concentrated set of actors. The impact of deconcentration is referenced in Mozambique's PFM-PR which states that, "Monthly reconciliation is possible only for Treasury-managed bank accounts.”

40. Twenty six dimensions were coded as involving 'concentrated' actors only (like Budget Directorates, Debt Units, Treasuries). The average score across these dimensions is 2.42, which is significantly higher (at 0.01) than the average for deconcentrated dimensions (1.97). 5.8 countries score Ds on concentrated dimensions, on average, while 12.9 countries (on average) score Ds on de-concentrated dimensions. Figures 8 and 9 show these differences for all of the PEFA dimensions.

Fig. 8. Average scores in concentrated and deconcentrated areas

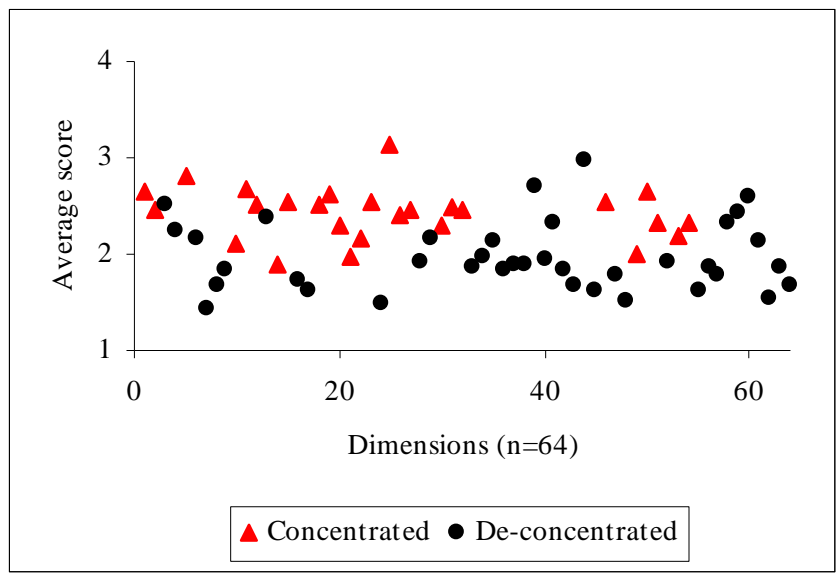

Fig. 9. Number of countries scoring $D$ in concentrated and de-concentrated areas

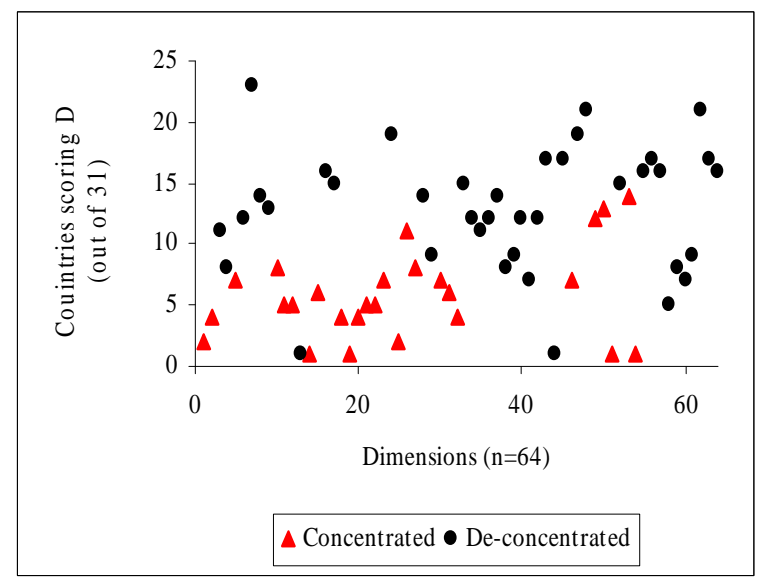

41. Content analysis of the 31 PEFA documents yielded 116 references linking weaker performance with de-concentration, equating to about 4 per document. This theme reflects itself indirectly as well, however, as PFM-PRs relate weaknesses that arise because of de-concentrated connections across processes. The ability of MDAs to develop strategies is undermined by the lack of accounting information in many 
governments, for example. Downstream performance of auditing entities and legislatures is also compromised by poor performance in other areas, particularly the late and/or poor production of financial reports. Table 3 illustrates how a fallen domino in the financial reporting area can cause dominos to fall in areas of audit, response to audit and legislative audit examination. The problem could be going the other way for sure: lack of legislative demand for timely accounts undermines incentives to produce the accounts. Regardless of causal direction, one can see the connectedness of different players in different process areas, and resulting deconcentration of reform, complicates performance.

Table 3. Problematic dependencies and domino effects in the PFM downstream

$$
\text { If score }=1 \text { on } \quad \text { Then likelihood score }=1 \text { on }
$$

Timeliness of submission of $\quad$ Timeliness of audit reports submitted $\quad=\mathbf{7 9} \%$ financial statements

If score $=1$ on

Timeliness of submission of

financial statements

If score $=1$ on

Timeliness of submission of financial statements to legislature

Then likelihood score $=1$ on Follow-

up on audit findings

$$
=71 \%
$$

Then likelihood score $=1$ on

Timeliness of examination of audit

reports

$$
=92 \%
$$

42. The relative weakness of interdependent and de-concentrated PFM process areas also manifests in contrasting outcome performance. Most countries score higher in aggregated outcomes that are directly influenced by the top-down control of specific, concentrated entities and score worse when many entities are involved in achieving disaggregated results. Figure 10 shows that aggregated revenue performance has the highest average and lowest number of countries scoring Ds.

Fig.10. Comparing averages and d-scores in outcome areas

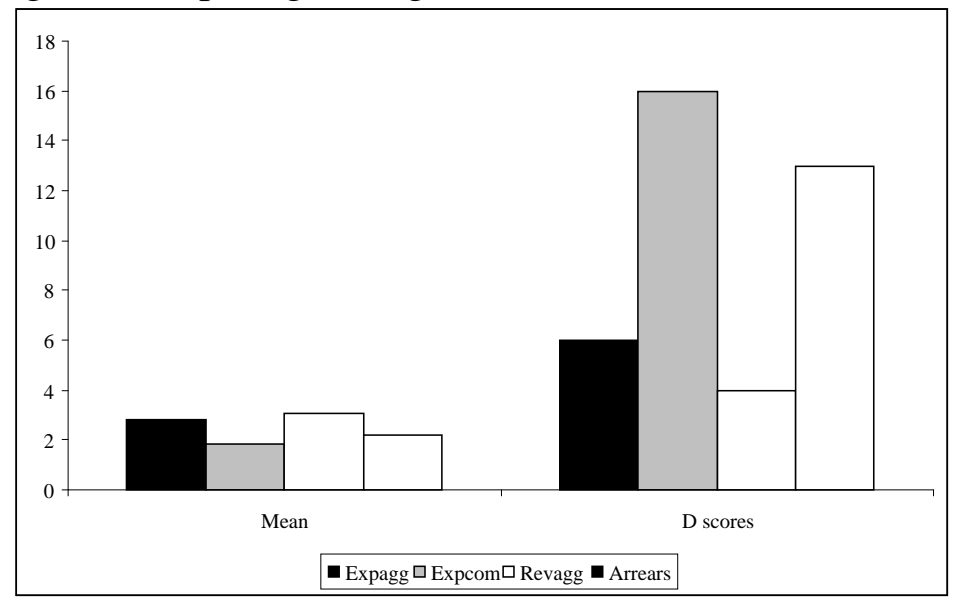

43. Aggregate revenue reliability (Revagg, which measures whether actual receipts reflect those forecast in budgets) averages 3.03 (above a B) across the 31 countries, reflecting a variety of strong interventions by central budget and revenue agencies, including tighter and more conservative forecasting and better revenue collection. Average aggregate expenditure (Expagg, which measures whether on aggregate actual expenditure matches budgeted expenditure) performance is also high 
(at 2.8), largely because of the improved control from budget departments and treasuries (through more formal procedures, calendars and the use of ceilings in budget preparation and in cash management, for example, an important part of the 'top down' model of budgeting touted in development). When one looks at disaggregated outcomes, where de-concentrated actor sets are more directly involved, performance drops considerably. Performance in managing the stock of arrears is more than half a point below aggregate expenditure and revenue performance, on average-with a mean of 2.2 and 13 countries scoring D. Descriptions like the following (from Swaziland) tie such directly to the problem of de-concentration: "There is no reliable data ... It is practically impossible to document arrears ... because the collection of data is not centralized. Data are scattered among line ministries and agencies and are not kept up to date." Countries perform the worst on the highly disaggregated 'composition of expenditure' dimension (Expcom), which assesses the match between expenditure composition in budget papers and actual outturns (asking if the disaggregated detail of actual expenditure matches the disaggregated detail of budgets). The average for this dimension is 1.8 and there are 16 countries scoring Ds, reflecting a variety of different issues ranging from the failure of central control mechanisms to shape allocations to weak formulation and execution in MDAs-problems outside of the purview of the central budget department or treasury.

44. PFM-PRs provide a usual suspect list of reasons why concentrated processes seem more advanced: capacity constraints, political interferences and problems with culture and acceptance are the most commonly noted as being worse when multiple de-concentrated entities are involved. There are other problems peculiar to this theme, however, related to 'reach' in governments, and the information and communication weaknesses underlying such: Central entities engaged in reform need to control and communicate with affected entities that are distributed. Weak information and communication mechanisms undermine system integrity. Some countries have addressed the distributed engagement problem by introducing Financial Management Information Systems (FMIS) to systematize engagements. Automated systems can enhance the reach of new sets of standards, rules, accounting methods and such that have been introduced centrally. Mozambique hopes that its e-SISTAFE system will help concentrate information. But other stories of FMIS introduction suggest the intervention is itself limited by the concentration/de-concentration theme. Tanzania's FMIS reform is widely considered successful, for example, but is still limited in scope and coverage, related to problems of de-concentration-opposition to reform from de-concentrated entities, weak capacity in de-concentrated entities. Rather than the FMIS solving these problems, the problems have appropriately become the focus of ensuring successful FMIS reform itself (still, 6 years after reform began).

45. Other approaches to de-concentration involve improving coordination across the PFM system. Opportunities for coordination seem greater in areas where international entities are working with MDAs on sectoral strategies already. Sectors like education and health in countries like Country 11 constitute enclaves of excellence in this regard, with projects and other kinds of technical links to donors also facilitating ties to central PFM reform processes. These projects can bridge organizations and ensure greater reach for reforms. Civil Society Organizations are 
also playing important roles in connecting entities and mitigating the weaknesses of de-concentration in PFM systems, discussed briefly in Box $3 .^{23}$

\section{Box 3- Can CSOs help reach de-concentrated actors?}

A key PFM pattern in Africa reflects the relative strength of interventions under the control of single, concentrated entities. PFM performance declines in areas involving multiple, de-concentrated role players. General constraints are exaggerated in de-concentrated settings. An extra set of challenges arise in regard to information transfers and communications with such entities. CSOs are well positioned to play a role in addressing some of these challenges, bridging concentrated and deconcentrated players and facilitating reach through capacity building and professionalization programs.

Lesotho's PFM-PR notes the important role regional professional accounting entities can play in entrenching new accounting mechanisms throughout government, especially in support of its IFMIS. The initiative is an imperative because "financial controllers need to take a more pro-active role in ensuring financial probity in their ministries." The initiative is being accommodated by "Moves ... to develop a training program through the Eastern and Southern African Associations of Accountants General...in collaboration with the Chartered Institute of Public Finance and Accountancy.” Similar initiatives to strengthen professional accounting bodies are in place in Mozambique.

The African Capacity Building Foundation has been working to build bridges between deconcentrated MDAs and central budget and planning entities in West Africa. The aim is to strengthen the platform for enhanced dialogue among the public sector and a Network of Chambers of Agriculture of Benin, Guinea, Côte d' Ivoire, Mali, Niger and Togo. The project is currently improving information access on agricultural issues, allowing better policy development and budgeting.

The convening power of civil society was vital to ensuring success in Uganda's PRSP and budget reforms thereafter: "Despite the short time-frame, Uganda succeeded in mobilizing people at grassroots level to participate in influencing policy planning and sharing information” largely because of the work of "The Ugandan Debt Network, [other] national non-governmental organisations, research institutions, other civil society groups as well as hundreds of individuals from all walks of life.” The advocacy and watchdog roles of organizations like the Ugandan Debt Network (UDN) are often emphasized more than its fundamental role as a convening entity. The UDN manages to engage CSOs from many different sectors in its activities, allowing monitoring across de-concentrated parts of the Ugandan government. Broad engagement like this is vital to creating incentives for de-concentrated entities to improve PFM. facilitate cadacitv building opdortunities and accommodate information transfer.

\footnotetext{
${ }^{23}$ As noted earlier, the evidence of CSO engagement was typically not identified in World Bank analytical products but rather through personal correspondence with civil society groups in specific countries. This correspondence was corroborated with published references of civil society engagement, in the media as well as - where possible - literature coming out of development organizations. References are available from the author.
} 


\section{Themes from stories across countries}

46. The themes identified thus far help to understand why different PFM dimensions and process areas appear to 'perform' differently in Africa. Performance varies across African countries in the sample as well. This is explored in the current section, which shows how the PEFA data shows countries falling into different 'leagues' and then explores five country characteristics to better understand why: (i) Income and income growth; (ii) Country fragility; (iii) Revenue source and dependence; (iv) General reform commitment; (v) Colonial legacy.

\section{A. Countries are in different PFM performance leagues}

47. Introductory sections of the PFM-PRs suggest major differences in the PFM system qualities in different countries, similar to the variation one would find in sporting teams competing in different leagues. The PFM-PR for country 5 describes a "context of dysfunction...in respect of public financial management." Contrast this with the comment that Benin's PFM system provides important "conditions [for] the success of the poverty reduction strategy" and the following description of Mauritius: "The Government has well developed and consolidated the potential of the present PFM platform ... The major next steps will aim to position the Mauritian Government at par with international standards and best practice in PFM.” Figure 11 uses PEFA data to illustrate variation implied in these written descriptions. It shows how average dimension scores (over 64 dimensions) vary for each country (with averages calculated without any weighting). Some countries are given a number, not a name, because of confidentiality issues pertaining to their PEFA reports.

Fig. 11. The average PEFA score, for all 31 countries (over 64 dimensions)

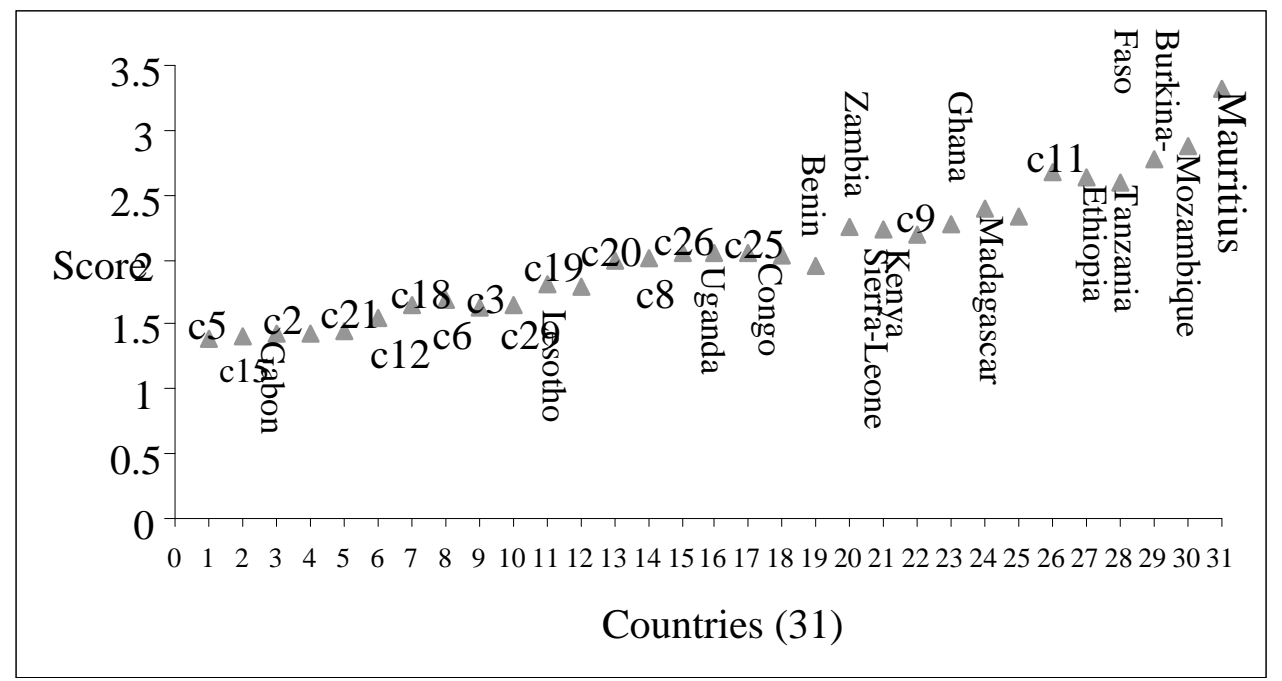

48. The figure reveals a pattern of different PFM performance leagues. These can be organized in various ways. Five leagues were constructed to allow greatest differentiation and contrast. The top league (5) includes Mauritius, Mozambique, Burkina Faso, Tanzania, Ethiopia and country 11. These countries all score a notch above the next league. Country 11 is at the break-point with the next league, scoring 
marginally higher but recording a substantially larger proportion of plus 2 and plus 3 scores. Country 11's average dimension score is 2.67, which stands in stark contrast to 1.54 , country 12 's average score (the highest in the lowest league). Performance differences in the 5 leagues are shown further in Figures 12 and 13 . Figure 12 illustrates differences in the 18 process indexes introduced in Figure 1 while Figure 13 presents differences by league in an index of outcomes. ${ }^{24}$ Taken together, the two figures show simply that countries are in different PFM performance leagues in which-mirroring any sports league-competitors in different leagues have significantly different characteristics and results. The extent and significance of the differences between leagues is obviously most marked when comparing the top and bottom groups. At the extreme, league 1 lags league 5 by more than one point in 17 of 18 process areas (and in outcomes).

Fig.12. Process index scores by league

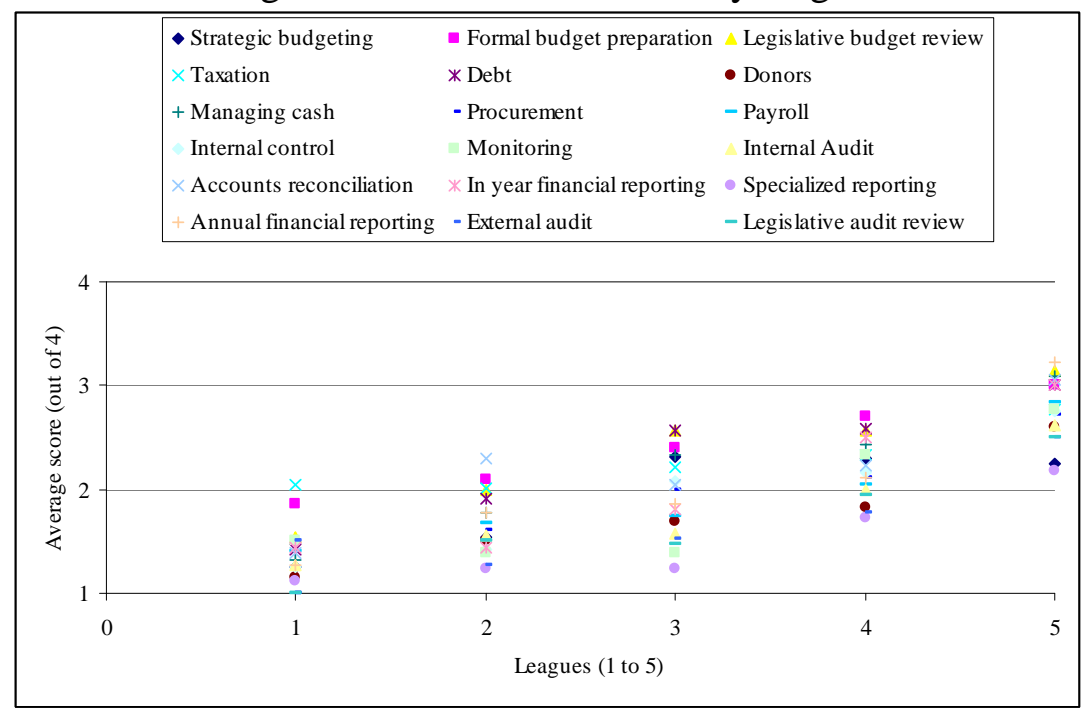

Fig.13. Outcome scores by league

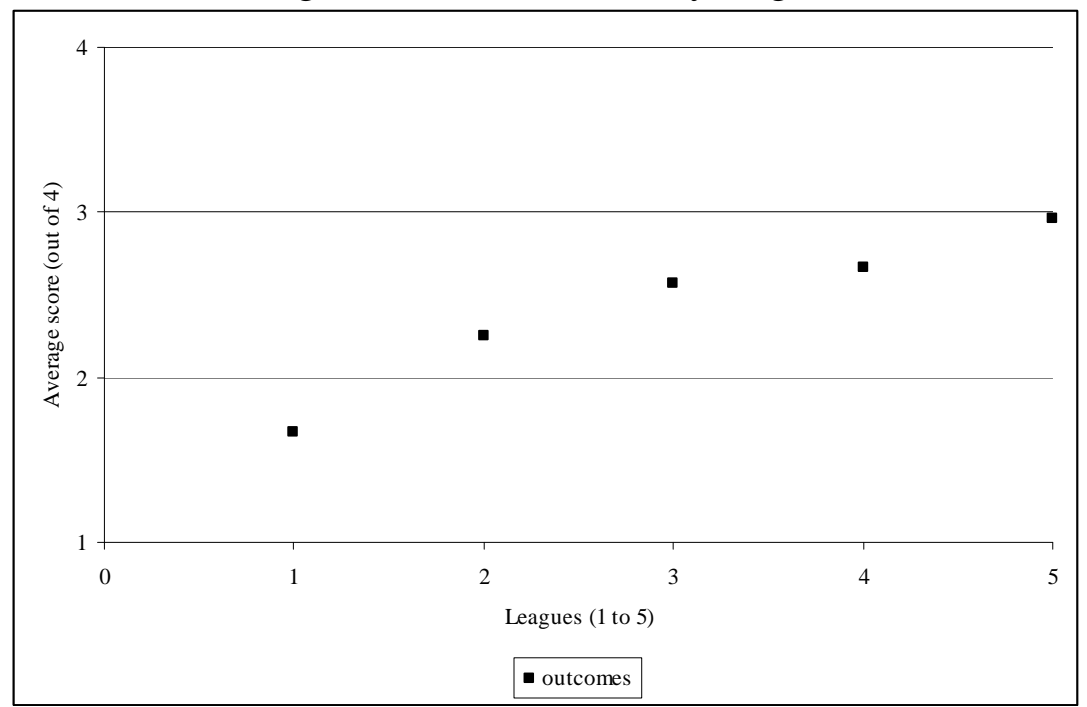

\footnotetext{
${ }^{24}$ The outcome index sums scores for aggregate expenditure and revenue, expenditure composition and
} size of arrears. A score out of 4 is then derived or each country and subsequently averaged for leagues. 
49. Figure 14 shows how different leagues vary in the way they perform on the process types introduced earlier-upstream, downstream, de facto, de jure, concentrated and de-concentrated. Ovals cluster certain averages, showing which group averages are significantly lower than others, in a statistical sense. League 5 dimensions are significantly stronger than those in leagues 1 and 2 in five out of six thematic areas, the exception being concentrated dimensions (where higher league 5 scores are not statistically different from those in other leagues). League 5 averages exceed league 3 averages in all areas as well, but its advantage is only statistically significant in three of these-the downstream, de facto and de-concentrated dimension areas. League 3 countries are significantly stronger than league 1 and 2 countries in exactly these areas - particularly upstream and de jure dimensions.

Fig. 14. Fleshing out the differences between leagues, by theme

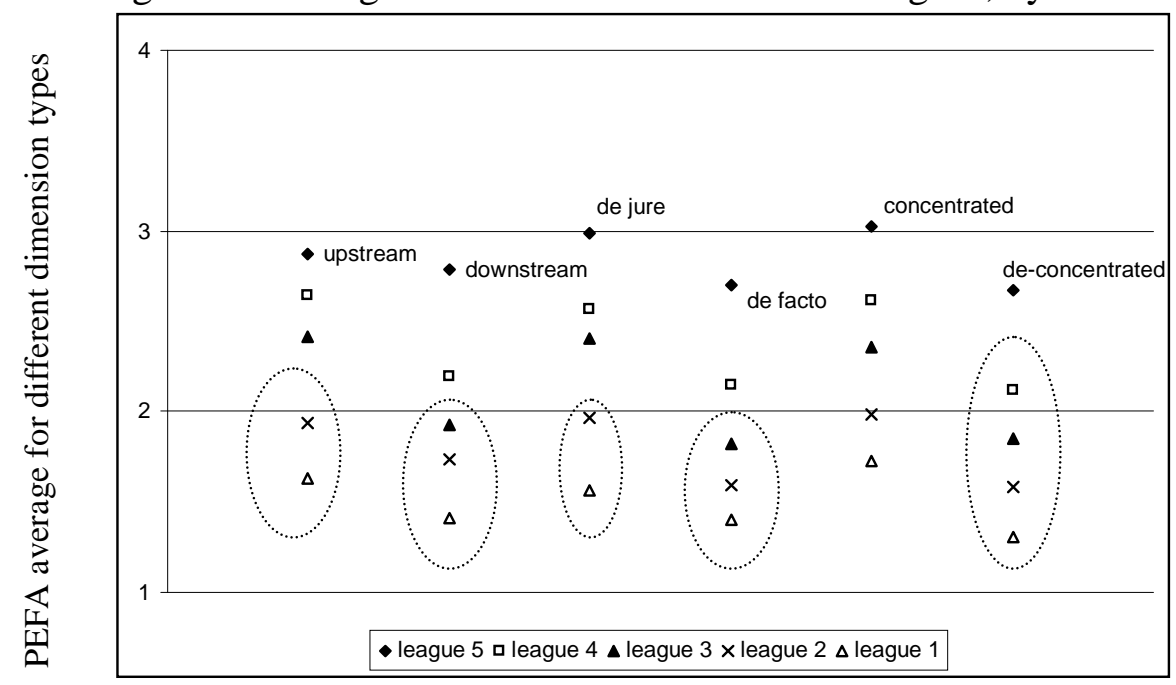

50. Figure 15 sums the story of PFM leagues in Africa, showing what seems to differentiate lower from mid and mid from top league countries.

Fig.15. Summing up the differences between leagues

\begin{tabular}{|c|c|}
\hline $\begin{array}{l}\text { Upstream: Weak } \\
\text { Downstream: Weak } \\
\text { De jure: Weak } \\
\text { De facto: Weak } \\
\text { Concentrated: Weak } \\
\text { De-concentrated: Weak }\end{array}$ & $\begin{array}{ll} & \begin{array}{l}\text { Upstream: Strengthened } \\
\text { Downstream: Strengthening } \\
\text { De jure: Strengthened } \\
\text { De facto: Strengthening } \\
\text { Concentrated: Strengthening }\end{array} \\
& \begin{array}{l}\text { Upstream: Strengthening } \triangle \\
\text { De-concentrated: Strengthening } \\
\text { Downstream: Weak } \triangle\end{array} \\
\text { De jure: Strengthening } \\
\text { De facto: Weak } \\
\text { Concentrated: Strengthening } \\
\text { De-concentrated: Weak }\end{array}$ \\
\hline 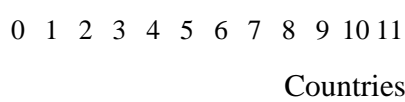 & $\begin{array}{l}1213141516171819202122232425262728293031 \\
\text { (31, organized by league) }\end{array}$ \\
\hline
\end{tabular}


51. Figure 15 illustrates the following: Lower league countries ( 1 and 2$)$ have weak dimensions no matter how these are categorized; de jure and de facto are weak, as are concentrated, de-concentrated, upstream and downstream. League 3 countries share weak downstream, de facto and de-concentrated dimensions with lower league countries; but league 3 countries are strengthening PFM dimensions that are in the upstream, de jure in nature, and centered on the engagement of concentrated actor sets. League 5 countries have already strengthened upstream, de jure and concentrated PFM areas; but these countries are currently challenged to strengthen the other dimensions - downstream, de facto and de-concentrated.

52. This evidence thus far speaks to the fact that African countries have quite different PFM system strengths. The evidence also suggests different challenges facing these countries. The above observations do not, however, help explain why countries fall into the leagues they do. They do not indicate which contextual issues influence PFM system strength and why. Such explanations flow from both the quantitative and qualitative data, however, and speak to the influence of various factors: Income and growth; Social, political and economic fragility; A country's revenue source; The length of uninterrupted national reform, and; Colonial legacy.

\section{B. Growing economies have stronger PFM}

53. Figure 2 compared African and non-African country group averages on PEFA dimensions, finding Africa lagging behind the other sample in most dimensions. The comparison was considered unfair, however, because of different wealth profiles of the countries in the two groups. Countries in the non-African group had higher incomes per capita which was seen as a driver of their significantly higher PEFA scores, matching a finding by de Renzio in another recent study using similar data. So, one would expect to find income per capita influencing PEFA performance in Africa as well, with the top league countries expected to have higher per capita incomes and the lower league countries having lower per capita incomes.

54. The evidence does not support such expectation. Two of the six league 5 countries (Ethiopia and Country 11) have among the weakest incomes per capita in the 31 country sample. Eight of the top twelve PEFA performers have incomes at or below $\$ 1,000$ per capita. In contrast, five of the ten countries with incomes per capita above $\$ 1,500$ are in the lowest two leagues (the bottom twelve performers). This finding arises partly because of a relative lack of variation in country income levels in the African sample. The full PEFA sample of 73 countries includes eight countries with incomes per capita above $\$ 4,000$ but the current sample only has two with one more on the margin. Two of these, Country 29 and Gabon, boast higher incomes per capita as the only reflection of a middle income type status-looking like less wealthy countries in every other respect-partly because both draw money from opportunistic revenue sources (external trade and remittances in Country 29 and oil in Gabon). It is interesting to note that Mauritius does show up as a positive outlier, significantly ahead of all other countries in most areas. Its average scores for both de jure and de facto dimensions are more than two symbols above Gabon's (with both significant at 0.01). If the countries in higher income per capita brackets in the 
African group were all like Mauritius (examples perhaps being Botswana and South Africa) one might find a positive country wealth effect on PFM quality. This would not change the fact, however, that lower income countries do appear in the top leagues. This is an important finding that speaks to the idea that low income is not a fatal limit on how high a country can climb on the 'reform ladder'.

55. The relatively strong performance of lower per capita countries in Africa is not only due to a lack of truly middle income countries in the sample, however. PFM systems in lower income countries may be higher because they have been boosted through interventions particularly targeting poor nations. Countries like Benin, Burkina Faso, Ghana, Guinea, Madagascar, Malawi, Mali, Mozambique, Sao Tome and Principe, Tanzania, Uganda and Zambia were all beneficiaries from the Highly Indebted Poor Countries initiative (HIPC) which bought them some debt relief and made them subject to early PFM assessment and high reform pressure and engagement. Various countries cite the HIPC intervention as a vital influence on the PFM reform agenda, referencing the PRSP in similar respect. It appears that HIPC and PRSP created fiscal and reform space that has facilitated PFM improvement in these lower income settings. Fourteen of 31 countries speak of HIPC and PRSP in positive terms, referencing either the demand for reform spurred by debt relief or the opportunities for reform emerging from HIPC-linked technical assistance.

56. HIPC beneficiaries in the sample have mostly seen significant economic growth in the past ten years. This rate of growth in incomes per capita seems to matter a great deal to PFM performance, accommodating fiscal and reform space and underlying domestic and international demand for reform. The evidence strongly suggests that growing economies have stronger PFM. Figure 16 shows that three of the top five PEFA performers and eight of the top twelve PEFA performers recorded per capita economic growth of twenty percent or more between 1996 and 2006. In contrast, five of the bottom six countries (league 1) recorded growth below zero percent in the period. The differences in growth rates between league 1 and league 5 PFM performers are quite apparent in the figure, with both isolated in the ovals to left and right. The average PFM score in lower growth countries (below 1\% per annum) lags that in higher growth countries in $84 \%$ of the PEFA dimensions, with $22 \%$ of these differences being statistically significant.

Fig. 16. Per capita GDP growth rates (96-06) for weakest to strongest PFM performers

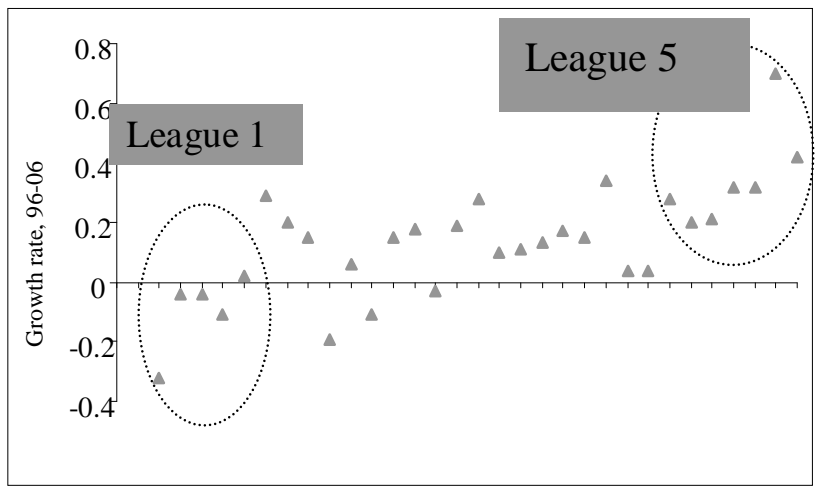


57. It is beyond the scope of this paper to examine how the interaction of economic growth and PFM strengthening works. Indeed there are various schools of thought on this, which have different perspectives on the reasons for interaction and the directions of causality. Some suggest that economic growth creates demand for improved governance and generates a necessary supply of skilled people. Others suggest that commitments to improved governance can generate economic growth, so that a PFM reform commitment might just be a way for political leaders to attract FDI and facilitate growth. Others suggest that the issue is rather one of changed culture, which could come from the private or public sectors and which may facilitate both improved governance and growth. Future research on this topic is vital and could assist policymakers in working out exactly what the connection is between the technicalities of PFM reform and the real world realities of economic development and growth.

58. As noted, this paper does not delve into such question. It does, however, identify the PFM process areas seemingly most influenced by economic growth. These emerge as the process areas in which fast and slow growth countries record the biggest differences in index scores. They are manifest throughout the PFM system except monitoring. Figure 17 shows differences in all process indexes: Dark arrows indicate where differences in means are significant at 0.01 (strategic budgeting and legislative budget review) and lighter arrows indicate significance at 0.05 .

Fig. 17. Comparing average process index scores, in lower and higher growth country groups

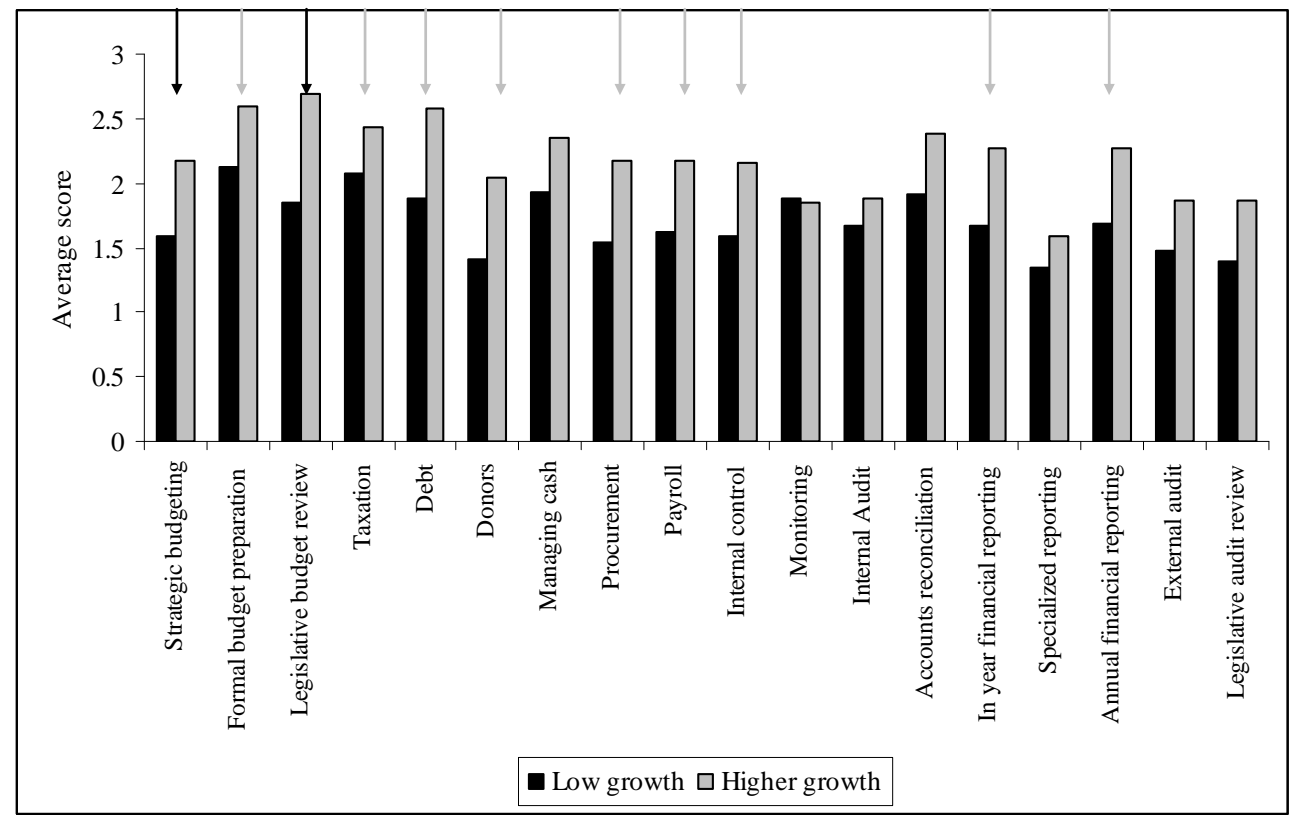

Note: The dark arrows indicate statistical significance of the difference in means at 0.01 ; lighter arrows indicate statistical significance of the difference in means at 0.05 .

59. HIPC inspired debt relief and associated reform opportunities, together with sustained economic growth, seem to have accommodated PFM improvements in a number of African countries over the past decade, creating space for new ideas and approaches and demand for such. It is interesting to note that CSO engagement in some of these countries also seems to reflect new opportunities emerging from more 
developed economies. The growth of private business interests has spawned CSOs representing such in countries like Ghana and Mozambique, for example, and new tax advocacy groups are proving influential in holding governments accountable for the way they raise and spend resources. CSOs in these settings face their own challenges, however, because of the increased sophistication of the economies they are engaged with. One is seeing opportunities for CSOs working to build capacity of other CSOs in such settings, as yet another role for these entities (see Box 4 for examples).

\section{Stability delivers PFM progress}

60. Economic growth is often influenced by political and social conditions. Instability or fragility can undermine growth prospects and the development of government systems. Figure 18 illustrates this in the African group, organizing the countries in their leagues but showing their per capita growth rates and identifying which ones are considered fragile. Five of the six weakest PEFA performers (all in league 1) are also considered 'fragile' (given IMF classifications) because of instability, and four of these had sub-zero growth rates between 1996 and $2006 .{ }^{25}$ Three of the six countries in league 2 are similarly labeled. ${ }^{26}$ Only one country outside of the bottom two leagues is considered fragile, and this is Sierra-Leone.

Fig. 18. Fragility, growth, and the African leagues of nations

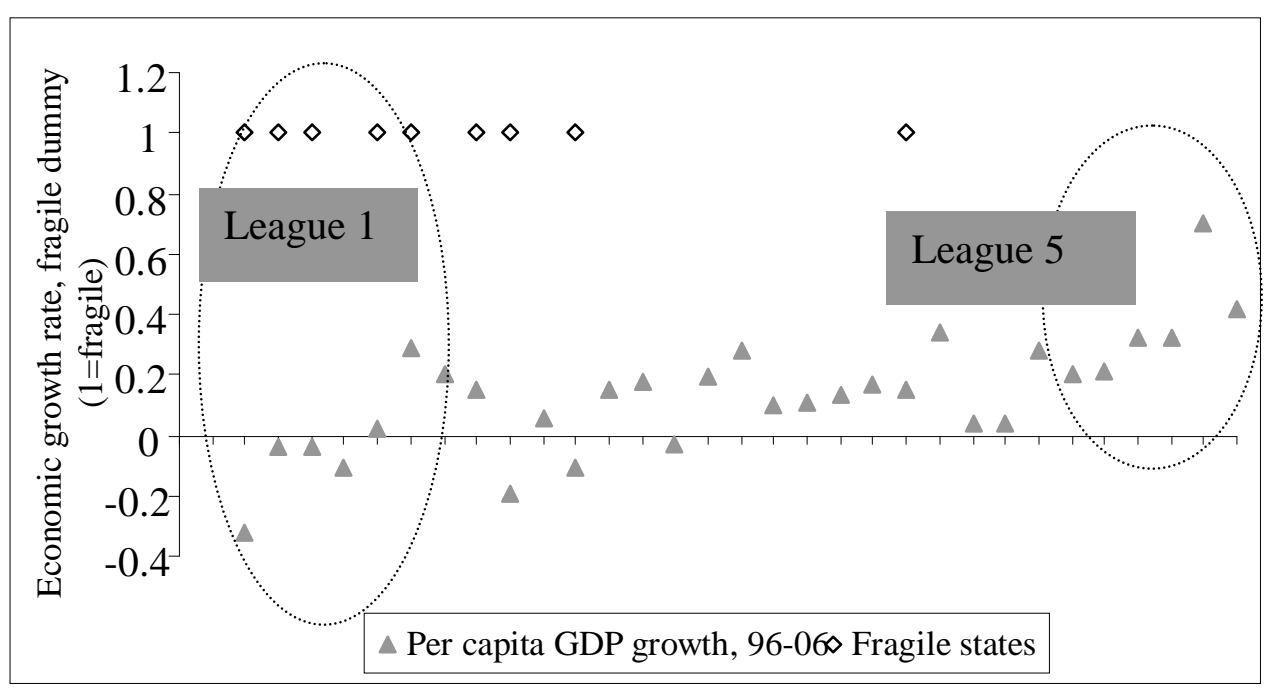

61. The impact of fragility on PFM system performance is startling. Fragile country averages are lower than non-fragile countries in respect of $95 \%$ of the PEFA dimensions. ${ }^{27}$ The difference in means is greater than 0.75 and statistically significant in respect of more than half of the dimensions. ${ }^{28}$ Legislative dimensions of all kinds

\footnotetext{
25 These are countries 2, 5, 12 and 15. The 'fragile' classification is made according to the IMF's 2007 Regional Economic Outlook for Sub-Saharan Africa. IMF. 2007. Regional Economic Outlook: SubSaharan Africa. IMF: Washington, D.C.

${ }^{26}$ These are countries 3,6 and 19.

${ }^{27} 61$ out of 64 .

2833 differences in means exceed 0.75; 35 differences in means are statistically significant at 0.05 or better.
} 
are weaker in fragile countries. ${ }^{29}$ All dimensions in strategic budgeting and budget preparation process areas are significantly weaker as are the dimensions reflecting budget transparency and crucial downstream processes like cash management, procurement, payroll control and internal control. ${ }^{30}$ Interestingly, fragile states score relatively better on concentrated PFM dimensions - in areas of budget management, treasury and revenue management, for example-than they do on any other dimensions. This seems to reflect the fact that some of the fragile states maintain small, concentrated cadres in select areas, even through political and social turmoil (budget offices or treasuries might remain intact).

62. Figure 19 shows the processes in which aggregated dimension scores yield major differences between fragile and stable countries. Eight out of eighteen differences in mean between fragile and stable countries are statistically significant at 0.01 and a further six are statistically significant at 0.05 .

Fig. 19. Comparing average process index scores, in fragile and stable country groups

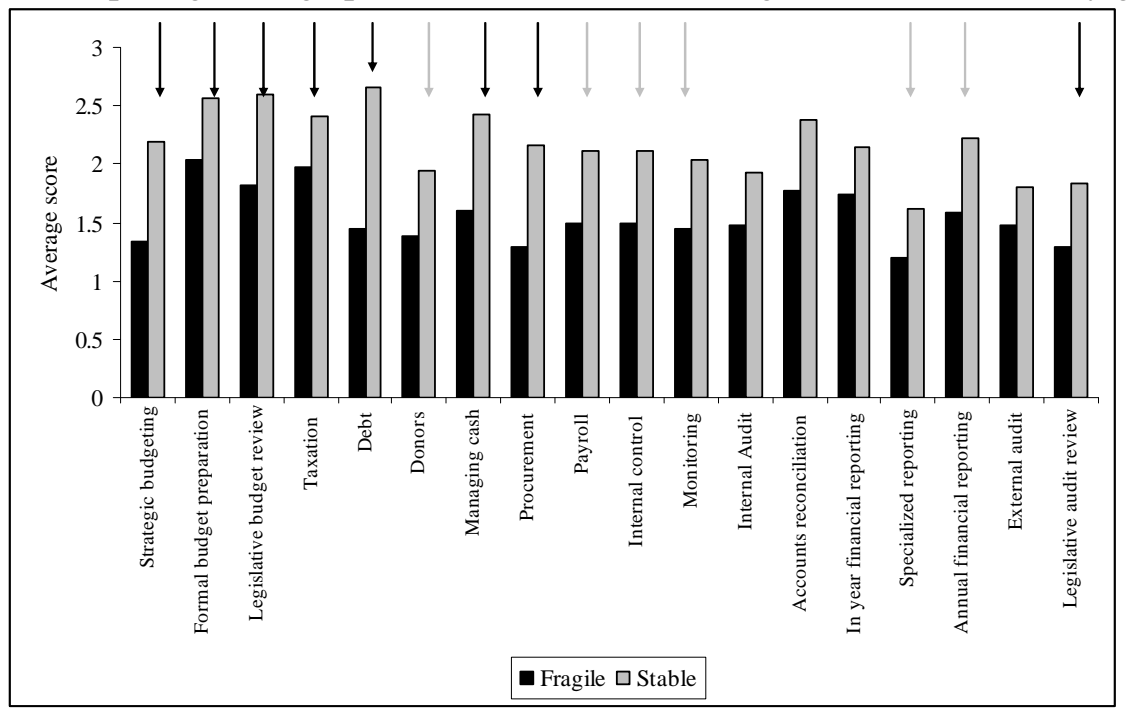

Note: The dark arrows indicate statistical significance of the difference in means at 0.01 ; lighter arrows indicate statistical significance of the difference in means at 0.05 .

63. The PFM-PRs for these fragile countries all describe costs of conflict for development, and the particular challenges fragility brings to PFM. Country 2 is described as "characterized by a climate of insecurity ... [which] ... has a negative impact on the economic development and the living conditions of the populations." Ongoing conflict in country 15 is blamed for making the "economy ... dull, particularly fragile and vulnerable" and "degrading ... the financial standing of the State.” Country 5's PFM-PR links such developmental interruptions and PFM weakness, manifest in the failure to pass key laws and produce budgets: "The various political crises and conflicts ... since 1998 ... [led to a] deterioration of the economic situation. The resulting financial difficulties generated dysfunctions in public finance management which resulted in delays in adoption of the finance laws of the years

\footnotetext{
${ }^{29}$ All seven dimensions lag by more than 0.75 and all of the differences are highly significant (six at 0.01 ).

${ }^{30}$ In all of these areas every single dimension is more than 0.75 points weaker in fragile countries, and in all cases these differences are statistically significant (at 0.05 or better).
} 
2001 and 2002, the absence of a budget in 2003 and the recourse to exceptional budget execution procedures.”

64. The various PFM narratives suggest that fragile countries sport the kinds of weaknesses one finds associated with PFM problems in the other countries, but in an exaggerated form. Capacity is not just weak, it is non-existent (apart from some concentrated areas). Informality reigns almost unchallenged in government processes, because of a lack of formal mechanisms (most visible in failures to even produce budgets in Country 5). Political will is lacking because politics is focused on conflict rather than public value creation. A basic message is that countries in such situations cannot do much to strengthen their PFM-basic political legitimacy must precede technical intervention.

65. In light of such observations it is interesting to note the kinds of areas where fragile states lag most behind the others. These include, particularly, dimensions related to the political side of the budgetary process. Fragile states average about a point lower than other countries on most aspects of legislative engagement, with differences in scores statistically significant in all cases. Fragile states also average weaker scores in the political aspects of budget preparation. The difference in means for the dimension related to "political involvement in the guidance on the preparation of budget submissions" is 1.24 (the difference between a D and B-, perhaps), which is significant at 0.01 . Statistically significant differences in means also exceed one in regard to legislative approval of the budget, production of multi-year fiscal forecasts and existence of costed sector strategies. Every one of the fragile states scores a D in the dimension focused on producing multi-year sectoral strategies. Should we be surprised that countries in political turmoil are so far below their African counterparts in these political and policy dimensions? Should we expect anything more?

66. These questions are quite sobering, and actually make one inquire about the appropriateness of the PEFA dimensions in different contexts. PEFA stakeholders imply that their indicators are "objective measures of performance" that are "generally accepted as 'best practice."”31 One has to ask, "Best practice for whom?" (A question frequently raised in the general critique of best practice literature itself.) Is the focus on developing a multi-year budget best or even appropriate in countries that recently failed to develop annual budgets? Is a strong emphasis on achieving political consensus and medium-term budget control through rational, top-down control mechanisms (like ceilings and multi-year projections, or sectoral strategies) really objectively accepted as best practice in emerging polities? ${ }^{32}$ In PFM areas where political decisions are being made, it is important to remember that different political cultures, maturities and such may require different solutions at different times. The mechanisms implied in the PEFA dimensions may not work for Norway and may work even less for post conflict states.

\footnotetext{
${ }^{31}$ PEFA Secretariat. 2008. PFM Performance Measurement Framework Monitoring Report 2007. p.27.

${ }^{32}$ Recent OECD studies show that some prominent countries do not even use ceilings as much as others do, relying on alternative political mechanisms for consensus and to ensure reliable fund flows to policy areas. Norway's recent PFM-PR defends a D for the dimension related to multi-year forecasting and budgeting.
} 
67. The negative story of fragility's impact on PFM systems, and also of the implications of weak politics on governance in general, has a positive side to it. More than two thirds of the African countries are not fragile but are enjoying stability, and the evidence suggests that stability delivers PFM progress. This is most noticeable in countries like Sierra-Leone which has emerged from fragility to a state of relatively strong PFM in five years (if one considers 2002 the end of the civil war). The current paper started with a reference to the fact that Sierra Leone's Ministry of Finance was burnt down during the civil war, meaning that everything needed to be rebuilt. This opportunity to rebuild, and the political stability and economic growth recorded since 2002 seem to have accommodated major PFM progress. One has to ask, "Is there a peculiar reform dividend post conflict countries can benefit from?”

\section{Can post-fragility yield reform dividends?}

68. Country 11 is in a similar position to Sierra Leone; its experience also suggests some kind of peculiar post conflict reform dividend. Having emerged from civil turmoil in the mid-1990s, government leadership used the subsequent twelve years to create a first class league 5 African PFM system (See Figure 12). It appears that countries experiencing stability after periods of fragility may find peculiar opportunities to start 'from scratch' that others do not have. Mozambique and Madagascar are also somewhat examples of this, both being relatively strong PFM performers despite having experienced and/or emerged from turmoil within the past fifteen years. Mozambique did not start 'from scratch' however, building at least partly on the old Portuguese system it had inherited. Its PFM-PR notes now that the new reforms (particularly based on the SISTAFE Law and e-SISTAFE technology, which were adaptations of the Portuguese system) are being hampered by old ways of thinking: "If reforms are to be sustainable and to have impact over the long term, there is a clear and pressing need to break with past systems and approaches.” The citation refers to a reform problem Brinkerhoff and Goldsmith call "institutional dualism"; 33 situations where, "Well intended legal, regulatory and procedural changes often produce a shell of proper governance that has little bearing on how public decisions are actually made and implemented. Meanwhile, preexisting and deeply embedded understandings and practices survive and continue shaping the way people are ruled.”

69. It appears that Country 11 and Sierra Leone may not have faced the dualism problem as severely as others do, partly because they treated their emergence from fragility as an opportunity to modernize and do something new. In the absence of a pre-existing system and norms, they were able to build 'from scratch' and not in parallel to pre-existing mechanisms. This is an important potential comparative advantage such governments might have, and one currently fragile states should be attentive to. It is also relevant to the discussion of the role CSOs can play in PFM development in fragile states. Is this role potentially greater and more creative than in other settings, unfettered by past role paradigms? One sees CSOs and NGOs occupying spaces in sectoral projects in fragile countries that they did not in the past,

\footnotetext{
33 Brinkerhoff, D. and A. Goldsmith. 2005. "Institutional Dualism and International Development: A Revisionist Interpretation of Good Governance” Administration \& Society, Vol. 37, pp.199-200 cited.
} 
and still do not in many more stable settings. Box 4 cites examples of this, and potential opportunities for CSOs in the PFM domain. ${ }^{34}$

\section{Box 4 - Different countries, different CSO opportunities and roles}

Economic growth and democratic reform across Africa has led to greater pressure for government accountability. Civil society is playing a growing role advocating such, on both the revenue and expenditure sides. EITI and Revenue Watch have empowered CSOs in countries like Nigeria, Gabon and Ghana to question government. The Integrated Social Development Center (ISODEC) in Ghana actively monitors government reporting on revenues as well as the tax code. CSOs are also emerging in the form of vibrant business coalitions in growing economies. Ghana's BUSAC (Business Sector Advocacy Challenge Fund) provides policy analysis and advocacy services for business. Some business oriented CSOs in countries like Ghana and Burkina Faso adjust to represent interests of the disempowered as well. Burkina Faso's Action for Development of Rural Women (GRADE-FRB) advocates for developing mechanisms that allow citizen participation in government decision-making.

Economic growth is also bringing greater market and governance sophistication in many countries. While this creates opportunity for CSO engagement it also demands that the CSOs ramp up their own capacities and sophistication. A recent UNDP report on CSOs in Mozambique emphasizes the importance of "quality" in their engagement. It cites the role of the Fundação para o Dseenvolvimento da Comunidade (FDC) in mapping CSOs and building capacity for quality engagement.

It is interesting to note just how much economic growth and governance reform can accelerate CSO opportunities for PFM engagement. The 2008 CIVICUS Civil Society Index for fast growing Ghana asks about CSO involvement in the budget process and in monitoring government. ${ }^{1}$ The answers to both sections entail descriptions of 936 and 843 words respectively. Answers to the same questions number 230 and 295 words in the case of Sierra Leone, where per capita incomes have grown in the past ten years but only after declining for the ten years prior (such that the country is still not at its 1990 levels). Togo's per capita income has reflected a negative trend almost continuously since 1990, falling $4 \%$ in the last decade. CSO engagements in budget and monitoring activities are described in the CIVICUS database in only 65 and 92 words, ${ }^{1}$ suggesting limited engagement.

Togo's CSO engagements and economic growth experience have both been affected by its fragile state. Opportunities for CSO engagement in fragile states are quite different to those in growing, stable economies. The focus my be less on holding government to account and more on providing organizational frameworks and capacities and providing forums for political and policy deliberation. CSO roles will differ even across these settings, depending on historical tensions within societies themselves (and how CSOs might have been implicated in such). Countries vary in these respects, with CSO representatives in Togo believing that "government perceives civil society as part of the opposition, and considers the budget its private domain" thus limiting opportunities for engagement. Rwanda's government is described as being "open to dialogue" with civil society.

CSOs play important roles in Cote d'Ivoire. The local branch of CARE manages the country's Global Fund HIV project, aimed particularly at interventions in rebel controlled areas. Government has no reach in these areas, so it is an appropriate role for CARE. In managing the project, CARE is shoring up decentralized capacities in local entities that struggled previously, developing new supply chain and procurement processes, planning and monitoring mechanisms that might well become important bases for future financial management capacities in the health sector.

\footnotetext{
${ }^{34}$ As noted earlier, the evidence of CSO engagement was typically not identified in World Bank analytical products but rather through personal correspondence with civil society groups in specific countries. This correspondence was corroborated with published references of civil society engagement, in the media as well as - where possible - literature coming out of development organizations. References are available from the author.
} 


\section{Fiscal states have stronger PFM systems}

70. The Extractive Industries Transparency Inititaive (EITI) has been mentioned a number of times already, something indicative of the dependence many African countries have on revenues from extractive industries. Does PFM look different in countries with such dependence? The link between extractive industries and other economic and social characteristics is a popular research theme. Many might argue that the 'resource curse' associated with large natural resource deposits has a direct effect on economic growth and fragility prospects. Proposed economic growth and fragility impacts on PFM quality may be purely endogenous, therefore, driven by this underlying issue. Others argue that dependence on natural resources for government revenues undermines PFM and other governance reform prospects directly, however, and the fiscal sociology literature holds more broadly that all revenues not collected from citizens undermine the quality of governance. This literature differentiates between fiscal states (where most revenues are collected domestically from citizens) and rentier states (where revenues are accrued from external sources to which government is not accountable, including natural resources, trade taxes and even external donors).

71. In the study at hand four countries are classified as oil-rich (based on IMF classification) ${ }^{35}$ while nineteen could be called rentier states because more than half of their government revenues come from non-domestic sources (mostly trade fees and taxes). Figure 20 shows which countries are classified fragile, rentier and resource (oil-rich rentier).

Fig.20. Where are the rentier, oil-rich resource states?

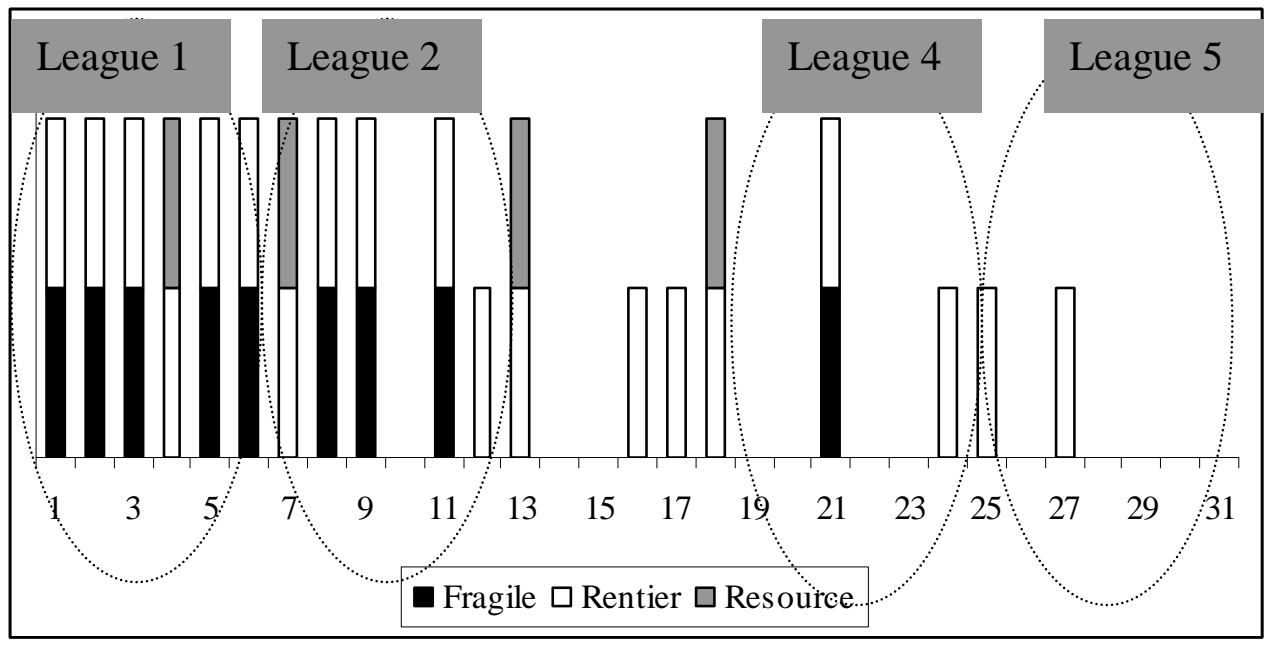

72. Interestingly, none of the oil-rich (resource) states are fragile. However, eleven of the twelve governments in the bottom leagues 1 and 2 are rentier states (with more than half government revenues derived from external sources), ${ }^{36}$ and all

\footnotetext{
${ }^{35}$ Congo, Gabon and countries 18 and 20. IMF. 2007. Regional Economic Outlook: Sub-Saharan Africa. IMF: Washington, D.C.

${ }^{36}$ Country 29 is the only fiscal state in these lower leagues.
} 
six in league 1 are rentier states. The four oil-rich rentier states are in lower leagues. In contrast, all but one of the league 5 countries are more 'fiscal' in nature. ${ }^{37}$

73. The evidence is thus apparent but not conclusive that a rentier state will have a weak PFM system and a fiscal state will have a stronger system. However, further evidence emerges in comparing PEFA dimension scores in fiscal states, rentier states (broadly defined as the nineteen mentioned above) and oil-rich countries (the four noted). In these comparisons rentier states' average scores lag fiscal states in 63 out of 64 dimensions, and 22 of these differences in means are statistically significant. Oil-rich rentier states' average scores lag fiscal states in 57 of the 64 dimensions, with 18 statistically significant. At least half of the dimensions lagging in the case of the rentier states relate to monitoring, reporting and accountability mechanisms - the focal points of the EITI. Table 4 shows these (and other) lagging dimensions (clustering some under single bullets), centered on the lack of controls in budget execution (of all types in the broad rentier state group) and formal budget preparation mechanisms (in the oil-rich states).

Table 4. Dimensions in which rentier states and oil-rich rentier states lag fiscal states

Rentier states broadly defined lag behind other countries in statistically significant ways in respect of:

- Comprehensiveness of budget documentation

- Reporting on receipts from donors

- Monitoring of AGAs and PEs

- Monitoring and control of sub-nationals

- Public access to information

- Debt sustainability analysis prepared

- Sectoral strategies prepared

- Penalties for tax non-compliance

- Tax audits and investigations

- Cash flow forecasting

- In-year budget adjustments

- Authority to change HR records and payroll

- Use of open competition in procurement

- Process for resolving procurement complaints

- Expenditure commitment controls

- Quality of internal controls

- Degree of compliance with internal controls

- Frequency and coverage of internal audit reports

- Management response to internal audit findings

- Regularity of bank reconciliations

- Scope of in-year budget reports

- Quality of information in in-year budget reports

- Follow-up on external audit recommendations

- Scope of legislature's scrutiny

74. As with the other findings of this paper, this evidence is presented simply to suggest a thematic relationship between a certain country characteristic and the quality of PFM. In this case the theme is that fiscal states have stronger PFM

\footnotetext{
${ }^{37}$ Although two of these are severely dependent on aid sources they were classified as fiscal because of growing domestic revenue collections in recent years.
}

- Sub-national reporting

- Monitoring of AGAs and PEs

- Monitoring and control of sub-nationals

- Existence and adherence to budget calendar

- Clarity of political guidance in budget preparation (through formal mechanisms)

- Investments selected strategically

- Management response to internal audit findings

- Information provided on resources received by service delivery units

- Timeliness of submission of annual budget reports

- Timeliness of submission of audit reports to legislature 
systems. Showing a relationship does not explain why it exists, or even the direction of causality. Many would suggest the revenue source impacts on PFM quality. However, one can think of the relationship running in the other direction as well; rentier states may have low domestic revenue sources because of the weak governance systems in place. Regardless of which causal direction is in play, the evidence speaks of a relationship between rentier/fiscal state characteristic and PFM system quality. And it is reinforced by qualitative references in the PFM-PRs of sixteen of nineteen 'rentier' governments, which emphasize peculiar problems these settings have with issues of reliability, accountability and transparency.

\section{E. Longer periods of reform commitment foster PFM progress}

75. It is interesting that rentier states have shorter and weaker legacies of broadbased national reform. Simultaneously, the evidence suggests that longer periods of broad reform commitment (reflected in time since first PRSP) foster PFM progress. The PRSP is used as a measure of broad reform commitment because it is routinely referenced in the PFM-PRs as a vital influence on PFM reform. ${ }^{38}$ When omitting Mauritius from analysis (because it was not engaged in PRSP dialog at all) one finds 61 out of 64 PEFA dimensions higher in countries with PRSPs older than 3 years as compared with countries having newer (or no) PRSPs. 24 of these differences in means are statistically significant. When comparing countries with PRSPs older than 3 years against countries that had no or more recent PRSP at the time of PEFA assessment, one finds 62 dimensions lagging in the latter; 37 of these differences in means are statistically significant. Figure 21 shows how these dimensions cluster into process indexes and what differences in averages look like between the two groups.

Fig.21. Comparing average process index scores, in country groups with different PRSP histories

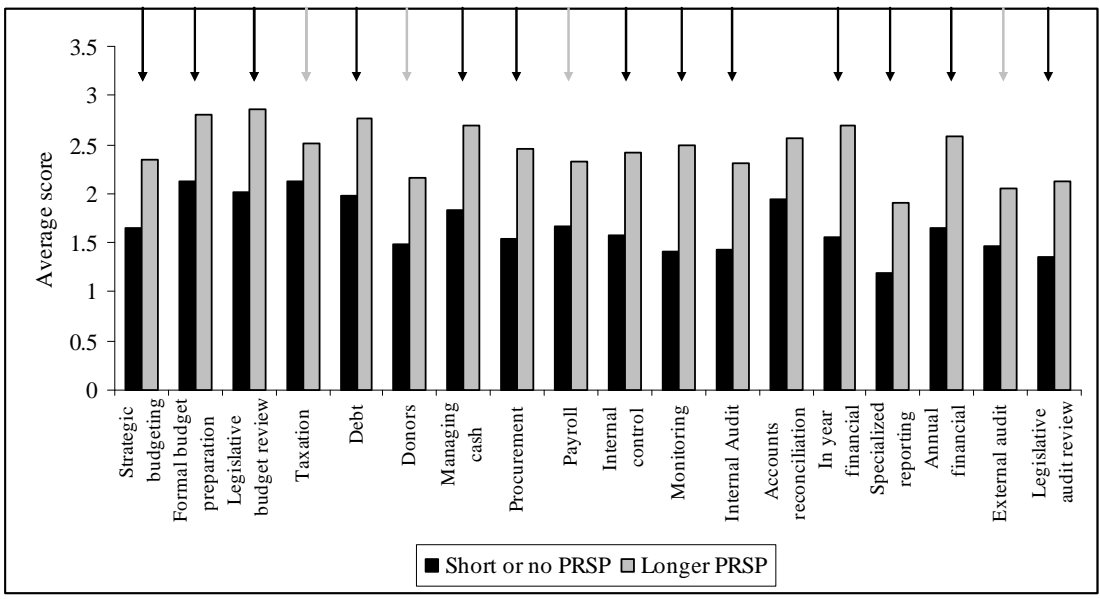

Note: The dark arrows indicate statistical significance of the difference in means at 0.01 ; lighter arrows indicate statistical significance of the difference in means at 0.05 .

\footnotetext{
${ }^{38}$ Twenty one of the thirty one countries had PRSPs in place at time of writing the PFM-PR and all these countries mention the PRSP favorably, with seventeen locating PFM reforms within the PRSP context. Five countries that did not have PRSPs when the PFM-PR was written were either thinking about developing one (or an equivalent) or were in the process of finalizing one. These five countries also presented the PRSP as a central influence or catalyst or facilitator of PFM reform.
} 
76. The country group with PRSPs in place for 4 years or more yield significantly higher averages in 17 of 18 process areas. Fourteen of these differences in means are significant at 0.01 . Those with a longer period of PRSP-driven reform score half a point or more above the others in 16 process areas, and more than one point above in two areas-in-year financial reporting and monitoring (with internal audit close to one as well). The extent to which newer and non-PRSP countries lag the others resonates with the startling impact of fragility on PFM system quality, but appears even greater. One has to wonder why and if this has anything to do with having a PRSP or is really reflective of something else?

77. Figure 21a. suggests the complexity of the situation, showing that lower league countries are mostly fragile and non-PRSP. They are also typically low economic growth countries. Thus, even though one might observe a PRSP theme independently of a fragility or economic growth theme, the three themes seem related.

Fig. 21a. Years since PRSP, fragility, growth and league position

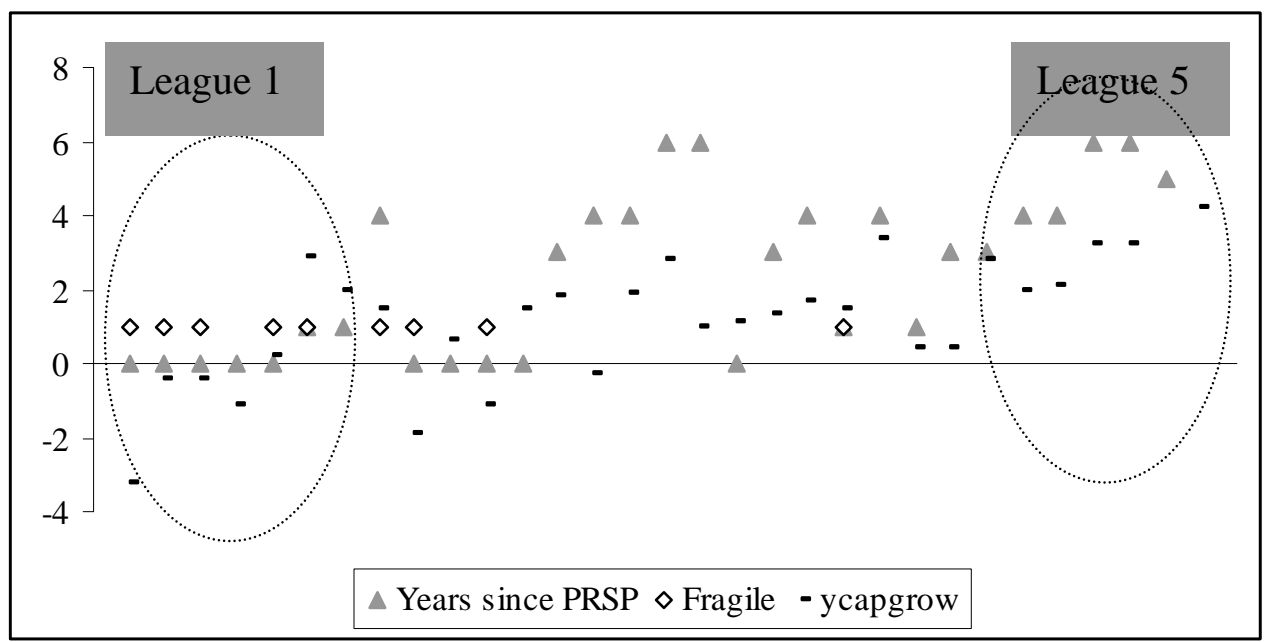

Note: ypcapgrow is 1996-2006 growth in income per capita, multiplied by 10 to facilitate easy comparison with the other series.

78. At the very least the three themes seem to reinforce each other, but most likely they are all reflecting endogenous country characteristics that are still not effectively identified. The underlying variable might be some form of leadership that readily capitalizes on the opportunities provided (like HIPC or PRSP). The positive effect having a PRSP has on PFM quality thus reflects this longer-term government engagement in reform and not the PRSP presence itself (with the PRSP merely the tool used to lock policy and reform direction in). Many developed countries do not have PRSPs or multi-year national plans like PRSPs, partly because these governments 'lock in' their policy and reform programs in alternative ways, mostly emerging from the political process more directly (and arising from the development path established often decades earlier). The question is thus not whether a PRSP exists, but whether governmental actors have the ability to pursue one reform agenda for a period of time. The PRSP creates an opportunity to facilitate this and its existence is thus a useful proxy (of reform engagement) for researchers to use, but the 
opportunity it provides must still be taken in practice. Country 6 is currently developing its second PRSP: One wonders if the country's politicians and managers will better appropriate the initiative's opportunities a second time around?

79. The same story of opportunity requiring appropriation can be told regarding potential the PRSP created for CSO engagement in PFM. The PRSP made room for CSO involvement in policy development and monitoring. In most instances CSO engagement was not as strong as many had hoped. However, in places like Uganda and Mozambique CSO experiences in these processes helped to catalyze umbrella CSOs. CSOs must appropriate these kinds of opportunities, as discussed in Box $5 .{ }^{39}$

\section{Box 5 - CSOs as vehicles for engagement: Opportunities that must be appropriated}

The PRSP created opportunities for CSO engagement in policy development and monitoring. In many cases direct evidence of low CSO engagement in both kinds of activities upset many, who saw PRSP as another vehicle with little value for the CSO community. However, a softer view may be possible with a few years of experience, especially in countries where the PRSP actually survived its first few years. In Mozambique, for example, a 2003 assessment of participation in the PARPA concluded, "In the face of the observed experiences ... it cannot be said that the PARPA's development and early implementation period reflects the kind of participation required in principle ..." It went on to say that, "You cannot blame anyone if you think there was insufficient participation and consultation... When one talks about consultation...it depends upon what people have in mind."1 A variety of examples have been provided in this paper to show the vibrant CSO engagements in Mozambique now (in 2008). It should be appreciated that PRSP experiences - both good and bad-aided in the development of umbrella organizations like LINK, learning of lessons about the importance of CSOs having capacity to engage, etc. The PRSP may not have delivered immediately, therefore, but provided a vehicle that CSOs have used to learn through and grow.

The EITI is likely to provide similar opportunities, even though it will probably produce more frustration than results for many CSOs. In 2006 Publish What You Pay (PWYP) identified, for example, problems with EITI including "the failure of several endorsing governments to recognize the central role of civil society organizations, intimidation and marginalization of civil society activists." Earlier references provided examples of CSOs working under the EITI rubric even in the face of 'marginalizing' governments (in Gabon), however, suggesting that CSOs like PWYP are learning to take advantage of the initiative as a vehicle-in all sorts of circumstances.

In 2004 Warren Krafchick of the International Budget Partnership implicitly identified decentralization as another opportunity area for CSOs, but one that needed to be taken with both hands. He commented that, " "The fact that decentralization is only happening now, sometimes without any planning, opens up a space for civil society to monitor and increase public participation. While the focus has been on decentralising services to increase the quality of services for poor regions and poor people, often the money has not been decentralised. Instead, decentralization sometimes helps the government to steer away from the political issue of social services. While participative budgets work at municipal level, for example at Porto Alegre, it doesn't work at national or regional levels yet. There are good citizen participation practices around budget monitoring in India. The auditor general visits villages, and goes through the budget with citizens, line by line, at the end of each budgetary year. "More and more, governments are aware of the work we are doing. We are forcing the government to listen to us".

\footnotetext{
${ }^{39}$ As noted earlier, the evidence of CSO engagement was typically not identified in World Bank analytical products but rather through personal correspondence with civil society groups in specific countries. This correspondence was corroborated with published references of civil society engagement, in the media as well as - where possible - literature coming out of development organizations. References are available from the author.
} 


\section{F. Colonial heritage matters (maybe)}

80. Two of the four countries with six years of PRSP behind them are in Francophone Africa. The other two are in Anglophone countries. Seven out of the ten countries with no PRSP history (or working on a PRSP at time of PEFA assessment) were also Francophone. Does this suggest anything about the impact of colonial heritage on the propensity to reform and the likelihood to have high quality governance and PFM systems? Figure 22 provides evidence to assist an answer.It shows the location of Francophone countries (the black triangles) in respect of others (grey triangles), and the leagues discussed to date. One can see that the 16 French heritage countries have disproportionally high representation in league 1 (4 of 6) and disproportionately low representation in league 5 (only 2 of 6). The representation as a whole has these countries located mostly in the lower leagues but with some variation, suggesting they may perform worse as a group, but that at least four cases of higher-than-average performance infer the issue may not be colonial legacy-at least not predominantly.

Fig.22. League locations of Francophone (in black) and non-Francophone countries

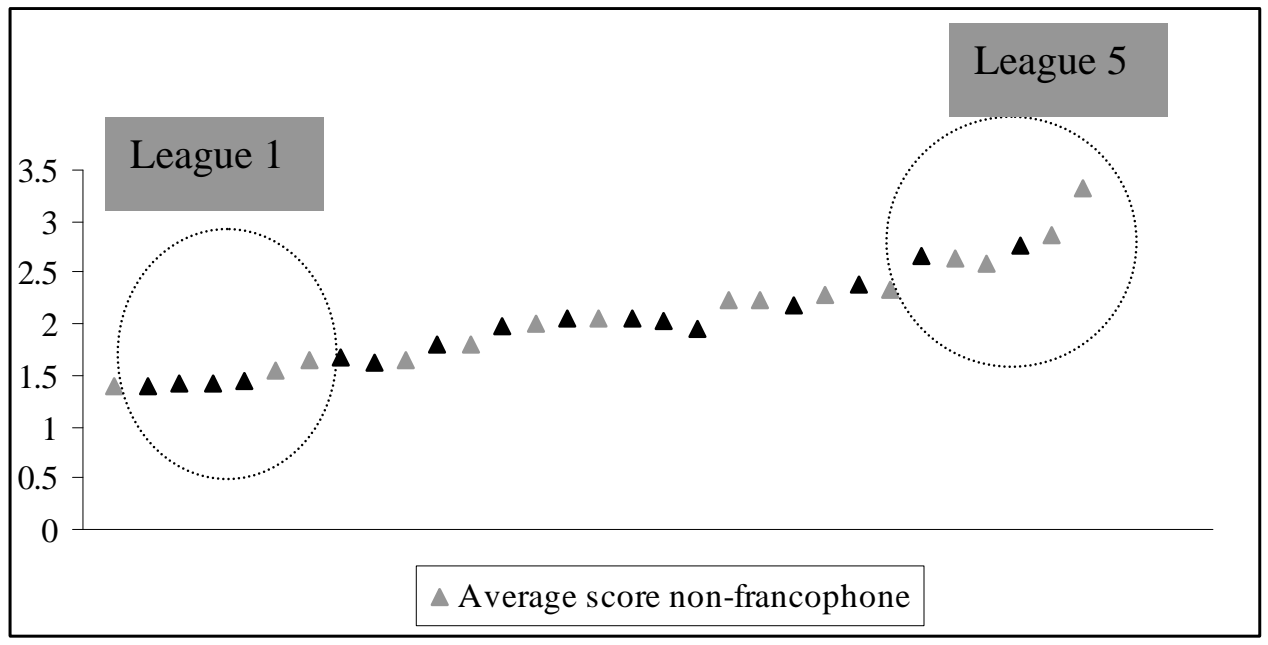

81. A second source of data-based evidence comes from assessing differences between Francophone and other countries on PEFA's 64 non-outcome and non-donor process dimensions. The average PEFA dimension scores for French heritage countries lag those of English heritage countries in 45 dimension areas, with 8 of these differences in mean being significant. The eight statistically significant lagging dimensions relate to the public availability of fiscal information, adherence to the budget calendar, internal audit coverage, timeliness and submission of audit reports, evidence of follow up on external audit reports, legislative hearings on audit findings and issuance of recommended actions by the legislature, and legislative scrutiny of external audit reports. External accountability dimensions (external audit and legislative audit review) are between 0.84 and 1.47 lower in Francophone countries, compared with Anglophones. This amounts to a one symbol difference and more; in the case of legislative hearings English heritage countries score 2.7 while French and Belgian heritage countries score 1.3. Figure 23 isolates these areas of difference, 
showing how Francophone countries compare with Anglophone countries and those of Portuguese heritage.

82. The figure is presented to examine why Francophone countries perform so poorly in the downstream, external accountability areas. Readers should note that French heritage countries lag both other groups substantially in external audit and legislative audit review (as mentioned and shown in the dotted oval to the right). Interestingly, Francophone countries actually score higher than the other two on the legislative budget review index, raising some interesting questions about why the legislature would perform so well in these countries on one side of the budget and so poorly on the other. It would appear that, at least in this area (but maybe also in internal audit and other processes) colonial heritage matters a great deal. All of the francophone countries have been challenged to create anew or reform their external audit function in the past decade. The function did not resemble the kind reflected in PEFA, or the international audit and accounting approaches informing PEFA.

Fig. 23. Comparing average process index scores, in country groups, by colonial heritage

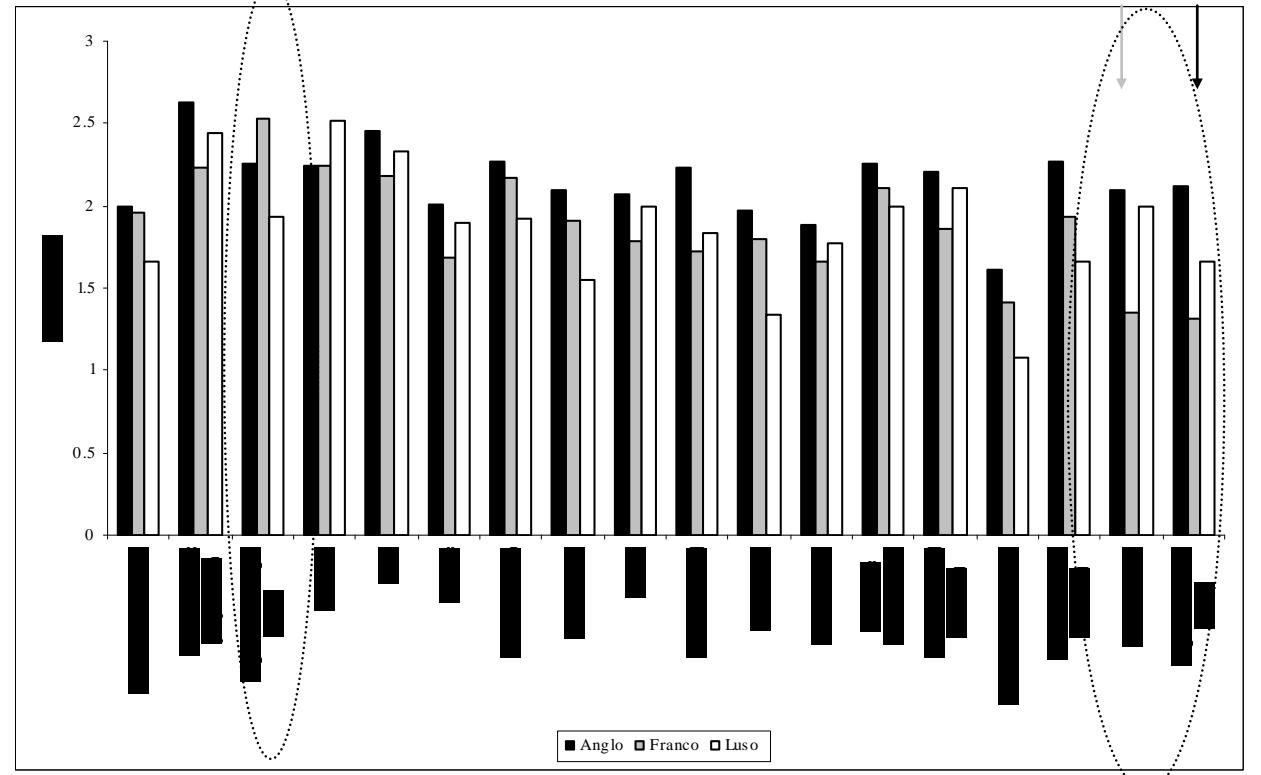

Note: The dark arrows indicate statistical significance of the difference in means at 0.01 ; lighter arrows indicate statistical significance of the difference in means at 0.05 .

83. The French system itself varies quite substantially from many of the 'objective' 'best practice' criteria presented in PEFA. ${ }^{40}$ The French legislature is significantly less engaged than many others, for example, as reflected in various recent assessments. ${ }^{41}$ A few PFM-PRs incorporate discussion of the differences in these areas. In country 20's PFM-PR, for example, a two page note relates a debate about the draft of the PEFA report, underlining problems in interpreting internal and external audit/control functions as performed in the nation, given PEFA guidelines.

\footnotetext{
${ }^{40}$ And French countries mostly have to ensure their systems harmonize with the West African Economic and Monetary Union's (WAEMU) texts on public finance.

${ }^{41}$ See Andrews, M. (2008) Good Government Means Different Things to Different Countries. Paper presented at 2008 American Political Science Association, Boston, MA
} 
Donor comments responding to this discussion criticize the 'mechanical approach' of the PEFA methodology and its imposition of a standard not fitting with the context.

84. These kinds of comments are interesting, but there are also examples of Francophone countries (like Country 11) that have willingly adopted a path towards the kind of external audit and legislative engagements implied in PEFA. Further, it is unclear that some aspects of PEFA are more relevant for strong Westminster democracies-especially given that these countries traditionally have the weakest legislative engagements of all (with the UK, Canada and Australia weaker than France in these areas). Essentially, it would appear that conceptions of political engagement, oversight and control have deep historical roots, cultural meaning and political context that PEFA and other indicator sets will not be able to effectively consider. These differences potentially explain why countries like Belgium get onto slower paths towards internal audit development, for example, ${ }^{42}$ and may explain the Francophone. The lags may also have nothing to do with colonial legacy, given that the weaker Francophone countries are also those with apparently more challenged political systems (characterized by low levels of PRSP adoption and fragility).

\section{G. Summing the country-specific themes}

85. As with process areas there are a variety of key PFM themes reflected across country experience in the sample of 31 African countries. While not presented as a theme, the central most important observation is that, Countries are in different PFM performance leagues. Five different leagues are identified, with countries in each differing in terms of process and outcomes performance. The difference between leagues 1 and 5 is substantial, equaling nearly two points. Using the PFM performance ladder metaphor, league 1 countries are just above the bottom rung whilst league 5 countries are just under the second highest rung. Countries in the different leagues have different characteristics, with the bottom leagues weak in most respects, the mid leagues strengthening their upstream, de jure and concentrated PEFA dimensions and the top leagues building on already strengthened upstream, de jure and concentrated dimensions to now focus on downstream, de facto and deconcentrated areas. Interestingly, Figure 24 shows that countries within leagues also have commonalities in terms of the contextual variables identified: The higher bars on the right reflect more 'positives' in place (high growth, stability, fiscal state, policy commitment, not Francophone), apparently facilitating PFM reform and reform space and, ultimately, better PFM performance.

\footnotetext{
${ }^{42}$ Andrews suggests reasons why Belgium stands out having lower internal audit coverage than other effective OECD governments. He cites a variety of path-related constraints (including) "differences in institutionalization of the internal audit profession ... in the formation of professional institutes" weak talent bases [and the constraints posed by] differences in the "larger social and cultural context in which such talent is produced" and legal institutionalization ... reflected in "the fact that internal audit was legally recognized and mandated as a public sector function at very different times in the governments-1978 in the United States and 2001 in the Netherlands" as well as "the importance of managerial acceptance of internal auditing as a function (especially the modern version) ... [and] what this acceptance hinges oncultural awareness (and the professionalization issue already referenced), social and economic pressures to manage risks, risk and uncertainty avoidance, perhaps?” See Andrews, M. (2008) Good Government Means Different Things to Different Countries. Paper presented at 2008 American Political Science Association, Boston, MA.
} 
Fig. 24. Country characteristics combine to impede, facilitate PFM across leagues

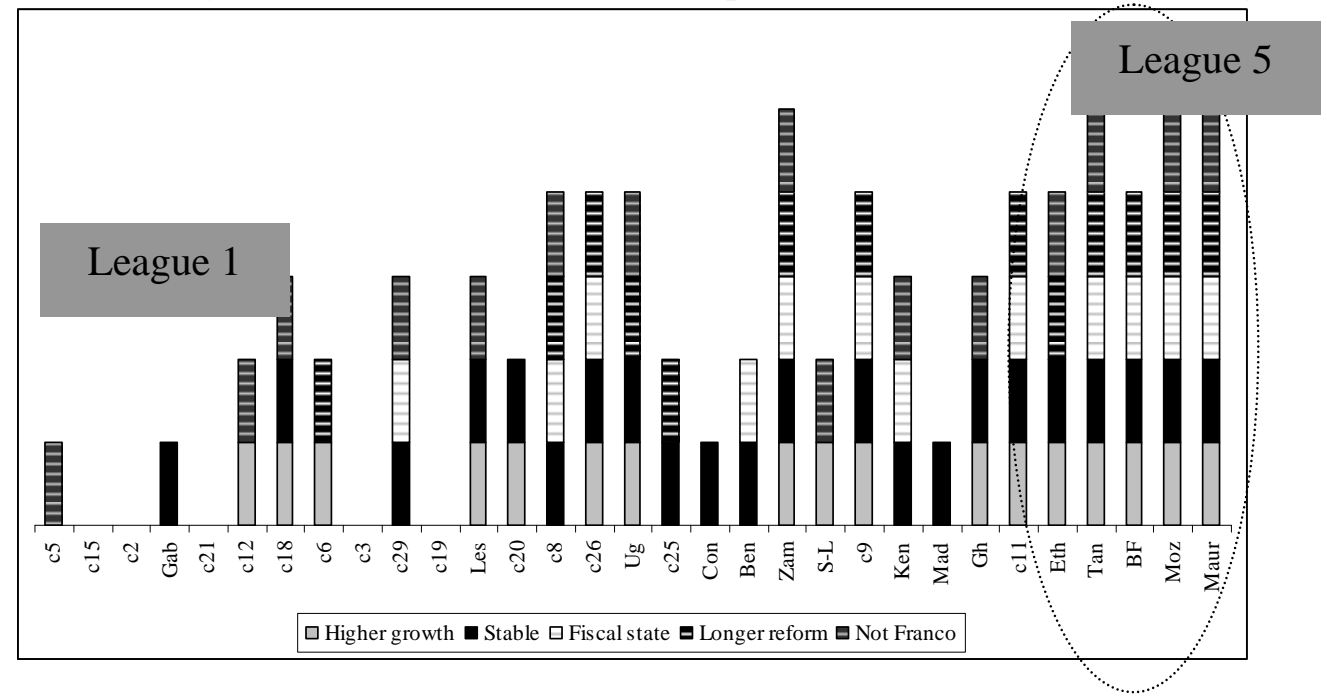

86. The figure suggests quite strongly that an unmeasured, endogenous factor is at play, creating more space for PFM success in some countries than others. This paper aims to identify themes, not disentangle them, hence the job of working out which effects are predominant in influencing PFM; even if there is a common endogenous driver behind all of these must wait for other work.

87. The basic idea to take away is simply that country characteristics matter a great deal in understanding what PFM systems look like. Some countries are substantially ahead of others in a general sense because they fall on the positive side of all the themes identified. They are in the top leagues in Africa, climbing rungs at the very top of the PFM performance ladder (at least as this is defined in PEFA). Other countries find themselves struggling with contextual realities that put them on the negative side of the themes discussed. Their PFM processes and outcomes are weak, and they are in the bottom leagues, struggling to get past the lower rungs of the PFM performance ladder. These observations, and the themes underlying them, raise important questions for reformers, chief among these being, "Is context taken seriously in reform design?” 


\section{Themes from past reforms, ideas for the future}

88. This query raises its own secondary questions: What kinds of reforms have countries pursued in the past decade (or more)? Where have reform ideas come from? What lessons can be learned from past approaches? What are the current challenges and how well do existing reform approaches address these? These questions drive this final section, which discusses themes emerging in reform experience across the 31 African countries. The discussion has four major parts to it: The first two tell a story of interventions in which similarities belie country differences and where reforms do deliver better law and stronger central agencies, and lessons across leagues. The third part argues that existing reforms may fail to deliver more than legal and concentrated gains, however-particularly failing to meet current challenges. The fourth argues that adjustments are needed to meet emerging challenges.

\section{A. Reform similarities belie country differences}

89. Content analysis was the main method used in analyzing PFM reform experience across the 31 countries. PFM-PRs were used to guide content searches and CFAAs (and equivalents), project documents and IMF Country Reports were used for the actual analyses. The key words and acronyms included MTEF, program budgets, Classifications of the Functions of Government (COFOG) and Government Financial Statistics (GFS), budget ceilings, Treasury Single Accounts (TSA), Financial Management Information Systems (FMIS), commitment controls, and International Public Sector Accounting Standards (IPSAS). These are all technical PFM standards.

90. The content analysis shows them as standards in the African reform agendas: 28 out of 31 countries have had MTEFs in place or are putting them in place; 25 are introducing some form of program, performance or activity-based budget; all refer to efforts to introduce GFS and COFOG classification schemes; 26 are using ceilings in some way in budget preparation; all refer to steps to create TSAs (or some kind of consolidated public accounts structure); 20 refer explicitly to FMIS/IFMS or some form of computerization in budget execution especially (and another 10 refer to the need for this); all mention commitment controls; all mention IPSAS or some other version of accounting standards (especially different for Francophone countries).

91. Searches also established that internal audit, external audit, procurement, payroll controls, internal controls and legislative issues were on the reform agenda (at least $80 \%$ of the time in all cases). The ubiquity of these reform mechanisms across such a varied set of countries (as discussed) suggests the presence of some kind of externally imposed model. Various authors explain the breadth of implementation of these mechanisms (like MTEF) in terms of their being a part of the development community's global public finance reform approach. Figure 25 shows in how these have been introduced in a number of the governments reviewed (at least in the stages that are most common to all governments; some have moved beyond these). All experiences overlap at least 60 percent with the stylized model presented. This is not to say that all interventions look the same in all places (MTEFs sometimes have less 
of a focus on MDA planning, for example). It is simply to point out that interventions are similar, belying the significant variation in the country group.

Fig. 25. A stylized version of common reform elements across the 31 country sample

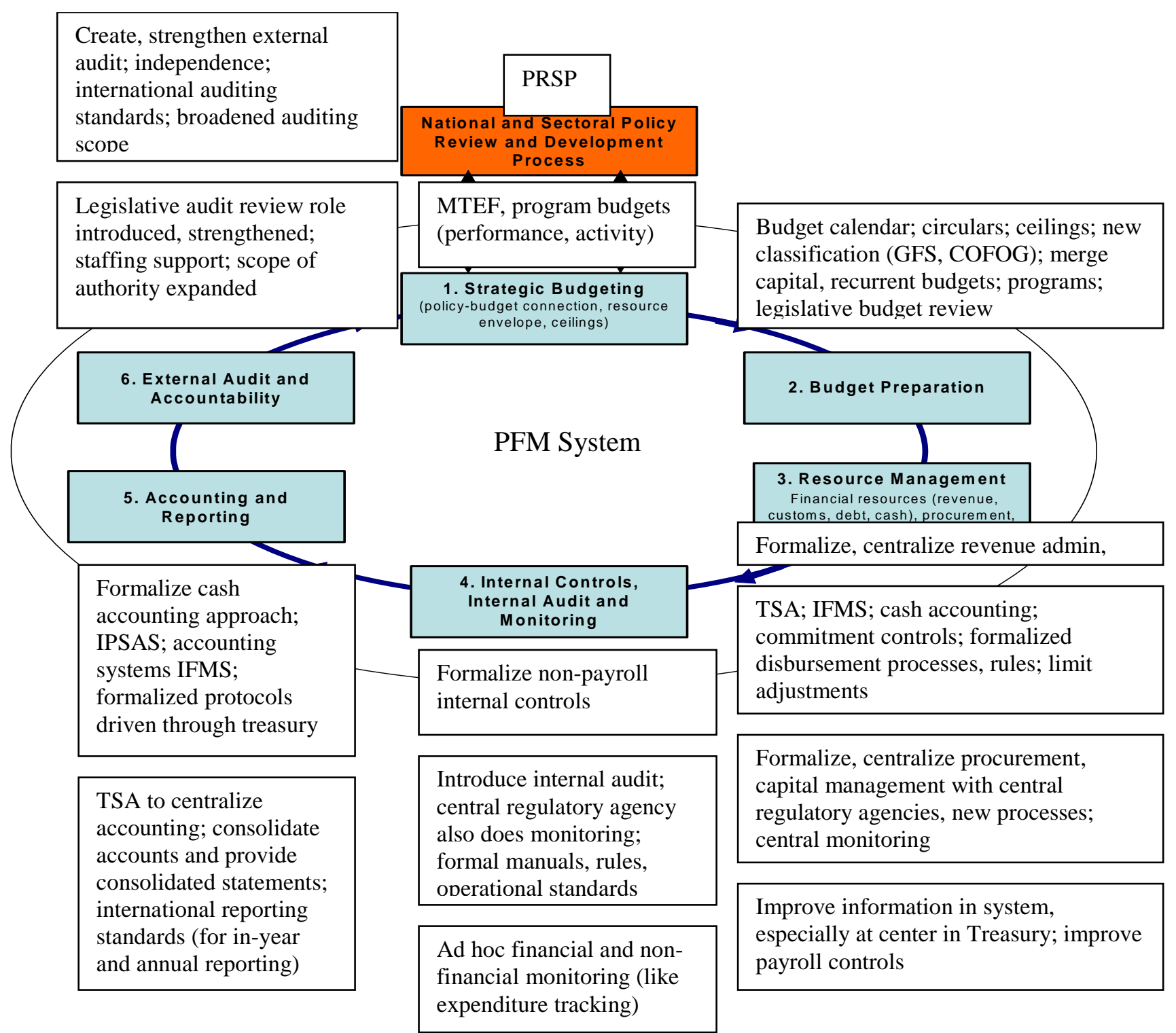

92. The strongest evidence of reform similarity is reflected in the comparison of agendas in league 1 and league 5 countries. The leagues were shown earlier to be significantly different. However, they have alarmingly similar reforms in place, shown in Table 5 which provides evidence of four interventions in the league 1 and 5 countries: PFM Laws; MTEF; Treasury Systems (TS); and Central Treasuries (CT). 
Table 5. Different leagues, similar reforms

\begin{tabular}{|c|c|}
\hline League 5 & League 1 \\
\hline $\begin{array}{ll}\text { - } & \text { Mauritius [PFM Laws; MTEF; TS; CT] } \\
\text { - } & \text { Burkina Faso [PFM Laws; MTEF; TS; CT] } \\
\text { - } & \text { Ethiopia [PFM Laws; MTEF; TS; CT] } \\
\text { - } & \text { Mozambique [PFM Laws; MTEF; TS; CT] } \\
\text { - } & \text { Country 11 [PFM Laws; MTEF; TS; CT] }\end{array}$ & $\begin{array}{ll}- & \text { Country } 15 \text { [PFM Laws; MTEF; TS; CT] } \\
\text { - } & \text { Gabon [PFM Laws; MTEF; TS; CT] } \\
\text { - } & \text { Country } 19 \text { [PFM Laws; MTEF] } \\
\text { - } & \text { Country } 5 \text { [PFM Laws; TS; CT] } \\
\text { - } & \text { Country } 6 \text { [PFM Laws; MTEF; TS; CT] } \\
\text { - } & \text { Country } 2 \text { [PFM Laws; MTEF; TS; CT] }\end{array}$ \\
\hline
\end{tabular}

\section{B. Existing reforms can deliver better law, stronger central agencies}

93. Beyond the commonness of reform terminology and typology, the evidence speaks to common reform modalities and gains. In particular, across all countries, PFM reforms have tended to focus on and succeed most in (i) formalizing PFM processes through new laws and procedures, and (ii) strengthening central, concentrated entities (like treasuries, debt and budget departments, even recently procurement and internal audit regulatory agencies). Countries have stronger performance in these areas also, ostensibly reflecting (at least partly) reform impact.

94. The analysis of documented reform descriptions unearths an emphasis on procedural interventions in and through specific, concentrated sets of actors in all 31 countries. The reform emphasis on concentrated entities and procedural reforms reflects itself in the kinds of system strengths observed through earlier analysis. Figure 26 shows the average scores of League 1,3 and 5 countries on four types of PFM dimension: de jure, concentrated; de jure, de-concentrated, de-facto, concentrated; and de-facto, de-concentrated.

Fig.26. How three leagues perform on different PFM dimension types

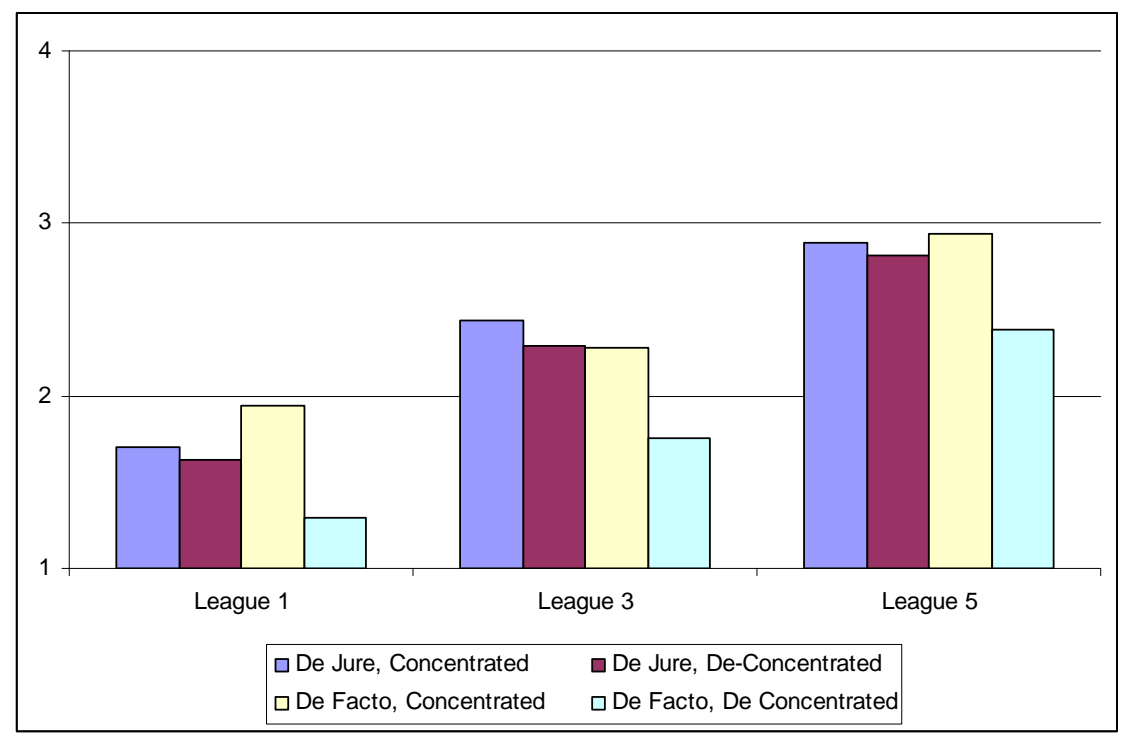

95. Dimensions involving concentrated role players account for the highest averages in all three leagues. The highest scoring dimensions in all leagues are those involving (directly) the engagement of the budget department, treasury, revenue regulatory agency, and such. Readers should note that even de-facto, concentrated scores are relatively high for all groups—-suggesting that the implementation gap may 
be overcome when the responsible implementer is a concentrated actor. One cannot make a direct connection between reforms and the average scores in Figure 26, given the lack of any information about prior states, but we can surmise that the areas of common strength in all settings reflect domains where reforms are most successful, and areas of weakness reflect reform limits. Interestingly enough, the areas of strength and reform impact are reflective of reform design as discussed. Reforms focus on concentrated groups which seem to deliver the best results. Reforms tend to emphasize legal and procedural de jure change, apparently reflected positively in the relative strength of these types of dimensions (at least in leagues 3 and 5).

Can countries learn from each other about strengthening dimensions?

96. Figure 26 shows more than the proclivity all countries' reform agendas have for strengthening laws and central agencies. It also shows that some countries have progressed further than others on these and other PFM dimensions. League 5 countries average stronger scores than league 3 countries in all dimension categories shown in the figure. League 3 similarly outscores league 1 in all categories. One wonders why, and if higher league countries can offer lower league countries lessons on how they could progress up the PFM development ladder?

97. Figure 27 illustrates this idea, showing that higher leagues record a greater number of average scores at top rungs of a proverbial PFM development ladder than others. League 5 countries average between 2.5 and 4 in 57 out of 64 dimensions; league 3 countries average 1.5 to 2.5 in 56 out of 64 dimensions; league 5 countries average between 1 and 1.5 in 52 out of 64 dimensions. Surely league 1 can learn from league 3 countries how to translate some of its 1 and 1.5 averages into 2's and 2.5's? And surely league 3 countries can glean some lessons from league 5 countries that could lead to more averages creeping up from 1.5 and 2 to 2.5 and 3 ?

Fig.27. How leagues perform on the PFM development ladder

\begin{tabular}{|c|c|c|c|}
\hline $\begin{array}{l}\text { PFM development } \\
\text { ladder rung }\end{array}$ & $\begin{array}{l}\text { League } 1 \text { rung location } \\
\text { (dimensions, out of } 64 \text { ) }\end{array}$ & $\begin{array}{l}\text { League } 3 \text { rung location } \\
\text { (dimensions, out of } 64 \text { ) }\end{array}$ & $\begin{array}{l}\text { League } 5 \text { rung location } \\
\text { (dimensions, out of } 64 \text { ) }\end{array}$ \\
\hline 4 & & & 1 \\
\hline 3.5 & & 1 & 7 \\
\hline 3 & 1 & 6 & 30 \\
\hline 2.5 & 3 & 19 & 19 \\
\hline 2 & 7 & 19 & 5 \\
\hline 1.5 & 29 & 18 & 2 \\
\hline 1 & 23 & 1 & 0 \\
\hline
\end{tabular}


98. The lessons one can glean from a PEFA-like database are cross sectional and not temporal-speaking to differences between countries and country groups and not necessarily to stories about why those differences came about. The lessons are also centered on how to improve PEFA scores (moving up the scorecard rungs shown in Figure 27), not necessarily PFM practice. The lessons center on a benchmarking approach, whereby different scores in different leagues tell us about the opportunities and constraints lower league countries might face when trying to reform individual PFM dimensions. In some dimensions lower league averages are close to the averages of higher leagues, as with leagues 1 and 3 in PI-21.i and PI-21.ii in Figure 28; and some of the lower league countries actually score the same as some of the higher league countries (yielding a statistically insignificant difference in means, suggested in the lack of any hard arrow between the league averages).

Fig. 28. How differences in league performance can point to reform opportunities

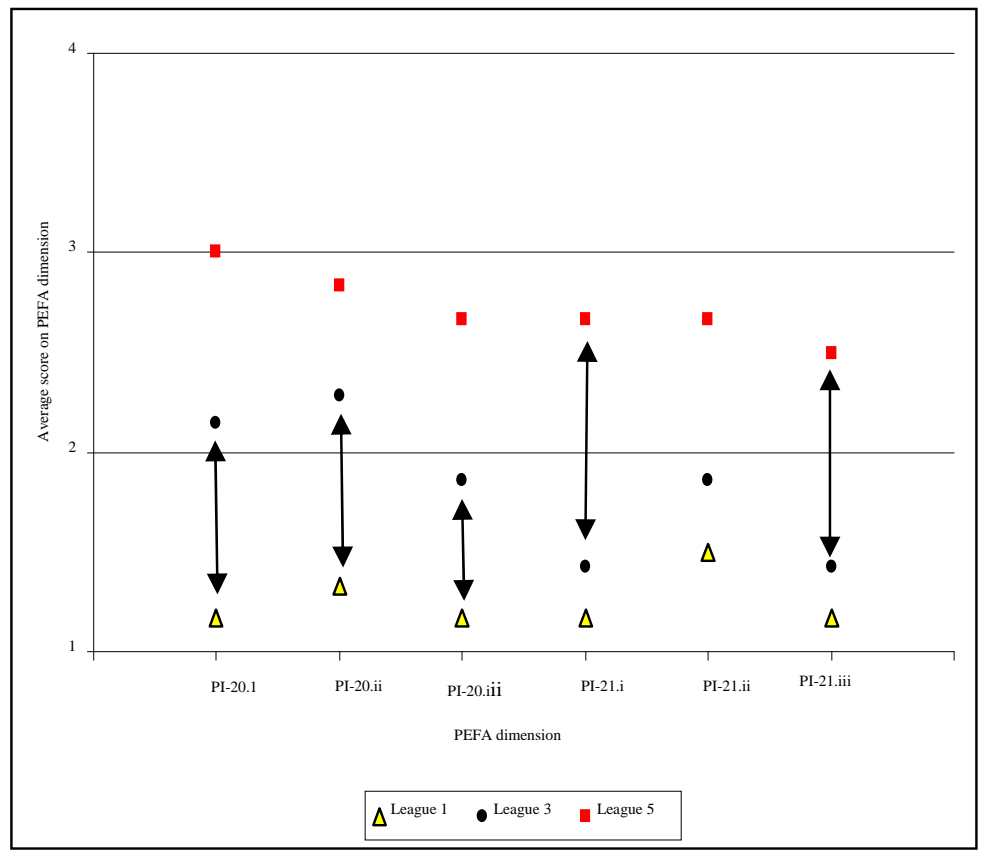

99. These dimensions seem to provide opportunities for lower league countries to improve and climb the rungs of the PFM development ladder. Other dimensions speak to a more sobering reality: lower league averages are much lower than higher league averages, like with leagues 1 and 3 in regard to PI-20.i and leagues 3 and 5 in relation to PI-21.i; ${ }^{43}$ very few lower league countries score anywhere near the

\footnotetext{
${ }^{43}$ League 1 countries average just above 1 for PI-20.i-the existence and effectiveness of commitment controls. This indicates that, on average, commitment control systems are generally lacking or are routinely violated in these countries. League 3 countries average just above 2, indicating that the countries are characterized (on average) as having expenditure commitment control procedures which are partially effective, but that may not comprehensively cover all expenditures or may occasionally be violated. League 5 countries average at a 3, meaning that (again, on average) expenditure commitment controls are in place and effectively limit commitments to actual cash availability and approved budget allocations for most types of expenditure, with minor areas of exception. League 3 countries are 0.98 above league 1 countries
} 
countries in higher leagues in these dimensions (yielding a statistically significant difference in means, suggested by the hard arrows between the two averages in these dimensions). Lower league countries will probably have greater difficulty closing the gap with higher league countries when it comes to these dimensions.

100. This approach allows one to identify what could be called the 'lower hanging' and 'higher hanging' fruit for reformers in leagues 1 and 3, respectively. Figure 29 summarizes these for league 3 , showing the low hanging fruit dimensions in green and higher hanging fruit dimensions in yellow (pink denotes dimensions where league 3 actually averages the same or more than league 5).

Figure 28. Opportunities league 3 countries have of improving to league 5 standards

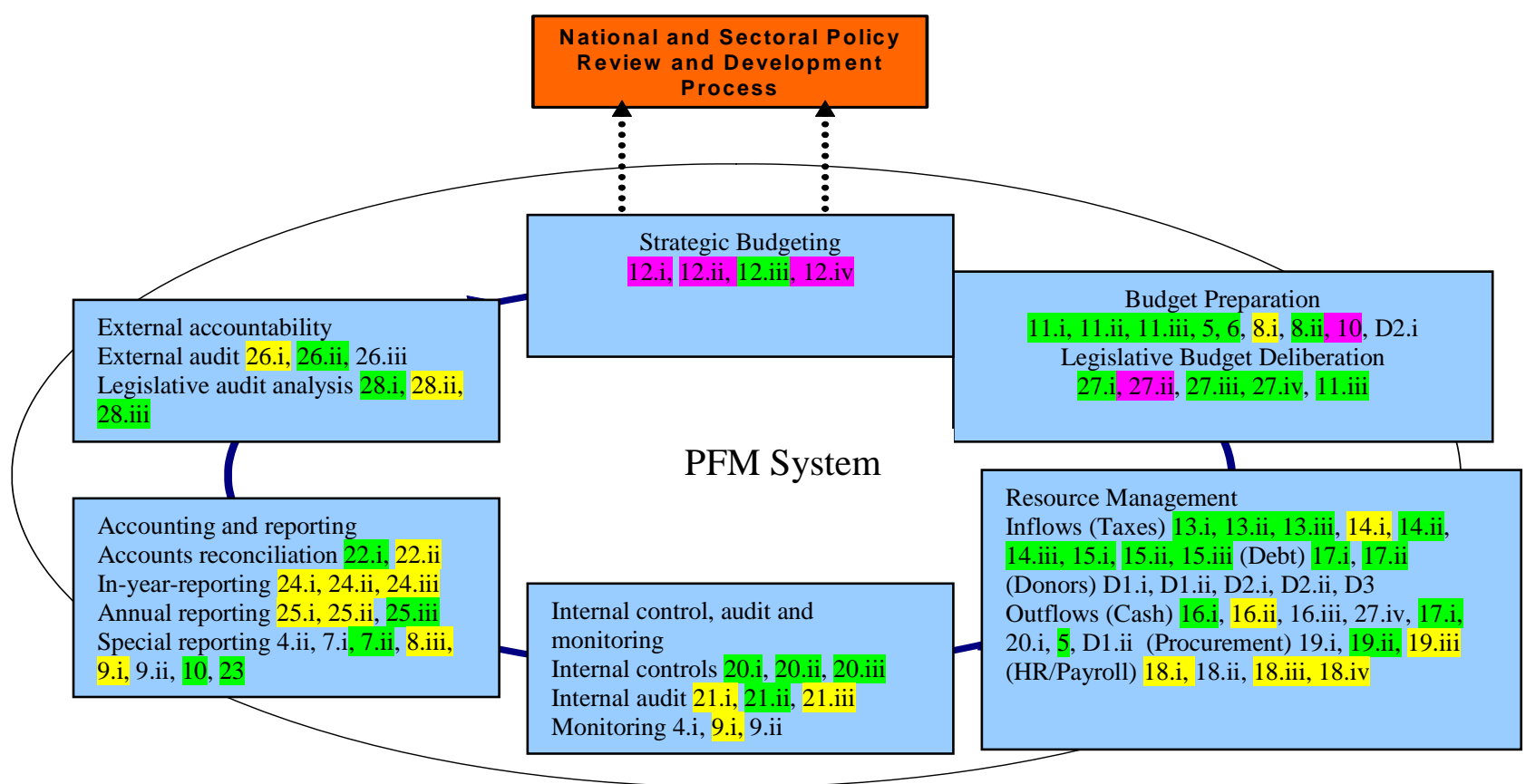

Note: Green highlights denote low hanging fruit reform options, given smaller differences between league 3 scores and league 5 scores; Yellow denotes higher hanging fruit reform options, given larger statistically significant differences between league 3 and league 5 scores; Pink denotes dimensions where league 3 scores already match league 5 scores.

101. The 33 low hanging fruit reform options identified for league 3 countries can be separated according to the size of the lag behind league 5 (and thus the amount of ground reformers need to make up) and the PFM development ladder location (some involve climbing from the first to second rung while others involve moving from a second to third). The ten dimensions with the smallest lags between leagues 3 and 5 are shown in Table 6, which also describes the 'rung' league 3 countries would need

on average, and the difference is statistically significant-meaning that most if not all league 1 countries score below league 3 countries on the dimension. In contrast, league 5 countries may be 0.86 above league 3 countries, but the difference is not significant: 4 of 6 league 5 countries and 5 of 7 league 3 countries score similarly (mostly 3) on the dimension. 
to master to effect gains. Different countries in league 3 will be motivated to improve different dimensions, as in all cases some countries have already reached higher rungs (showing it can be done). In regard to PI-13.i, for example, five of the seven league 3 countries are already scoring 3 or higher (the average in league 5) but Malawi, Uganda and Benin are still scoring 2 (a PEFA C). In regard to PI-12.iii Malawi and Congo lag significantly behind the rest of the group (scoring lowly 1s) and Cameroon and Senegal are lagging slightly (with 2s). All four countries should be inspired that 3 of their league members score higher 3s on this dimension, and that this is around the same score as league 5's average.

Table 6. Potential low hanging fruit areas of reform for league 3 countries

\begin{tabular}{|c|c|}
\hline Dimension number and description & $\begin{array}{l}\text { Which rung do league } 3 \text { countries need to reach next, and how is this } \\
\text { described in PEFA? }\end{array}$ \\
\hline $\begin{array}{l}\text { PI-13.i. Clarity and comprehensiveness } \\
\text { of tax liabilities }\end{array}$ & $\begin{array}{l}3 \text { (PEFA B): Legislation and procedures for most, but not necessarily all, } \\
\text { major taxes are comprehensive and clear, with fairly limited discretionary } \\
\text { powers of the government entities involved. }\end{array}$ \\
\hline $\begin{array}{l}\text { PI-12.iii. Existence of sector strategies } \\
\text { with multi-year costing of recurrent and } \\
\text { investment expenditure. }\end{array}$ & $\begin{array}{l}2.5 \text { (Between a PEFA C and B): Statements of sector strategies exist for } \\
\text { between } 25 \% \text { and } 75 \% \text { of primary expenditures, with increasing levels of } \\
\text { costing (full costing required for a B). }\end{array}$ \\
\hline $\begin{array}{l}\text { PI-11.ii. Clarity/comprehensiveness of } \\
\text { and political involvement in the } \\
\text { guidance on the preparation of budget } \\
\text { submissions. }\end{array}$ & $\begin{array}{l}3 \text { (PEFA B): A comprehensive and clear budget circular is issued to } \\
\text { MDAs, which reflects ceilings approved by Cabinet (or equivalent). This } \\
\text { approval takes place after the circular distribution to MDAs, but before } \\
\text { MDAs have completed their submission. }\end{array}$ \\
\hline $\begin{array}{l}\text { PI-17.i. Quality of debt data recording } \\
\text { and reporting }\end{array}$ & $\begin{array}{l}3 \text { (PEFA B): Domestic and foreign debt records are complete, updated and } \\
\text { reconciled quarterly. Data considered of fairly high standard, but minor } \\
\text { reconciliation problems occur. Comprehensive management and statistical } \\
\text { reports are produced at least annually. }\end{array}$ \\
\hline $\begin{array}{l}\text { PI-6. Comprehensiveness of information } \\
\text { included in budget documentation }\end{array}$ & $\begin{array}{l}3 \text { (PEFA B): Recent budget documentation fulfils 5-6 of the } 9 \text { information } \\
\text { benchmarks. }\end{array}$ \\
\hline $\begin{array}{l}\text { PI-13.ii. Taxpayer access to information } \\
\text { on tax liabilities and administrative } \\
\text { procedures. }\end{array}$ & $\begin{array}{l}3 \text { (PEFA B): Taxpayers have easy access to comprehensive, user friendly } \\
\text { and up-to-date information on tax liabilities and administrative procedures } \\
\text { for some major taxes, while for other taxes the information is limited. }\end{array}$ \\
\hline $\begin{array}{l}\text { PI-17.iii. Systems for contracting loans } \\
\text { and issuance of guarantees. }\end{array}$ & $\begin{array}{l}3 \text { (PEFA B): Central government's contracting of loans and issuance of } \\
\text { guarantees are made within limits for total debt and total guarantees, and } \\
\text { always approved by a single responsible government entity. }\end{array}$ \\
\hline PI-5. Classification of the budget & $\begin{array}{l}3 \text { (PEFA B): The budget formulation and execution is based on } \\
\text { administrative, economic and functional classification (using at least the } 10 \\
\text { main COFOG functions), using GFS/COFOG standards or a standard that } \\
\text { can produce consistent documentation according to those standards. }\end{array}$ \\
\hline $\begin{array}{l}\text { PI-11.iii. Timely budget approval by the } \\
\text { legislature or similarly mandated body } \\
\text { (within the last three years). }\end{array}$ & $\begin{array}{l}3.5 \text { (Between a PEFA A and B): The legislature approves the budget before } \\
\text { the start of the fiscal year, but a delay of up to two months has happened in } \\
\text { one of the last three years (no delays for an A). }\end{array}$ \\
\hline $\begin{array}{l}\text { PI-16.i. Extent to which cash flows are } \\
\text { forecast and monitored. }\end{array}$ & $\begin{array}{l}3.5 \text { (Between a PEFA A and B): A cash flow forecast is prepared for the } \\
\text { fiscal year, and updated monthly (or quarterly) on the basis of actual flows. }\end{array}$ \\
\hline
\end{tabular}

102. It is interesting to note that league 3 countries have more low hanging fruit opportunities in upstream dimensions and dimensions related to the management of inflows (taxes and debt particularly). 21 of the 33 opportunities that seem accessible gains fall into this area, reflected in the concentration of green in the budget preparation and inflows boxes in Figure 28. The dimensions seem to be lower hanging fruit because they build on already-established capacities—with most league 
3 countries having stronger upstream foundations and weaker building blocks in the downstream. Similarly, 16 of the 33 'accessible' gains involve further steps to strengthen laws and 18 involve primary engagement of concentrated actors, two more capacities league 3 countries are able to build on. Many of the lower hanging opportunities are also in clusters of PFM dimensions with high visibility to donors, foreign investors and domestic taxpayers: ${ }^{44}$

- Formalizing the budget preparation process, including legislative engagement,

- Clarifying and formalizing the tax process,

- Formalizing and strengthening debt management, and

- Improving reporting.

103. Interestingly, league 1 has fewer lower hanging fruit prospects and those that do exist are more randomly located around the PFM system, as shown in Figure 29.

Figure 29. League 1 opportunities of improving to league 3 standards

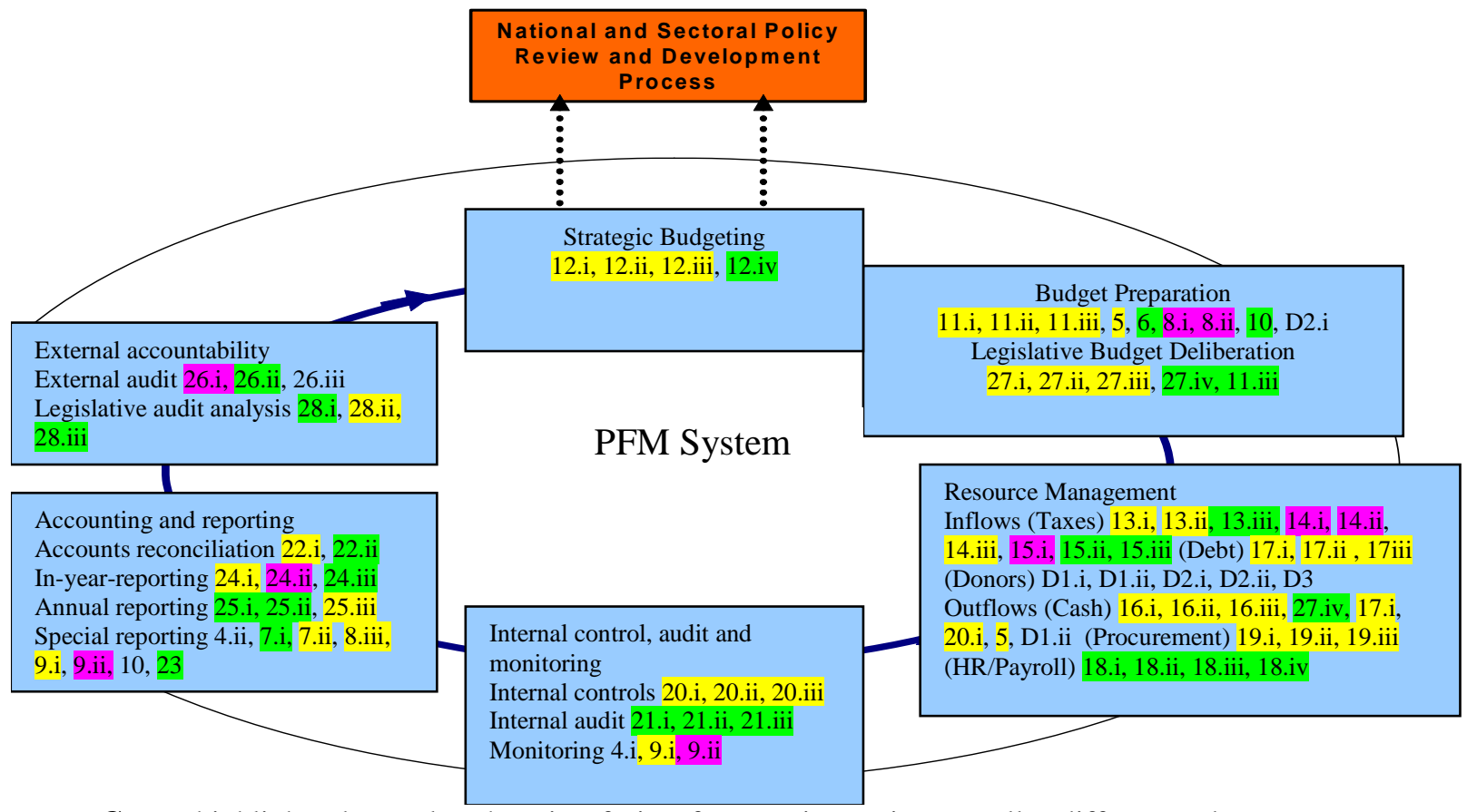

Note: Green highlights denote low hanging fruit reform options, given smaller differences between league 1 scores and league 3 scores; Yellow denotes higher hanging fruit reform options, given larger statistically significant differences between league 1 and league 3 scores; Pink denotes dimensions where league 1 scores already match league 3 scores.

\footnotetext{
${ }^{44}$ The proposed next steps for league 3 countries on dimension 5 relate to further formalizing the budget formulation process by adopting a more policy-oriented classification scheme (based on functions) that facilitates external engagement, for example; improvement on dimension 6 involves building on a growing record of publishing budgetary documents to be even more open; dimensions 11.i, 11.ii, and 11.iii will all be strengthened if governments just continue formalizing their budget preparation processes (with laws and procedures that outsiders can see are being taken seriously); dimensions 13.i, 13.ii, 13.iii and 14.ii and 14.iii all pertain to steps that add to the growing formality and clarity in taxation processes, and even 23 and 26i and 26ii relate to the way governments report to outsiders and thus engage with important stakeholders (like business, donors and—one hopes—civil society).
} 
104. League 1 countries' averages are close to league 3 averages, and not significantly different, in 23 dimension areas-Figure 29's green 'low hanging fruit'. 8 of these dimensions are in the upstream or revenue management areas, while 15 are in the execution and external accountability process areas, spread quite evenly across resource management, internal audit, accounts and reporting, external audit and legislative audit analysis. Only 6 of the 23 more accessible gains relate to de jure interventions while 16 relate to de facto PFM progress, which includes preparing annual financial statements and making these available for audit within 15 months of the end of the fiscal year (25.i and 25.ii), and improving reporting of extra-budgetary expenditures, such that the size of unreported spending drops to between 5 and $10 \%$ of total expenditure (7.i).

105. The relatively low number of de jure interventions captured as 'low hanging fruit' for league 1 countries could reflect the apparent difficulty of developing laws in fragile countries (which most league 1 countries are). The quality of laws in these settings is often much weaker than in other countries, but the path to create laws is complicated by weaknesses in the political system through which laws can be developed. The opportunity cost of introducing new laws is also high, given the weak legal system through which such laws are enforced. This means that PFM reform in such settings may have to focus on de facto elements where in other places it might have a more natural de jure starting point. Beyond this important observation, one should note that most of the easier-to-close gaps between league 1 and league 3 countries are in dimensions where league 3 is weak rather than where league 1 is strong. This is one of the reasons why so many de facto, downstream dimensions feature in green in Figure 29; the potential to be like league 3 emerges because league 3 has not gotten far with these downstream, de-facto and de-concentrated dimensions (shown in the short spotted bars to the right of Figure 30).

Fig. 30. Differences between leagues, by dimension type

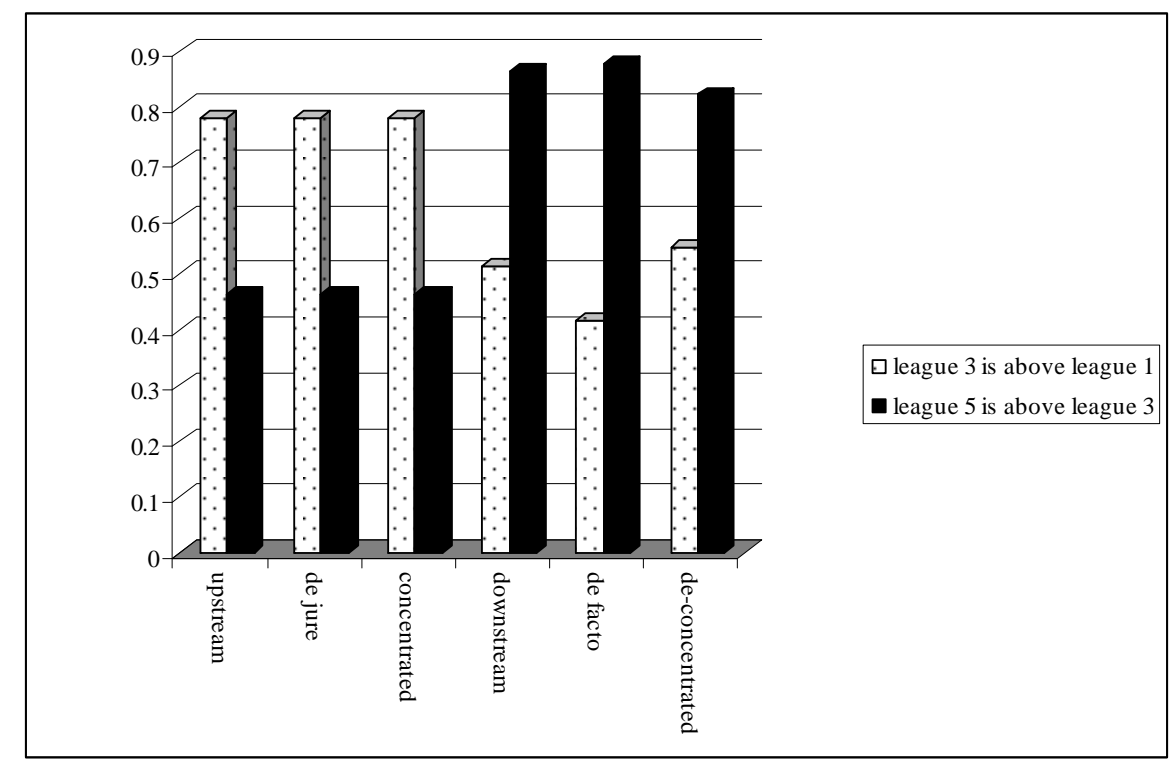

106. The 31 yellow shaded areas in Figure 29, which show the dimensions where league 3 is significantly ahead of league 1, tend to reflect league 3 strengths (the taller 
spotted bars at left of Figure 30): 16 are in the upstream, 18 are related to de jure dimensions and 15 involve concentrated actors. These are the 'high hanging fruit' that league 1 countries will probably struggle to reach through reforms (given the major lag in scores right now and the fact that few league 1 countries score anywhere near league 3 countries in these dimensions). Interestingly, these are the very areas that reforms in all countries are focused on (as discussed)-upstream dimensions that are de jure in nature and involve concentrated actors. Are they the right starting point for league 1 countries? Could more de facto interventions be more practical and offer higher gains?

107. League 3 countries will likely benefit from the de jure, concentrated type reforms in the short run, given the number of low hanging reform opportunities in such dimension areas. But the high hanging fruit for league 3 countries (shown in yellow in Figure 28) is of a different type: 17 of 19 are in the downstream, 14 of 19 are de facto and 13 involve de-concentrated actors. It is precisely these kinds of dimensions that separate league 3 and league 5 countries (reflected in the large differences in means and tall black bars at right of Figure 30). These are also the dimensions that diagnostics suggest league 3 countries should be most concerned about; the locus of major weakness in budget execution and accountability. This is borne out in Figure 31, where one can see the average scores each league achieved for different process areas. The bold figures indicate that the league in question averaged significantly higher scores than the one preceding it (a 'high hanging fruit' difference).

Fig. 31. Average scores in different process areas, by league

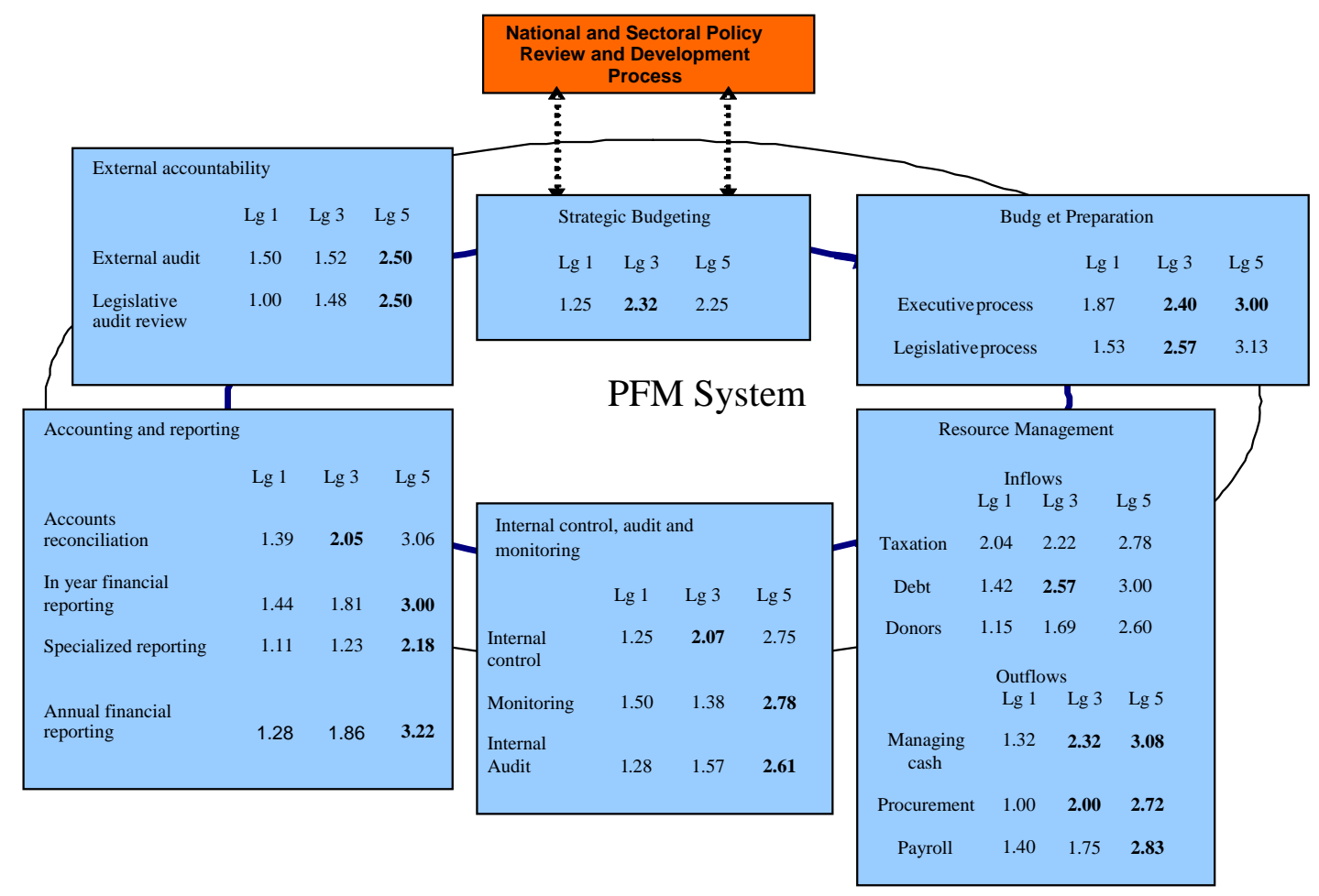


108. When looking at the non-inflow (tax, debt and donor) downstream (from managing cash through to external accountability), league 5 is significantly ahead of league 3 in ten out of twelve process areas (internal control and accounts reconciliation being the two exceptions). League 3 is only significantly ahead of league 1 in 4 of these twelve areas (and league 1 countries average similar scores or even better scores in the other 8 process areas, including monitoring and external audit). Many of the downstream dimensions in which leagues 1 and 3 are so weak are de facto in nature (requiring behavioral adjustments) and involve de-concentrated actors. Will current reform designs assist these countries in strengthening such dimensions, or will ‘higher hanging' fruit opportunities prove ‘too high’?

\section{Getting past reform limits: Some theory and ideas}

109. The question could be re-stated: "Can league 3 countries overcome reform limits to really improve downstream, de facto, de-concentrated dimensions?” Stories from higher league countries like Madagascar suggest similar reform limits, manifest in differences between strengths of upstream and downstream processes and contrasts between major legal advances and implementation concerns. Consider, as an example, "Madagascar [a league 4 country, which] recently deployed important efforts to improve its public financial management. All the legal texts were revised. The results of these reforms are however mitigated." The pressing question is whether the prevailing reform approach, focused on a fairly common model shown in Figure 25, will help Madagascar address its challenges and yield de-facto gains through deconcentrated entities? At the same time Figure 31 reminds us that some countries in lower leagues are not in the same position as Madagascar, and these may actually face very different challenges: Will the current reform approach help meet the PFM challenges in league 1 and league 3 countries as well?

110. This section does not provide final answers to either question, but raises concerns that lean towards negative responses. These emerge from observing the proclivity towards adopting common PFM models in Africa, which reflects a tendency organizations have of imitating characteristics that are generally considered effective-what new institutionalists call isomorphism. ${ }^{45}$ Isomorphism implies that common reforms are assumed to provide a rational means to attain desirable endsespecially organizational legitimacy in external settings. ${ }^{46}$ The use of terms like 'best practice', 'good practice' and 'international standards' are often associated with this assumption. Common paths of reform influence involve coercive, mimetic or normative pressures exerted on actors. All three types of pressure are likely in play in Africa and have much greater influence on central, concentrated actor sets than others. These actors are more engaged with donors (often the source of coercive pressure), enjoy more access to external ideas and examples underlying the reform

\footnotetext{
${ }^{45}$ Meyer, J. and B. Rowan. 1991. "Institutionalized Organizations: Formal Structure as Myth and Ceremony.” In DiMaggio, P and W. Powell (eds) The New Institutionalism in Organizational Analysis. P. J. Chicago, University of Chicago Press, 340-363; citation from page 340.

${ }^{46}$ Isomorphism is increasingly used as a theoretical approach to explain development in the accounting profession. For a recent example, see Lima Rodrigues, Lúcia and Russell Craig. 2007. Critical Perspectives on Accounting, Volume 18, Issue 6, pp. 739-757. Olowo-Okere and Tomkins (1998) also reference isomorphism in their effort to describe the path towards controls adoption in Nigeria.
} 
model we see being mimicked, and are commonly engaged in professional groupings where norms favoring reforms emerge. If actors in de-concentrated settings are less influenced by these pressures, can we expect them to adopt the reforms?

111. Research also asks about the kinds of impact external isomorphic influences can have on the way organizations work. Hannan and Freeman point to potential limits to isomorphic influence, arguing that pressures from outside an organizational environment might alter an organization's "periphery" but often leave its "core" intact. ${ }^{47}$ The periphery is typically composed of laws, regulations, structures and processes whilst the core is defined as embodying an organization's identity and value system, the basis of de-facto engagement. Hannan and Freeman would probably argue that externally imposed PFM models in Africa might be limited to achieving legal, procedural adjustments at the periphery, not de facto core behavior.

112. Figure 32 illustrates both arguments in the current context. It shows that external reform ideas might convey isomorphically to central, concentrated entities (connected by solid arrows). These entities are likely to adopt such ideas as changes to their periphery and also their core. Treasury directors will introduce new accounting standards in theory and try to ensure they become practice, because they have a normative affinity with them. The ideas do not convey as well to deconcentrated entities, however, because these are less influenced by coercive, mimetic and normative pressures at left in the figure (where arrows are no longer solid, suggesting limited reach). Where de-concentrated entities adopt these ideas, however, it is likely more on the periphery than in the core The top de jure dimensions rather than the bottom de facto dimensions). ${ }^{48}$

Fig. 32. Limits of the current reform model
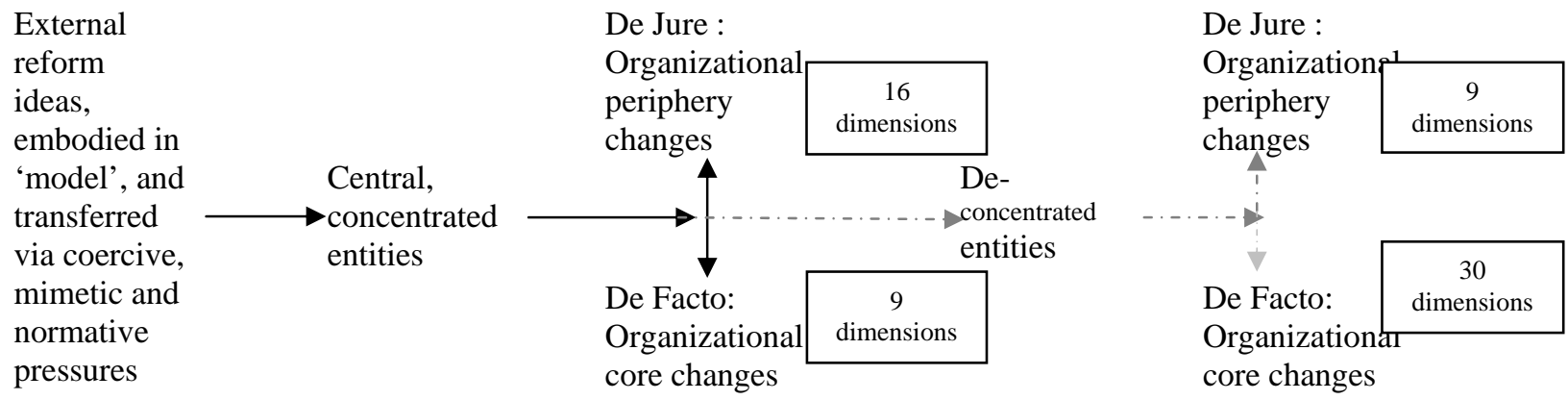

113. Figure 32's story can be told as a simple analogy: A soccer game is being officiated by a concentrated group of referees who know and agree with the rules and have introduced them to all of the players; but the players are used to playing by other rules, do not really understand or accept the new rules and procedures, do not

\footnotetext{
${ }^{47}$ Hannan, M. T., and J. Freeman. 1984. Structural inertia and organizational change. American Sociological Review 49:149-64.Reference to page 155.

${ }^{48}$ Dimensions involving de-concentrated actor sets average 2.8, 2.3 and 1.6 (for league 5, 3 and 1 countries) when reflecting de-jure issues at the periphery-introducing the formal role of 'internal auditor' and producing nominal internal audit reports, for example-as compared with 2.4, 1.7 and 1.3 averages for de-concentrated dimensions impacting de facto behavior "core" to the organization—like actually using internal audit reports.
} 
necessarily have abilities to comply, and are influenced by their pre-existing informal approaches that essentially authorize them to continue playing according to established rules; the new rules are thus not properly followed and the game, while reflecting new ideas in a peripheral sense, is actually being played according to the old conventions. The story is encapsulated in the earlier ideas of 'institutional dualism' which suggested that the challenge of reform is often greatest when it comes to substituting new ideas for old.

114. Figure 32 shows the extent of this problem for reformers, through the number of PEFA PFM dimensions falling in the different reform reach areas. Only 25 in total pertain to engagements with concentrated entities, where existing reform approaches are most effective. Almost half of the 64 are in the area reflecting the "core" de facto engagements of de-concentrated actors - the area with weakest 'reach' of current reform approaches. Existing reforms will not likely deliver results in these areas.

\section{Reform adjustments are needed to meet looming challenges}

115. The extent to which current reform modalities may be limited is certainly cause for concern. If the argument is right, reform adjustments are needed to meet looming challenges. But what of those who might argue that the translation of de jure to de facto, and from concentrated to de-concentrated simply requires more time than reforms have had to date? Such argument might also point out that these reform ideas have been adopted in practice across many governments; observers might reference countries from which the ideas were drawn as examples. It is impossible to definitively counter such claims. But evidence suggests they are qualified at best. Time has not proven the simple solution with MTEF reform in countries whose reforms date back ten years, for example. Ghana, Tanzania and country 6 still score Cs and Ds on MTEF related dimensions. Similar examples could be provided related to accounting, audit and other reforms which have progressed with concentrated engagement but not in de-concentrated actor groups. Furthermore, the argument that other countries have successfully adopted many innovations shown in Figure 25 is exaggerated. Finally, countries that do exhibit successful adoption of these ideas also exhibit very different modernization paths. The lessons one can learn from these paths point to important adjustments necessary for African reform.

116. Whether one looks at Australia, the United States, the United Kingdom or Western European and Scandinavian countries, one finds a tendency for laws, processes and standards to emerge and morph over long periods of time, along domestic paths of development. A path of progress in the normative "core" paved the way for adjustments to "peripheral” practices. One finds the creation of accounting professions preceding modernization of PFM systems by twenty or thirty years, for example, of social demand for rational and accountable government leading the supply of such, and of social norms leading legal developments. As an example, Box 6 discusses events in the United States that led up to 1920s legal and structural, suggesting that the social soil developed progressively prior to reform. Few observers would imagine the 1921 Budget and Accounting Act emerging without the preceding paths of preparation in the accounting profession, business sector, and government. 


\section{Box 6 - Are PFM reforms $21^{\text {st }}$ century plants in nineteenth century soil?}

Many trace the beginnings of modern PFM in the United States to the 1921 Budget and Accounting Act. In reality the story starts in the eighteen century, but for brevity this short piece begins in 1887. It was at this time that the American Association of Public Accountants (AAPA) was incorporated, even before an 1896 state law in New York first recognized the profession. There were only 250 Certified Public Accountants in the United States in 1900, and although some colleges had taught book-keeping as part of degree programs in the $19^{\text {th }}$ century, no American colleges recognized accounting as a major field in 1900. But the profession was growing, as referenced in an Editorial in the 1900 Public Accountant: "The profession is slowly, but surely forcing itself into its proper place among the other professions..." The period between 1900 and 1920 saw major advances in this area; By 1920 over 5,000 original certificates had been issued."

These accountants formed professional associations, leading to the creation of the American Institute of Accounting in 1917. Their concentration in New York was one of the reasons the city developed its Bureau of Municipal Research in 1906. The Bureau introduced the scientific accounting approach, opened a school of administration and was responsible for publishing early texts. Influenced by these advancements (and similar developments in the private sector), the Taft Commission Report (1912) called for a more formal budgeting process at the federal level of government. The country also transitioned to a domestic income tax at this time (1913) which led to greater levels of domestic revenue dependence. Various states modernized their budgeting systems in the period as well: From 1911 to 1919 forty four states enacted budget laws. California and Wisconsin were the first to pass such a law, in 1911. Arkansas, Ohio and Oregon followed. Then in 1915 seven more states passed budget laws, in 1916 four, in 1917 seven, in 1918 six, and in 1919 fifteen states adopted budgetary control.

Various Congressmen were emboldened by this experience and supported steps to reform the federal system, culminating in the 1921 Budget and Accounting Act, which centralized the budgeting system in the executive- specifically in the Bureau of the Budget. The Act ushered in a PFM era that some call the control phase, which ran from 1920 to 1935. The phase embodied the policy values of the Progressive era: accountability, executive leadership, and professionalism, and saw the Bureau of the Budget (BoB) populated predominantly by accountants, emphasizing efficiency and economy above all else. The Act also established a Supreme Audit Institution, clarified the accountability of budget heads in agencies and re-emphasized the importance of the single appropriations committee in Congress.

In many respects African countries find themselves at the same place as America in the 1900-1920 period: Rwanda has just created its Institute of Certified Public Accountants (2008), Benin's OECCA was founded in 2006 and has 45 members, Burkina Faso's ONECCA emerged in 1996 and has 54 members, Ghana has over 1,000 professional accountants though they are still earning their legitimacy. One can also consider similarities in dependence on trade taxes, the challenges of major urbanization, and such. But African countries are encouraged to develop systems adopted in the United States and other settings in the late $20^{\text {th }}$ and even $21^{\text {st }}$ century. Including advanced accounting reforms, systems and MTEFs. How feasible is this? Will the far less developed soil hold the more developed plants?

117. Salvatore Schiavo-Campo recently commented (in discussing MTEFs) that “A public management innovation cannot be transplanted $a s$ is to a different institutional soil ... nor implemented successfully except gradually and over a long period of time."49 A key observation here is that reforms emerge most successfully when they develop from within. Even though external accounting ideas were introduced into the United States from the United Kingdom, for example, they were ultimately honed and adjusted and fitted to the local context before being introduced into government.

\footnotetext{
${ }^{49}$ Schiavo-Campo, S. 2008. Of Mountains and Molehills: “The” Medium-Term Expenditure Framework. Paper presented at the Conference on Sustainability and Efficiency in Managing Public Expenditures Organized by the EastWest Center and Korea Development Institute Honolulu, Hawaii, 24-25 July 2008.
} 
Their value was normatively approved over a long period of time, creating 'space' for reform. What does that space look like in Africa? Is it sufficient to facilitate de-facto implementation of new reforms? Consider just the accounting element, and the kind of soil Africa's PFM reforms are planting advanced accounting products into:

- Sierra Leone, which has developed a raft of PFM laws recently, has a financial market described as "rudimentary" and an accounting profession with only 91 members (in 2006). There is a lack of normative appreciation and acceptance of accounting and auditing in the country, with public perception that "the audit profession...does not add value.”

- Ethiopia, with its elaborate public accounting reforms, new computerized systems and accounting classifications also has an immature accounting profession, with an estimated cadre of only 200 professional accountants in the country.

- Rwanda has recently adopted accounting laws based on international standards, even though it has an extremely small supply of accounting professionals; only 123 of the 263 accountant posts are filled and only 65 internal auditors even exist in the. The Institute of Certified Public Accountants of Rwanda was created by the Ministry of Finance only in August, 2008.

118. Readers should note that the achievements in these and other countries are immense, and initiating and ramping up the development of accounting professions has been a very positive PFM reform step for these countries. However, the relative youth of these professions suggests that one should not just assume that advanced accounting, MTEF, internal audit or other reforms will grow and mature and become "core" in these countries, given the limited soil. One can look beyond accounting and raise questions about the 'fit' between formal PFM reforms and informal African realities in general. Schick suggests, for example, that the problem with developing countries is not the lack of law, but the coexistence of dual systems-legal and informal-in most areas of society. The situation is reflected in Mauritius, whose formal bureaucracy receives high marks for being merit based and efficient but where accounts of actual bureaucratic structures suggest a different, more informal reality. ${ }^{50}$ Laws provide a peripheral structure that is not reflected in core behavior. Marcel Fafchamps shows that actual practices differ from formal rules in Africa's private sector as well, with Ghanaian firms contracting through informal relational ties more readily than formal, legal mechanisms, even though these exist. ${ }^{51}$

119. If the context does not provide the soil in which every-day laws are turned into practice, what chance is there for PFM reforms that are themselves legal in nature? Such comment is not intended to discourage African reformers, whose courage is exemplary (with the example of Rwanda in Box 6 being an example of such, and also of amazing progress). This discussion just reinforces how substantial some of these initiatives are, and why implementation is so hard. The reforms are aptly described in one case as “daunting for any well-resourced OECD Government.”

\footnotetext{
${ }^{50}$ McCourt, W. and A. Ramgutty-Wong. 2003. "Limits to strategic HRM: the case of the Mauritian civil service” International Journal of Human Resource Management 14, 4, 600-618. Reference page 609.

${ }^{51}$ Fafchamps, M. 1996. The enforcement of commercial contracts in Ghana. World Development, Volume 24, Issue 3, pp. 427-448.
} 
The fact for countries in this situation is that "Many of the reforms have still to be completed and/or substantially implemented" in situations "where these have not previously existed and where there is little tradition" supporting them. Country 11's PFM-PR appropriately calls this "an achievement in itself” but readers should ask: Without the tradition (or soil, or space) will these new mechanisms really stand a chance of being “completed and/or substantially implemented”?

120. Given the limits of the current reform model and the themes apparent in African PFM it is certain that reforms will need adjustment to facilitate a positive answer to this question. The following three reform directions are presented as starting points for such adjustment, given the PFM themes observed, hypothesized limits of current reforms, and experience in more advanced reformers. The presentation includes discussion of steps some leading reformers are taking in these three directions:

- Reforms need less focus on technicalities, more on 'space'.

- Reforms need less concentration, more coverage.

- Reforms need less similarity, more context-appropriateness.

Direction 1. Reforms need less focus on technicalities, more on 'space'

121. An earlier observed PFM theme noted that dimensions involving central, concentrated entities were stronger than dimensions involving many de-concentrated entities. It is important to credit reform designs in regard to this theme, essentially because reforms have fostered space for reform in concentrated entities. Reform designs frequently focus on bolstering capacity in budget departments, forecasting units, revenue agencies and treasuries, for example, and connecting personnel from these entities to peers in other governments (through training visits, for example). Other initiatives also create space. Sierra Leone's PFM-PR identifies one of its 2007 reform achievements as the appointment of a qualified Accountant General (AG). The appointment is important not just because of the AG's qualification but also because of his appreciation - of the norms implied in recent PFM reforms-and the role he can play in building acceptance for new laws. His presence enriches the 'soil' in the AG Office, creating space for implementation of reform elements.

122. Box 6 argued that more advanced PFM systems like those in the United States developed along paths, within specific soil. The box presented a broad social perspective on what such 'soil' involves, but change management literature has equivalent ideas at the organizational level. Figure 33 shows a basic approach emerging from such literature, which emphasizes the importance of acceptance, authority and ability to create reform space. ${ }^{52}$

\footnotetext{
52 Andrews, M. 2004. Authority, Acceptance, Ability and Performance-Based Budgeting Reforms. The International Journal of Public Sector Management, 17(4), 332-344.
} 
Fig. 33. The idea of reform 'space' and critical questions to ask of a reform setting

Is there acceptance:
Of the need for change and reform?
Of the specific reform idea?
Of the monetary costs for reform?
Of the social costs for reformers?
Within the incentive structure of the organization?
Is there authority:
Does legislation allow people to challenge the status quo
and initiate reform?
Do formal organizational structures, rules, allow
reformers to do what is needed?
Do informal organizational norms allow reformers to do
what needs to be done?
Is there ability:
Are there enough people, with appropriate skills, to
conceptualize and implement the reform?
Are there appropriate information sources (to help
conceptualize, plan, implement and institutionalize the
reform)?

Source: Andrews (2008). ${ }^{53}$

123. The basic idea in Figure 33 is that new ideas are only effectively adopted in organizations when the ideas are accepted, informal and formal mechanisms authorize these ideas, and organizational members are enabled to implement the ideas. The three must intersect to create space for reform, and the size of this space determines the extent of reform that is possible. The space can be created through isomorphic pressures - as in concentrated entities—but is mostly the product of internal management structure and engagement. This simple approach merges much of the organizational change literature, and can be used to explain why reforms often fail to institutionalize themselves, becoming de facto influences on behavior. The explanation requires thinking about the kind of space needed at different stages of a change process. The stages are: Conceptualization (where reform need is established and reform ideas are formalized); Initiation (where reforms are introduced into the setting); Transition (where new processes and rules start to replace old, pre-existing processes, rules, etc.); and Institutionalization (where reform processes, rules, and such are established as formal and social norms, driving behavior).

124. The argument is that necessary combinations of authority, acceptance and ability are different for different stages of reform. Reform space is often required in only concentrated actor groups in early conceptualization and initiation stages, for example, where laws and processes are developed (and sometimes piloted). This is in many senses where many African countries are with their PFM reforms. The challenge to create 'space' for transition and institutionalization is very much the problem countries face in trying to translate de jure interventions into de facto practice. It is also a challenge complicated by the need to engage with multiple, deconcentrated sets of actors and one that cannot be met through common isomorphic

\footnotetext{
53 Andrews, M. 2008. Creating Space for Effective Political Engagement in Development. In Odugbemia, S. and T. Jacobson (Eds) Governance Reform Under Real World Conditions. World Bank: Washington, D.C, 95-112.
} 
influences. The technical, normative, coercive and even mimetic influences that have accommodated conceptualization and initiation are too concentrated and focused on peripheral issues. They do not adjust the core issues centered on acceptance of values, ways of engaging and relating. Many reforms falter at this stage as a result.

125. Given this kind of experience, much organizational change literature emphasizes the importance of creating space for organizational creativity and innovation rather than simply reforming technical issues. The space is intended to accommodate organizational learning, innovation, problem identification and problem solving, as well as open windows for appropriate external influence (constructive isomorphism, perhaps). This is like enriching soil instead of trying to establish a plant that may or may not grow. Or perhaps like instigating change in the core mission-values of an organization before changing its peripheral structures.

126. There is some evidence of this kind of engagement in various recent PFM reform initiatives in Africa, ostensibly introduced to develop a culture conducive to implementing new laws. Tanzania's Accountability, Transparency and Integrity Project has an interesting component focused on strengthening oversight and watchdog institutions (OWIS), for example, which seeks to work with CSOs and professional organizations (like accounting entities) to develop and promote norms and ethics considered vital for acceptance of new PFM approaches. Mozambique has a project similarly focused on building the accounting profession, and Ethiopia is also looking into this issue. Country 11's Ministry of Economy and Finance has recently taken steps to create a professional accounting entity as well, and Ghana is considering developing a public sector financial management professional association, which could improve reach (to de-concentrated entities) and help build acceptance, authority and ability to institutionalize new laws.

127. Such reform dimensions are still marginal in even these countries, but could be vital to facilitating more de facto reform success - by expanding the space for reform. Another approach to achieving greater reform space involves strengthening internal institutional pressures for reform. An interesting study by Ashworth, Boyne and Delbridge found that the externally-imposed Best Value regime led to many de facto changes to English local governments because the technical interventions were matched with aggressive and hands-on engagement. Those driving the reform "deployed teams of inspectors to undertake "site visits" in order to check compliance" which placed "extra pressures on authorities to alter their culture and strategy [and] were believed to be most likely to deliver better results." ${ }^{54}$ The active engagement implied in a "site visit" approach to reform offers a vehicle reformers can use to try and create 'space' for transition and institutionalization of reform. This is a very demanding and time consuming approach, but one whereby de-concentrated entities have an opportunity to learn about the mission behind reform and its potential value to them, and reform leaders can coach others to implement. It could have similar results as an initiative to build norms through professional associations.

\footnotetext{
${ }^{54}$ Ashworth, R., G.Boyne and R. Delbridge. 2007. Escape from the Iron Cage? Organizational Change and Isomorphic Pressures in the Public Sector. Journal of Public Administration, Research and Theory (Advanced Access), cited page 18.
} 
128. Either intervention could also be instigated by a variety of agents, including government and CSOs. Indeed, where CSOs value the kind of reforms pioneered by concentrated entities like treasuries and budget departments, but are concerned that these reforms are having limited de facto effect, the CSOs themselves might engage in "site visits"-assuming, of course, that CSOs have the 'right stuff' to do this (appropriate 'space' themselves) —an issue discussed in Box 7. Without someone playing this kind of role and facilitating some changes to the narrow de jure, concentrated reform model, it is likely that reforms will continue to have only limited impacts on practice.

\section{Box 7- Do CSOs have 'the right stuff' to help develop space for new PFM reforms?}

Various boxes in this paper have suggested that CSOs have an important role to play in shaping and pressuring PFM reform agendas in Africa. What do CSOs need to do this work?

One answer focuses on the CSOs themselves, and can be illustrated with reference to a recent survey of NGOs in Uganda, which found many CSOs falling below good practice in their own governance structures. ${ }^{1}$ The NGO sector was found to be funded primarily by international non-governmental organizations and bilateral donors (Are they themselves domains of concentrated isomorphism?); Most NGOs were small and underfunded and focused on raising awareness and advocacy (often related to fund raising) rather than more complex issues of governance (Do they have the ability to engage with greater complexity?); Many NGOs were found not to file income tax returns, and few respondents were able to provide coherent financial accounts (Do NGOs appreciate the PFM norms and approaches.

One has to ask if, given their own shortcomings, these kinds of CSOs have the right stuff to contribute to initiatives aimed at building social space for governance reform in government? Box 5 discussed an initiative in Mozambique aimed at ensuring they do. The FDC in Mozambique is working with CSOs to enhance the quality of financial systems, appreciation for transparency and overall organizational legitimacy sought to promote access to information as an independent right. This kind of work can go a long way to ensuring CSOs have legitimacy to do the work ahead.

But even with this legitimacy, we are reminded that CSO engagement is indeed limited by government PFM itself. A recent set of work by the Open Budget Initiative (OBI) argues that CSOs, no matter what their abilities, cannot get anywhere without transparency in governance. It is important to note that the OBI finds greater transparency in the PFM upstream and-mirroring discussion in earlier boxes-says that CSO engagement is also strongest here. Poor processes and transparency in the downstream is correlated with limited CSO engagement in this domain.

Even the most legitimate and well-intentioned CSOs struggle to play a role in PFM systems that are closed and non-transparent. Transparency and legal access are thus also elements of 'the right stuff' CSOs need to help develop space for PFM reforms.

\section{Direction 2. $\quad$ Reforms need less concentration, more coverage}

129. Earlier examples showed that 'space' has been developed in many concentrated entities already, including central treasuries, budget departments, debt units and such all across Africa. This is arguably a major reason why 'concentrated' PEFA dimensions have higher averages than others. Active donor engagements in these areas have played a role in building this space, whether through IMF connections to debt units or World Bank relationships with budget departments. These relationships allow opportunities for learning, resourcing and other support vital to the isomorphic transfer of management approaches. 
130. As argued, opportunities for such transfer appear more limited in deconcentrated entities, partly because the 'PFM reform engagement' seldom extends to finance officers in Ministries of Agriculture, district offices or procurement officers in independent agencies. These entities are usually seen as consumers of the decisions taken by central, concentrated actors (like treasuries and budget departments). In a sense they are subjects of monologic demands rather than participants in dialogic communications, where the former involves being told what to do and the latter involves a process of "problem solving informed by multiple or dialectical perspectives." 55 Effective change generally requires the latter kind of dialogic engagement, however, considered appropriate for the design of "public policy measures that can then find willing compliance and enforcement." 56 Involving deconcentrated entities in dialogic communication creates 'space' for reform in these entities.

131. PFM reforms that address future challenges must be less concentrated and facilitate more coverage, or reach, to create space for reform implementation in these de-concentrated entities. Interestingly, there are a number of opportunities for such expanded coverage in the current experience of the 31 countries. In Mozambique, for example, projects that have PFM dimensions are being pursued in various areasagriculture, district development, health, education and so forth-and foster relational links between external agents and de-concentrated players. The financial management approaches embedded in engagements ranging form Global Fund grant activities to World Bank projects emphasize similar values and even mechanisms - transparency, monitoring and evaluation, reporting, and such, for example. They are vehicles of influence that could facilitate enhanced coverage of the PFM agenda.

132. The rub-off from non-PFM sectoral projects on the quality of PFM systems is evident already in the fact that various countries score high on the PEFA PI-12.iii strategic planning dimension because of plans developed in past health and education projects. Given that the sectors often account for significant shares of expenditure, the existence of costed strategies developed as part of broader projects (or even in PRSP creation, as in Mozambique) allows a high PEFA score! Connections between these various engagements might accommodate expanded reach in the PFM reform agenda. Concentrated entities at the center (like budget departments) could engage with those involved in projects at the MDA level, who could engage with projects at the district level, who could engage even beyond. The web of engagements suggests a network of nodes and ties, where concentrated entities do not always engage directly with deconcentrated entities, but have pathways of connection through other players. As such, one could imagine a mixture of strong and weak tie relationships fostering localized learning and experiment (suited to weak ties) as well as "site visit" type forced replication (suited to strong ties). ${ }^{57}$ The mix of connections will allow expanded coverage and accommodate improved 'reform space' in the PFM domain.

\footnotetext{
${ }^{55}$ Singh, J.P. 2008. Dialogues as Communication Strategy in Governance Reform. In Odugbemia, S. and T. Jacobson (Eds) Governance Reform Under Real World Conditions. World Bank: Washington, D.C, 69.

56 Ibid.

57 The strong and weak tie was introduced by Mark Granovetter in 1973. The idea is simply that some relationships are stronger than others. Evidence indicates that strong ties can be useful for some things and
} 
133. The challenge to coordinate and bridge concentrated and de-concentrated entities is a new one for many leading PFM entities, however. It is a role that requires some flexibility in the reform agenda - and a willingness to engage on creative ideas that de-concentrated entities feel might suite them better than standardized solutions. It also requires creating mechanisms for inter-organizational communication that do not appear extensive in any African countries. CSOs can be an important role player in bridging groups in this engagement. Box 3 earlier argued that CSOs can help reach de-concentrated actors, citing examples of Lesotho's Chartered Institute of Public Finance and Accountancy in trying to expend 'reach' amongst government accountants, for example, and the Ugandan Debt Network's initiatives to connect CSOs together with each other and with relevant government entities-facilitating dialog, learning and support and advocacy relationships. CSOs often have significant social reach, especially when they themselves are subject to some kind of umbrella coordination (like in Mozambique, Burkina Faso and Uganda). These CSOs can introduce new ideas into the PFM debate themselves, through modern financial management methods that they then discuss with governments. CSOs can hold these discussions simultaneously with national, district and local governments, and ensure that the various conversations are shared. In so doing, they could allow expanded coverage of ideas and be domestic vehicles of innovation transfer. Once again, however, they need to be well positioned to do so and have 'the right stuff' discussed in Box 7-transparent and accountable financial management systems, legitimacy and relational connectedness.

\section{Direction 3. Reforms need less similarity, more context-appropriateness}

134. Broadening the reform dialog should enhance the creativity of such. It also allows greater context-appropriateness in the reform design. Reforms need less similarity and more context-appropriateness. The observed similarity in reform agendas in the 31 countries analyzed in this research contrasts severely with the different country contexts also discussed. It is self evident that league 5 countries do not have the same governing or PFM challenges as those in league 1. It is also arguable, therefore, that current reform models lack the specificity required for meeting either set of challenges. It is interesting to note that, while the current reform model ostensibly draws from experience in more developed countries' 'good international practice', these countries are actually not as convergent on these practices as one might expect.

135. OECD countries differ in the degree of adoption in almost every PFM area discussed here, including multi-year budgeting, moves towards more strategic classifications, use of budget ceilings and rules, cash and accrual accounting practices, internal audit, and legislative engagement. One should also note in-country variation in these settings (Ministries of Defense often have different systems to others) and the fact that systems looked very different in most settings even fifteen

weak ties for others. Weak tie relationships can be more creative than strong tie relationships, for instance, whilst strong ties could be more useful in situations where an individual is looking for dependable financial assistance. 
years ago, and definitely 30 years ago. ${ }^{58}$ Variation in PFM dimensions is the norm, not the exception, it seems. It also seems that the reform approach taken in Africa recommends a degree of similarity across these countries not observed in other country groups. Research into these other groups suggests systems and reforms to systems vary with context. In short, "Context is important".

136. One is reminded of the 5 leagues identified earlier and the finding that top league 5 countries score more than a PEFA symbol higher than bottom league 1 countries for many dimensions and for fiscal outcomes. League 1 and league 5 countries have different contextual features-levels of economic growth, political stability, and such. It is suggested that these different country groups have different types of PFM problems requiring different solutions. These different solutions will not only be technically different (some countries need a strong annual budget only, perhaps, whereas others urgently need a multi-year one) but will also involve different things from different sets of role players, different sequencing and different types of external engagement. Earlier figures illustrate how the different leagues are performing on four types of PFM dimensions. There are various ways one could think about shaping reforms to contextually reflect the information in these figures. League 5 countries are scoring quite well in de jure and concentrated dimension areas, but less well in de facto, de-concentrated dimensions. Perhaps there should be less focus on creating or even improving law in these contexts and more on implementation, especially in MDAs and other de-concentrated entities? League 1 countries score below 2 for the quality of legal processes (both de jure measures). Many would emphasize bolstering law as a first reform step and strengthening central entities to control the system. But consider that these countries tend to lack legal processes and have limited capacity; perhaps some de facto interventions focused on specific domestic problems (like service provision) would ensure better use of limited capacity?

137. This paper cannot advise on exact approaches different countries could take to ensure reforms match context, but the above discussion notes that this should be done. It should yield reform packages that are significantly different to those adopted currently. These packages might reflect the kinds of factors literature increasingly finds influence government structures, and which even this brief discussion suggests matter in the African case. These include: Legal culture (are laws really the vehicle of social influence?); Economic challenges (do governments face special costs, revenue or expenditure issues that demand more flexibility than control?); Strength of the political system (and of actors in this, which influence control designs, paths of accountability); Broader cultural and economic development (Are financial management norms in place in society, to support their introduction in government). Other factors emerge from literatures on contingency in the implementation of Management Control Systems, public financial management reform in the OECD,

\footnotetext{
${ }^{58}$ The emphasis here is on choices being made to shape PFM systems. "History tells us that such 'choices' change as contexts change-NASA's early space program successes, arguably a major highlight in twentieth century administrative achievement, were born out of considerably less transparency and "best practice' competitive procurement than its more recent (though less remarkable) endeavors, for example.” See Andrews, M. (2008) Good Government Means Different Things to Different Countries. Paper presented at 2008 American Political Science Association Meeting, Boston, MA.
} 
and other settings. ${ }^{59}$ Considering these factors in Africa's PFM context could materially improve the 'fit' and impact of reforms.

138. Most important of all the factors around which to fit the agenda, however, is the problem requiring fixing. Instead of focusing incessantly on achieving external legitimacy, governments should attend to where PFM systems need strengthening for better service delivery, macroeconomic stabilization, allocation, and such and pursue reforms relevant to the domestic problem. This approach will likely allow greater contextual application, reach and space.

\footnotetext{
${ }^{59}$ See, for example, Chenhall, R. H. 2003. "Management control system design within its organizational context: Findings from contingency-based research and directions for the future.” Accounting, Organizations and Society 28(23): 127-168; Hallerberg, M, R. Strauch, and J. von Hagen. 2007. "The design of fiscal rules and forms of governance in European Union countries.” European Journal of Political Economy Vol. 23, 338-359; Hauptmeier, S., M. Heipterz and L. Schuknecht. 2007. "Expenditure Reform in Industrialised Countries: A Case-Study Approach" Fiscal Studies, Vol. 28, 3, 293-342; Handler, H, B. Koebel, P. Reiss and M. Schratzenstaller. 2005. "The Size and Performance of Public Sector Activities in Europe” WIFO Working Papers 246, WIFO.
} 


\section{Conclusion}

139. This paper intended to provide a stylized picture of African PFM, addressing questions like: How strong has African PFM become? In what ways do African PFM systems in place now facilitate effective public financial management? Where are the next challenges and how can they be met? It sought to address these questions in a fairly general manner, identifying what might be considered the central themes of the continent's recent PFM story. The themes were also used to examine the role of Civil Society Organizations (CSOs) in African PFM: How much have CSO's been a part of the main story lines to date? Where could they occupy the story more in future?

140. Themes arise from the analysis of recent quantitative and qualitative data on PFM system characteristics and reform initiatives in 31 African governments, emerging in three main parts focused first on themes identified across PFM processes, second on themes across countries, and third on themes across reforms. Discussing these themes leads to identification of current and future challenges to African PFM.

141. Three themes are first identified in looking across the many process areas in African PFM systems: (i) Budgets are made better than they are executed; (ii) Practice lags behind the creation of processes and laws; and (iii) Actor concentration pays. The first theme relates the observation that budget preparation processes are comparatively stronger than budget execution and oversight processes across all African countries. In PFM jargon, this is commonly presented as 'upstream processes are stronger than downstream processes'. The second theme is more nuanced, showing across all process areas that African PFM systems suffer from an implementation deficit-laws and processes seldom affect behavior. The third theme offers suggests that processes are stronger when concentrated sets of actors are involved. Processes are weaker where they involve multiple players, especially outside of central PFM entities like the budget department, treasury or debt agency.

142. These themes capture general differences in dimension strengths. There is substantial variation in dimension strength and process quality between countries, however. The variation is significant enough to suggest that different countries fall into different 'PFM performance leagues'. These leagues are identified empirically, based on PEFA scores, and are also reflected in major inter-league differences in PFM process and outcome performance. Lower league countries have weak dimensions no matter how these are categorized; de jure and de facto are weak, as are concentrated and de-concentrated dimensions, as are upstream and downstream. League 3 countries share weak downstream, de facto and de-concentrated dimensions with lower league countries; but league 3 countries are strengthening PFM dimensions that are in the upstream, de jure in nature, and centered on the engagement of concentrated actor sets. League 5 countries share strengthened upstream, de jure and concentrated PFM areas with league 3; but these countries appear to be strengthening the other dimensions-downstream, de facto and deconcentrated - their current challenges.

143. Themes also arise in explaining why countries fall into different leagues. A range of factors are seen to influence the quality of PFM systems and outcomes, 
presented as five major themes: Growing economies have stronger PFM; Stability delivers PFM progress; Fiscal states have stronger PFM systems; Longer periods of broad reform commitment foster PFM progress; and, Colonial heritage matters (maybe). It is apparent that these themes interlink and that there may be an as yet unidentified factor underlying them all. Even without identifying such factor, however, the section suggests a basic message: Country characteristics matter a great deal in understanding what PFM system quality looks like. The message raises important questions, chief being, "Is context taken seriously in reform design?”

144. The final section addresses this and other questions pertaining to PFM reform experience across Africa. The main theme identified centers on the apparent similarities in reform models across the 31 countries. The theme is reflected in the observation that similarities belie country differences. The 'similar' model is composed of a set of international reform 'products' and follows a common modality of engagement whereby central, concentrated entities like treasuries, budget departments and even revenue and procurement agencies are strengthened and laws and processes are modified. This reform approach is seen to deliver better law and stronger central agencies, but may be limited to these gains only. The paper proposes adjustments needed to meet looming challenges embodied in calls for less focus on technicalities, more on 'space', less concentration and more coverage, and less similarity, but more context-appropriateness.

\section{A. Summing up thoughts on CSOs and PFM in Africa}

145. The paper consistently explores the potential for CSO engagement in Africa's future PFM story and evidence of its existing role. It finds many opportunities exist, in context of the 'gaps' implied in themes, and in many cases CSOs already fill these gaps. It does argue that CSOs face their own challenges in engagement, however, with serious questions about how CSOs ensure they have the 'right stuff' for engagement. Opportunities for CSO engagement are identified in the relative weakness of downstream PFM processes. CSOs have significant room to move in situations where laws allow and even require practices that governments are not acting on. Finally, the lack of PFM reach to de-concentrated entities also plays into potential CSO strengths to convene and connect over organizational bridges in ways that many other role players cannot. The themes emphasizing country context and about reform experience suggest a number of challenges for CSOs. One expects CSO roles to differ depending on country context-with different opportunities in higher growth countries than may arise in post conflict settings, for example. CSOs will need to develop the acumen to choose appropriate roles for the different settings, working as partners in some instances, introducing new ideas in others, and occupying adversarial corners in others. It is vital that CSOs not become agents of one-best-way models of engagement, reflective of PFM reform modalities. CSOs could play a role challenging these reform modalities, contributing to creative space, facilitating greater reach, and helping to shape interventions to context. CSOs need legitimacy to do this, reflected most basically in having their own financial management 'house in order'. CSOs also need basic access to do this, and will be constrained by weaknesses in transparency of PFM in general. If CSOs do not have the 'right stuff' of legitimacy and access they will be marginalized in the PFM story. 